\title{
Bogs, birds, and berries in Belarus: the governance and management dynamics of wetland restoration in a state-centric, top-down context
}

\author{
Lucas Dawson $^{1,2}$, Marine Elbakidze $^{2,3}$ Marie Schellens $^{1,4}$ Anton Shkaruba $^{5}$ and Per K. Angelstam ${ }^{2}$
}

\begin{abstract}
Wetlands are complex social-ecological systems, which provide both important habitat for species, and multiple tangible and intangible benefits for people. Sustaining long-term benefits through restoration, conservation, and sustainable use is often linked to integrative and adaptive approaches to wetlands management. Such approaches assume democratic ideals, and require multilevel, multisector, and multiactor participation in governance and management arrangements. How then can functional wetlands be restored and sustainably managed as social-ecological systems in strongly state-centric, top-down governance contexts, such as in former Soviet republics? Using three case studies of wetland restoration and management for ecosystem functionality, biodiversity conservation, and human livelihoods, we employ a complex systems approach to analyze key governance and management dynamics underpinning initiatives toward sustainable wetlands in Belarus. We identified five core processes, namely, planning, garnering stakeholder support, obtaining key inputs (financial, human, material, technological, fixed capital), implementing core activities, and integrating learning and knowledge cycles. Key constraints concerned institutional hierarchies, onerous regulations, "negativism," and financing difficulties. Strategies relating to perception management, risk mitigation, and learning are identified as key to enabling beneficial feedback loops relating to core processes. Although path-dependent societal dynamics of the Soviet era continue to influence wetland systems, combinations of social and ecological crises created windows of opportunity for active participation among nongovernmental actors. Major opportunities for enabling emergent management approaches included identification of confluences of interest amongst stakeholders, as well as the continued mutual integration of Belarus with the international community.
\end{abstract}

Key Words: biodiversity conservation; complex systems; environmental governance and resource management; habitat restoration; socialecological system dynamics; sustainability strategies; sustainable enterprise

\section{INTRODUCTION}

Wetlands are complex coupled social-ecological systems (SES) that provide a range of benefits for biodiversity and human livelihoods (Verhoeven 2014). Although humans have exploited and managed wetlands for millennia (Rippon 2000), widespread drainage during the 20th century for the development of agriculture, forestry, or peat extraction has led to the long-term loss of more than $50 \%$ of the world's natural wetlands (Davidson 2014). In Europe, less than $20 \%$ of original natural wetlands remain (Finlayson and Spiers 1999, Verhoeven 2014). This has led to losses of both biodiversity and ecosystem services (Roodbergen et al. 2012, IPBES 2018, Manton and Angelstam 2018, Valasiuk et al. 2018). These issues underscore the need to understand the development and implementation of initiatives to restore functionally degraded wetlands, and thus conserve biodiversity and support human livelihoods through the development of social-ecological value chains based on ecosystem services (e.g., Dawson et al. 2017).

The limitations of rigidly top-down, command-control environmental governance and management approaches have been increasingly highlighted in recent decades (Cilliers et al. 2013, Kirschke et al. 2017). This has led to a revival of holistic conceptualizations regarding SES (e.g., Folke et al. 2005) and landscapes (e.g., Angelstam et al. 2019), and support for evidencebased, integrative, and adaptive approaches to wetlands governance and management (Turner et al. 2000, de Blaeij et al. 2011, Chaffin and Gunderson 2016). Such approaches are underpinned by concepts from complex systems theory, and are typically idealized as hybrid models, where decision-making power is distributed amongst a variety of actors throughout a polycentric architecture of hierarchies, markets, and networks (Kronsell and Bäckstrand 2010, Ruíz et al. 2011). However, the state-centric, top-down governance contexts surrounding wetland restoration in many countries, such as former Soviet republics, are not considered to be consistent with such approaches (Kluvánková-Oravská et al. 2009, Shkaruba and Kireyeu 2013). This stresses the need for understanding the extent to which sustainable wetlands and their benefits, as integrated SES, can be restored in such contexts.

Belarus, which became an independent state following the breakdown of the Soviet Union in 1991, is a good example. The country retains a strong legacy of top-down command-control environmental governance, including state ownership of all land and natural resources. Formerly covering roughly $15 \%$ of Belarus, wetlands are now the most threatened ecosystem type, with nearly 1.5 million hectares $(>50 \%)$ of pristine peatlands lost between the 1950s and 2001 to large-scale draining for agricultural purposes (USAID 2001, Bambalov 2009, Wichtmann et al. 2013, Kozulin et al. 2018). These wetlands provide habitat for many species, which are threatened and endangered in other parts of Europe (Valasiuk et al. 2018). The number of wetland areas with official conservation status grew continuously in the 1990s, when perceived land value was low and unprofitable peat production enterprises were closed (Otto et al. 2011). As of 2018, Belarus

${ }^{1}$ Environmental and Resource Dynamics Group, Department of Physical Geography, Stockholm University, ${ }^{2}$ Forest-Landscape-Society Research Network, School for Forest Management, Swedish University of Agricultural Sciences, ${ }^{3}$ Faculty of Geography, Ivan Franko National University of Lviv, Ukraine, ${ }^{4}$ Environment and Natural Resources Programme, Faculty of Political Science, University of Iceland, ${ }^{5}$ Department of Environmental Protection and Landscape Management, Estonian University of Life Sciences 
hosts 26 Ramsar sites, covering 778,303 ha. At the same time, Belarus is ranked eighth in the world for national greenhouse gas emissions from degrading peat (Joosten 2010). Loss of wetlands in Belarus has triggered efforts toward different kinds of restoration initiatives ranging from conservation of rare species confined to traditionally mowed fens (Valasiuk et al. 2018) to rewetting of drained areas to restore the natural peat forming capacity (Tanneberger and Wichtmann 2011). Several of these restoration initiatives show clear positive outcomes on the ground for biodiversity and human livelihoods.

Although supported by the Ministry for Natural Resources and Environmental Protection, wetland restoration initiatives are often greatly constrained in Belarus, particularly because of strict legislation regulating many active management measures in nature conservation areas (Shkaruba and Kireyeu 2013). Additionally, national environmental objectives regarding wetlands are subject to persistent lobbying from industrial and agricultural actors, as well as state ministries propagating renewal of wetland reclamation projects and continued investment in peat extraction (BelTA 2018). At the international level, Belarus has expressed high environmental ambitions, and has ratified multiple multilateral agreements relating to biodiversity conservation, ecological networks, and green economy. These agreements have provided access to international donor mechanisms.

The aim of this study is to improve understanding of the governance and management dynamics of wetland restoration in state-centric, top-down governance contexts. We adopt a complex systems approach (e.g. Checkland 1981, Wolstenholme and Coyle 1983, Bosch et al. 2007, Inam et al. 2015), which is increasingly used in environmental management and sustainability science to provide systematic frameworks for identifying and supporting context-sensitive analyses and maintaining transferability across cases (Gonzalès and Parrott 2012, Lade and Niiranen 2015, Dawson et al. 2017). This approach is particularly useful for studying emergent phenomena in relation to the contextual constraints from which they emerge (Chu et al. 2003, Cilliers et al. 2013). Using three case studies, we identify and map aggregate patterns among causal dynamics underpinning wetland restoration initiatives in Belarus. These patterns are contextualized using narrative descriptions from semistructured interviews and group workshops. We develop a theoretical framework to enable us to answer our main research questions, which are the following: What are the main opportunities and constraints for the emergence of integrated, adaptive approaches to wetland restoration in strongly state-centric, top-down contexts? Which key management strategies might be employed to harness such opportunities and overcome constraints?

\section{THEORETICAL FRAMEWORK}

Many principles and criteria for the sustainable governance and management of SES (e.g., Folke et al. 2005, Ostrom and Cox 2010, Rijke et al. 2012, Garmestani and Benson 2013) are heavily influenced by two overarching concepts relating to complex systems (e.g., Pahl-Wostl et al. 2012, Halbe et al. 2013). First, the integration of cross-sectoral and multilevel system components, e.g., actor/stakeholder groups, policy instruments, values and perspectives, or different kinds of knowledge, into a coordinated system is proposed as an essential means for engaging with the structural complexity of SES governance and management
(Ostrom 2010, Koontz et al. 2015, Pahl-Wostl 2015) and to provide and account for institutional redundancy (Lemos and Agrawal 2006). Coordination is achieved by establishing and strengthening flexible links between interconnected, heterogeneous nodes of power and authority, to balance top-down and bottomup influences (Olsson et al. 2007, Pahl-Wostl 2015).

Second, adaptive approaches to natural resource management are seen as a key means by which to tame the dynamism, behavioral complexity, and inherent unpredictability of complex SES dynamics (Armitage 2005, Gregory et al. 2006, Olsson et al. 2006, Walters 2007, Rist et al. 2013, Koontz et al. 2015). Adaptive approaches aim to improve environmental governance and management through the development of explicit, systematic mechanisms and processes for iterative, reflexive learning, engendering a culture of continuous improvement by evaluation of past experiences (Pahl-Wostl 2007, Allen et al. 2011). Adaptive management is often split into active and passive forms, with the former characterized by multiple hypotheses and active experimentation, whereas the latter primarily relies on interpretation of best available data and monitoring regimes (Rist et al. 2013). Adaptive governance addresses the range of interactions between actors, networks, organizations, and institutions, which arise from management interventions in SES (Folke et al. 2005, Chaffin et al. 2014).

Integrative and adaptive approaches are theoretically underpinned by the fundamentally democratic ideals of "good" environmental governance/management, e.g., transparency, participation, equity, deliberation, and legitimacy (Ribot 2003, UNESCAP 2009, Bäckstrand et al. 2010), and are therefore primarily achievable by improving democratic institutions and the scope for nonstate actors to participate (Sending and Neumann 2006, Stringer et al. 2006, Lövbrand and Khan 2010). As a result, these approaches are claimed to satisfy demands for a more equitable distribution of decision-making power, enabling more effective governance processes because of a broader knowledge base, increased legitimacy of decisions, reduced conflict among stakeholders, and the establishment of long-term, trust-based relationships (Macleod et al. 2007, Lövbrand and Khan 2010, Stave 2010, Jager et al. 2016, Reed et al. 2016). However, integrated and adaptive approaches have been criticized for lacking sufficiently well-understood criteria for determining under which circumstances they might be appropriate, e.g., flexibility of decision-making, perceived risks of failure, or available institutional capacities (Gregory et al. 2006, Rist et al. 2013, Kininmonth et al. 2015), and are typically unable to replace the accountability of existing hierarchical bureaucracies (Bäckstrand 2004, Lemos and Agrawal 2006, Garmestani and Benson 2013).

Multiple powerful feedbacks, e.g., sunk costs, tend to reinforce the status quo in natural resource governance and management, hindering reforms toward more sustainable approaches (e.g., Folke et al. 2005, van Bueren and ten Heuvelhof 2005, Garmestani and Benson 2013). These dominant feedbacks exemplify path dependence, whereby complex systems integrate past policies with present behavior, irreversibly constraining system trajectories to a subset of all possible futures (Juarrero 2000, Grubler et al. 2015). However, the same feedbacks also create inertia and rigidity, making adaptation to radically new 
Fig. 1. Illustration of the case studies "Bogs," "Birds," and "Berries." Cases "Bogs" and "Birds" each focus on wetland restoration, to reduce greenhouse emissions from decaying peatlands, and promote species conservation. Draining of eutrophic fen mires, e.g., to increase agricultural land or wood production, destroys important habitats for globally endangered bird species like Corn Crake (Crex crex) and Aquatic Warbler (Acrocephalus paludicola; center). Landscapes with both large raised bogs (left) for safe roosting sites, and drained agricultural land (right) for food, are crucially important migration stopovers for Cranes (Grus grus). Case "Berries" focuses on value-added production based on cranberry (Oxycoccus spp.) and cloudberry (Rubus chaememorus), both growing on raised bogs. Illustration by Martin Holmer.

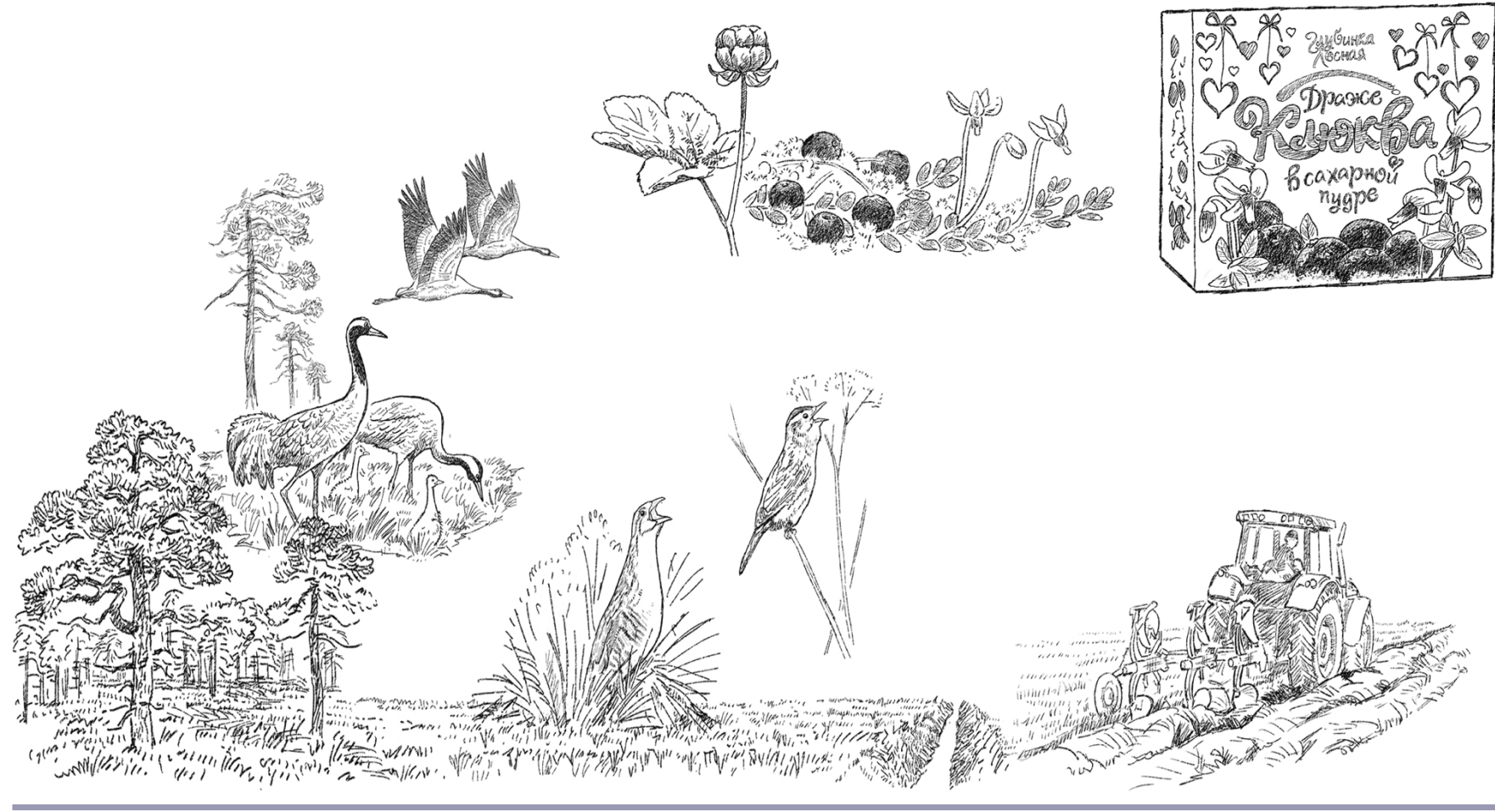

paradigms difficult, and leaving governance/management arrangements sensitive to random shocks and changes in the external context (Sterman 2000). Such events can unlock path dependent structures from current paths, shifting systems into emergent domains (Miller and Page 2007). For example, Weigle and Butterfield (1992) showed how systemic crises in the context of post-totalitarian regimes led to the emergence of civil society actors in Poland, Czechoslovakia, and Hungary.

Emergence refers to macro-level phenomena, which unexpectedly arise as a result of the dynamic interactions between microlevel components, and by their interactions with external contexts (Kurtz and Snowden 2003, Cilliers et al. 2013). From the perspective of this paper, wetlands management initiatives in Belarus emerge from the dynamic historical, political, cultural, economic, and environmental contexts in which they are embedded (Folke et al. 2005, Pahl-Wostl 2009). However, these contexts cannot be directly influenced by the management systems themselves over the temporal and spatial scales of interest (Pahl-Wostl 2015). Path-dependent dynamics relating to the external system context, e.g., Belarus's economic or institutional development, may therefore inhibit the realization of certain management configurations (Pahl-Wostl 2015) resulting in poor fit between decision-making structures, e.g., conventional hierarchies, and the changing social-ecological system (Epstein et al. 2015). Additionally, recent studies indicate that attitudes amongst decision makers and the general public in top-down domains remain skeptical of core democratic values (World Values Survey 2014, Teorell et al. 2018, Bui-Wrzosińska 2019). The degree to which integrated, adaptive approaches may prove useful and appropriate for wetland restoration initiatives in highly state-centric, command-control bureaucracies lacking fundamental democratic traditions, such as Belarus, remains therefore unclear.

\section{METHODS}

\section{Case studies}

Three case studies were selected, representing a spectrum of wetland ecosystem types and restoration objectives (Fig. 1), namely raised bogs as functional wetlands (e.g., Meli et al. 2014), habitat conservation for birds on fen mires (e.g., Valasiuk et al. 2018), and sustainable supply of berries and other natural resources (e.g., Stryamets et al. 2015). Taken together these cases encompass a wetlands-derived social-ecological value chain for supporting rural livelihoods. The cases represent initiatives from the civil, public, and private sectors respectively, occurring on the two main groups of wetlands, traditionally mowed fens and natural bogs. Case selection was based on two main criteria: cases had implemented clear changes toward the restoration and/or sustainable management of wetlands, which had been maintained 
over time; and, the management approach was clearly perceived by a wide range of stakeholders to be successful in terms of delivering multiple benefits over the longer term ${ }^{[1]}$.

Case "Bogs" focuses on wetland restoration activities at the Jeĺnia bog, a 23,200 ha complex of raised bogs and transitional mires in NW Belarus (Fig. 2; a more thorough description of the case studies is available in Appendix 1). Jelnia's hydrological balance was dramatically altered by drainage schemes in the 1960 s, although some drainage channels for peat mining date back more than 100 years (Kozulin et al. 2010). Since 1975, more than $77 \%$ of Jelnia's area has been burned by peat fires, including a major fire in 2002. The Jeĺnia bog restoration initiative commenced in 1999, coordinated by local ornithological NGO APB Birdlife Belarus. Management efforts have primarily focused on delivering ecosystem function outcomes and habitat for both resident and migratory bird species but also support environmental education, bird-watching, and fishing tourism activities.

Fig. 2. Case study locations. Locations of bogs and mires extracted from Bohn et al. (2000).

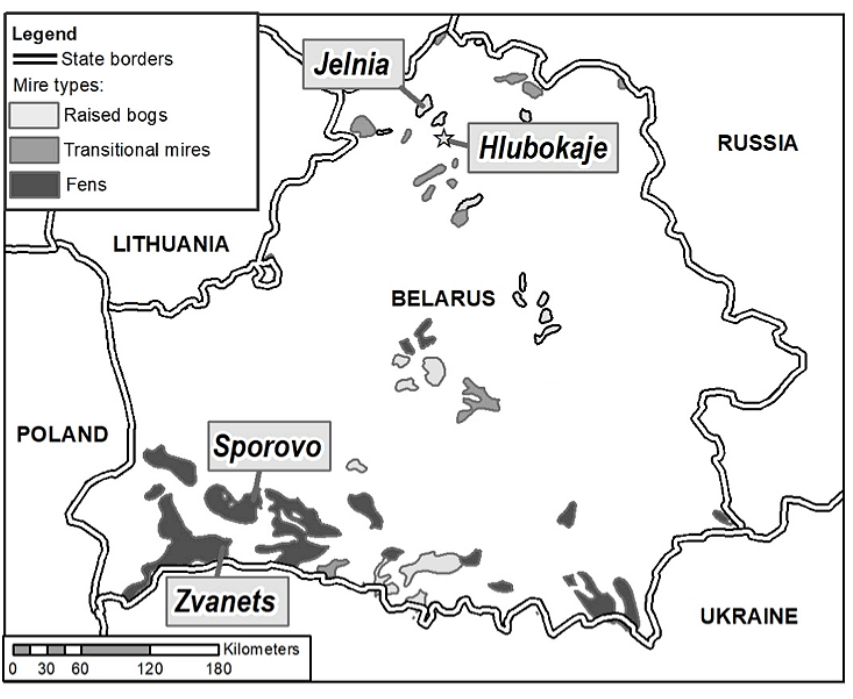

Case "Birds" focuses on restoration activities at Zvanets and Sporava protected areas in SW Belarus, which are among the largest fen mire peatlands in Europe at 15,000 ha and 18,000 ha, and host globally threated bird species. As in Jeĺnia, these peatlands have been subject to historical drainage resulting in large-scale fires in 1999 and 2002. These areas have undergone restoration efforts since 2006, with initial objectives focused on re-elevation of ground water levels to prevent further fires, restore ecological integrity for bird conservation, and allow resumption of local livelihoods and recreational activities (UNDP 2016a).

Case "Berries" examines a successful and unique privately owned, small-scale enterprise, Aržanica (https://arzhanitsa.by/en/), based on value-added production of wild foods harvested from raised bogs, for example, sugar-powdered cranberries. The firm explicitly supports sustainable wetland management by, e.g., participating in internationally sponsored wetland restoration and conservation initiatives (e.g., UNDP 2016b) and has developed a number of objectives and protocols, e.g., relating to harvest methods, in order to secure a sustainable supply of wild foods. Production occurs mainly at the local scale, in the small town of Hlubokaje near Jeĺnia bog.

\section{Research process}

The analyses focus on the experiences of management leaders of wetland restoration and management initiatives in Belarus, as sense-makers and situational actors providing a key locus of operational and strategic decision making (Checkland 1981, White and Fortune 2009). For our three cases, these leaders were: the director of an NGO, a senior scientist at a government agency, and the CEO of a private enterprise, respectively. These individuals had insight into all phases of their respective initiatives, and represent a unique source of three types of knowledge relevant for understanding complex systems, namely, (1) theoretical understanding of the system (system knowledge), (2) of the opportunities and constraints of decision making (orientation knowledge), and (3) of practical ways of implementing decisions (transformation knowledge; Becker 2009, Jahn et al. 2012, Popa et al. 2015).

\section{Data collection}

Figure 3 provides an overview of our research process. Data was collected in three steps. First, individual semistructured interviews were conducted with the leader of each initiative, using an interview manual of open questions to guide responses toward areas of research interest regarding all phases of the studied initiatives (Kvale and Brinkmann 2008). Digitally recorded interviews were taken in 2016, lasting 90-120 minutes, and were conducted and transcribed in Russian, before being professionally translated into English.

Fig. 3. Overview of the research process. Note: "CLDs" refer to causal loop diagrams.

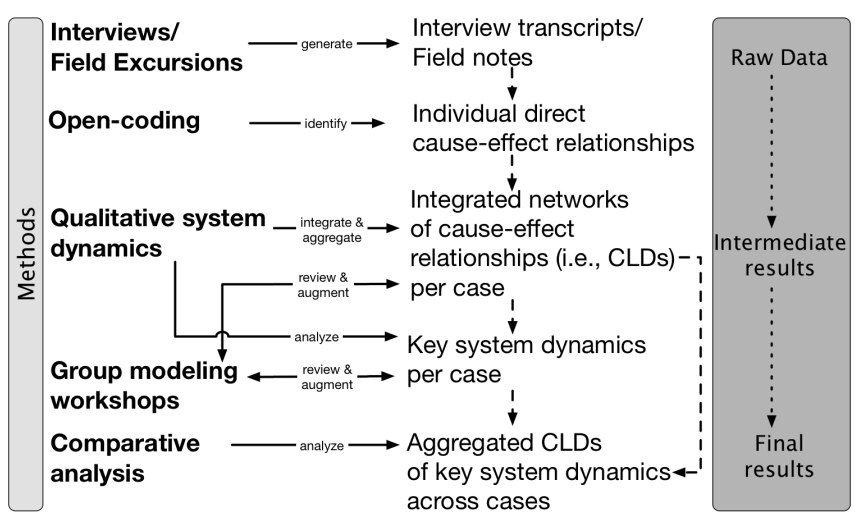

Second, management and operational representatives from cases Bogs and Berries conducted the researchers through their respective implementation areas. Discussions during these field excursions, 2-4 hour duration, clarified issues related to the history of wetlands in question as SES, the development trajectory of each sustainability initiative, the primary stakeholders involved, core objectives, achievements, and challenges. Case Birds provided a 2-hour presentation.

Third, two group workshops, 4 and 8 hour duration, were convened where initiative leaders participated together, 
examining causal structures and system dynamics of their respective initiatives as the basis for open, critical discussions. Additional data and context elicited from the workshops was subsequently integrated with interview data in an iterative aggregation process.

\section{Data analysis}

Using qualitative systems modeling methods (Coyle 2000, Eden 2004, Reichel et al. 2004, Bureš 2017) including causal loop diagrams $^{[2]}$ (CLDs), causal structures of the problem space were mapped for each case study (Dawson et al. 2017). CLDs were generated from both interview and workshop data in an iterative, inclusive process (Sterman 2000) using an open-coding method. Open-coding in this case refers to a data-steered process of meaning-making and categorizing data, providing for a qualitative analysis of relationships between identified codes and the context surrounding them (Bryman 2004, Corbin and Strauss 2008). Raw data, e.g., transcribed interview and group workshop data, were analyzed to identify direct cause-effect relationships. Identified relationships were integrated into networks of causal relationships, i.e., "complete" CLDs, for each case (see Appendix 2). These CLDs were subsequently iteratively aggregated toward identification of the key system dynamics underlying the emergent management approach and its outcomes in each case. A comparative analysis of these CLDs was then conducted to identify and aggregate key causal dynamics, i.e., common underlying dynamics, across the three case studies.

Two systems analysts (LD and MS) worked independently on the initial datasets in order to limit experimenter bias (Scholz et al. 2015), and as a verification process, by assessing the intersubjective comparability of the two independent analyses (e.g., Kvale and Brinkmann 2009). Independently generated model structures were then compared, discussed, and harmonized prior to assessing the fit between cases.

Generated CLDs were translated into Russian and presented to interviewees for validation; comments received were integrated into the final CLDs.

\section{RESULTS}

At the overview level, each case comprised an interconnected system (Fig. 4) consisting of three sets of key drivers: (a) the institutional environment and regulatory system, (b) adequacy of leadership, and (c) the wetlands ecosystem itself; and five core processes, relating to (1) planning, (2) garnering support, (3) obtaining key inputs, (4) implementing core activities, and (5) developing and integrating learning and knowledge processes. Although briefly presented below, the dynamics of each of the core processes and relationships with drivers are unpacked in greater detail in Appendix 3.

Interviewees frequently referred to historical institutional legacies, regarding the Soviet Union, its dissolution, and subsequent rapid changes in land use, as key elements that shaped the institutional environment and regulatory system in which wetlands restoration initiatives took place. Soviet-era land use practices and mismanagement were identified as a primary cause of the generally deteriorated state of many natural wetlands. Key economic drivers, such as lack of state funding for ecological initiatives, were linked to the continued fallout of the post-Soviet transition. Soviet- and transition-era policies were also identified as underlying rural depopulation trends, which impacted local livelihoods and availability of relevant knowledge. Such legacies underpinned a variety of contemporaneous drivers, e.g., focus on domestic energy security, leading to the development of plans in each case.

Fig. 4. An overview level causal loop diagram (CLD), synthesizing the core dynamics of studied wetland restoration initiatives in Belarus. Three sets of drivers triggered windows of opportunity and subsequently influenced five core management processes (in dashed box). Arrows connecting directly to dashed box indicate the influence of a given driver on multiple processes within the box. Figures 5-9 unpack the dynamics of each of the core processes and relationships with drivers.

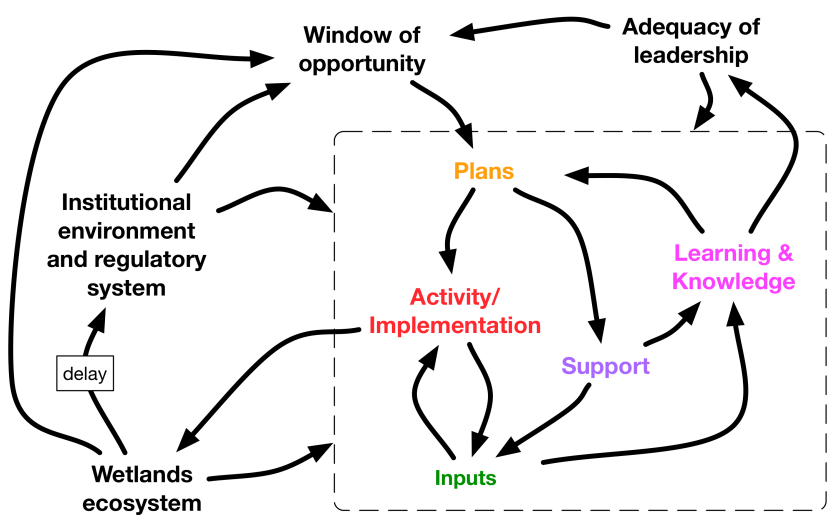

Interactions between these legacies created windows of opportunity triggering sustainability initiatives, and shaped the main thrust of key long-term objectives. For example, Soviet drainage and land-use regimes led to catastrophic bog fires when combined with intentional fire-setting behaviors among local peoples to reduce tick abundance. The scale and frequency of these fires became a call to action. The apparent failure of initial state-based responses, such as investment in fire-fighting infrastructure, provided opportunities for fire prevention through hydrological restoration.

A particular set of leadership characteristics was crucial to be able to perceive these windows of opportunity, including specific educational and professional backgrounds, personal interests and value systems, and employment status. Project initiators were all situated in decision-making capacities, e.g., director of NGO, chief engineer, etc.

Adequacy of plans (Fig. 5) encompassed a spectrum of formal and informal documents and processes, intended for both internal and external use. According to interviewees, adequate plans included clear, well-prioritized objectives and novel ideas and innovations, and were important to the identification and mitigation of perceived risk. Plans were developed through dynamic, iterative planning processes to identify and integrate broad sets of knowledge and input requirements (e.g., regarding problem urgency or financial requirements and opportunities), processes and organizational structures necessary to achieve strategic and operational objectives. In all cases, planning processes changed over time as new ideas, knowledge, stakeholders, and inputs came to hand. 
Fig. 5. Submodel unpacking the causal dynamics influencing the adequacy of planning for wetland restoration initiatives in Belarus. Core drivers and processes are in bold. Colored, nonbolded variables represent specific concepts unpacked from within respective core processes. E.g., Clear, well-prioritized objectives is a facet of adequacy of planning. Thick lines represent links between core drivers/processes. Several variables recur throughout Figures 5-9, representing points where core process dynamics link together in an integrated model.

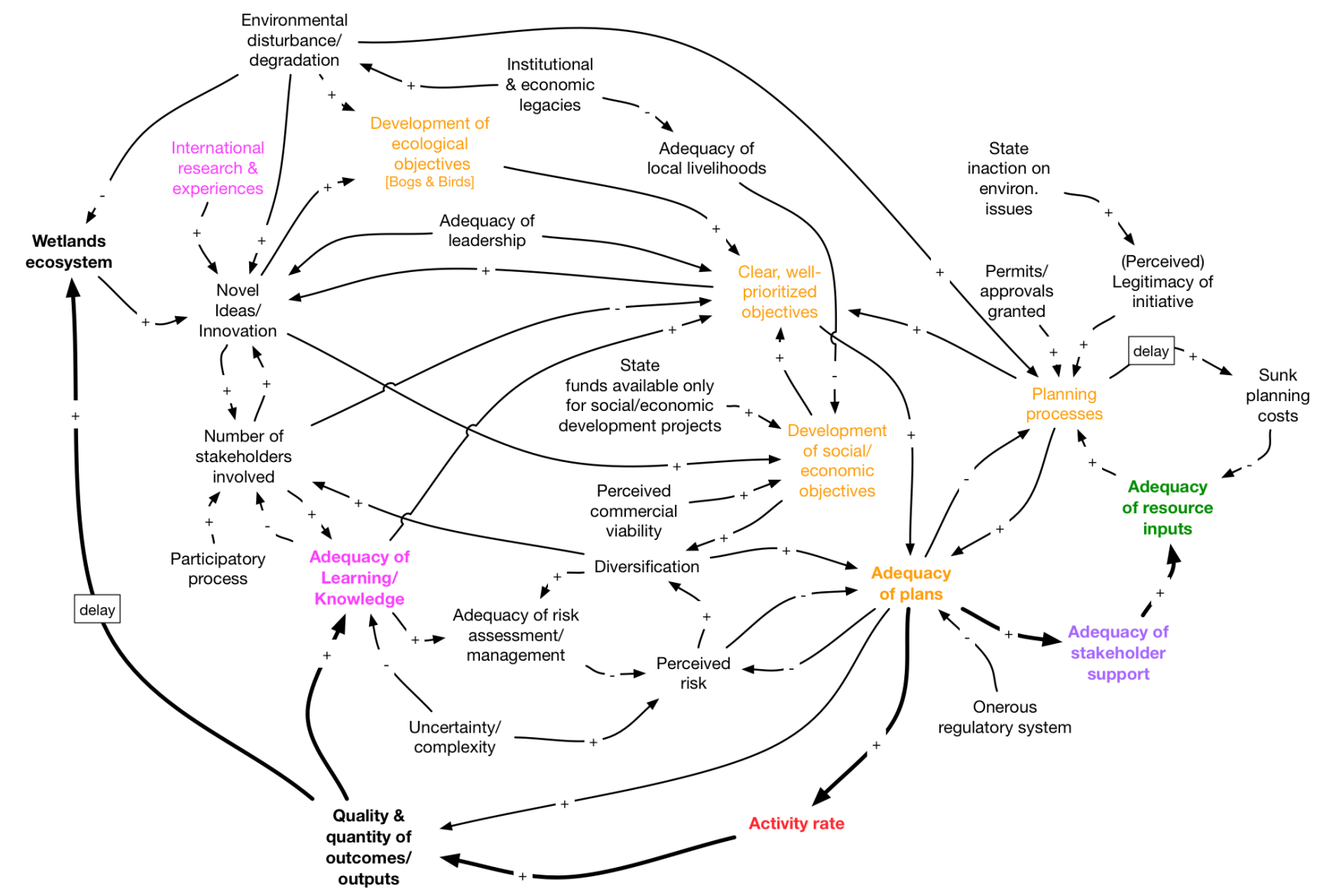

Adequate support (Fig. 6) of external and internal stakeholders was essential for the provision of a wide variety of essential permits and approvals. The degree of dependency on stakeholder support varied across the cases. The leader for case Berries, for example, perceived a considerable degree of self-sufficiency, albeit remaining dependent on permissions. Both leaders for cases Birds and Bogs expressed a greater need for stakeholder support, partly because of an increased exposure to regulatory requirements, and also for inputs (especially financial). Our analysis identified five key strategies by which our cases sought to garner support for wetlands management activities. These included cultivating relationships with key governmental decision makers, aligning management objectives with those of other stakeholders, developing public awareness-raising and communications strategies to promote "brand" visibility," ensuring the perceived legitimacy of management initiatives in the eyes of stakeholders, and by addressing and mitigating perceived risks.

Support and the scale of planned activities were both key determinants of the adequacy of inputs, which referred to the variety of financial, material, human, and technological/fixed capital resources available to initiatives (Figs. 7A and 7B). Financial resources were a key input, enabling other inputs and thereby activity rates and delivery of outcomes/outputs. Interviewees referred to two main sources of financial resources, donor funding and internally generated sales revenue. State funds were scarcely available, and then generally only to projects with a clear social/economic dimension. Materials and other variable inputs (Fig. 7B) referred to various materials harvested from wetlands and utilized in value-added production chains, but also to natural capital used in other initiative-driven activities, e.g., cranes for bird-watching tourism. The inherent properties, quality, and abundance of case specific material inputs determined whether available technology/fixed capital inputs were adequate (Fig. 7B). Diversification could lead to multiple uses of the same capital, but often led to the need for additional inputs. In most cases, human resources (Figs. 7B and 8) referred to internal team members or those of partner organizations although volunteers also provided important contributions in case Bogs, e.g., providing a low-cost substitute to otherwise unavailable financial and capital inputs. Human resources 
Fig. 6. Submodel unpacking causal dynamics influencing adequacy of stakeholder support, which is partially disaggregated in this diagram to clarify key dynamics relating to the support of two important stakeholder types, government authorities and key decision makers. Although other drivers of support, e.g., brand visibility, or legitimacy of initiative, also influence these subconcepts, these relationships are not explicitly represented here, for the sake of diagrammatic clarity and to avoid doubleaccounting.

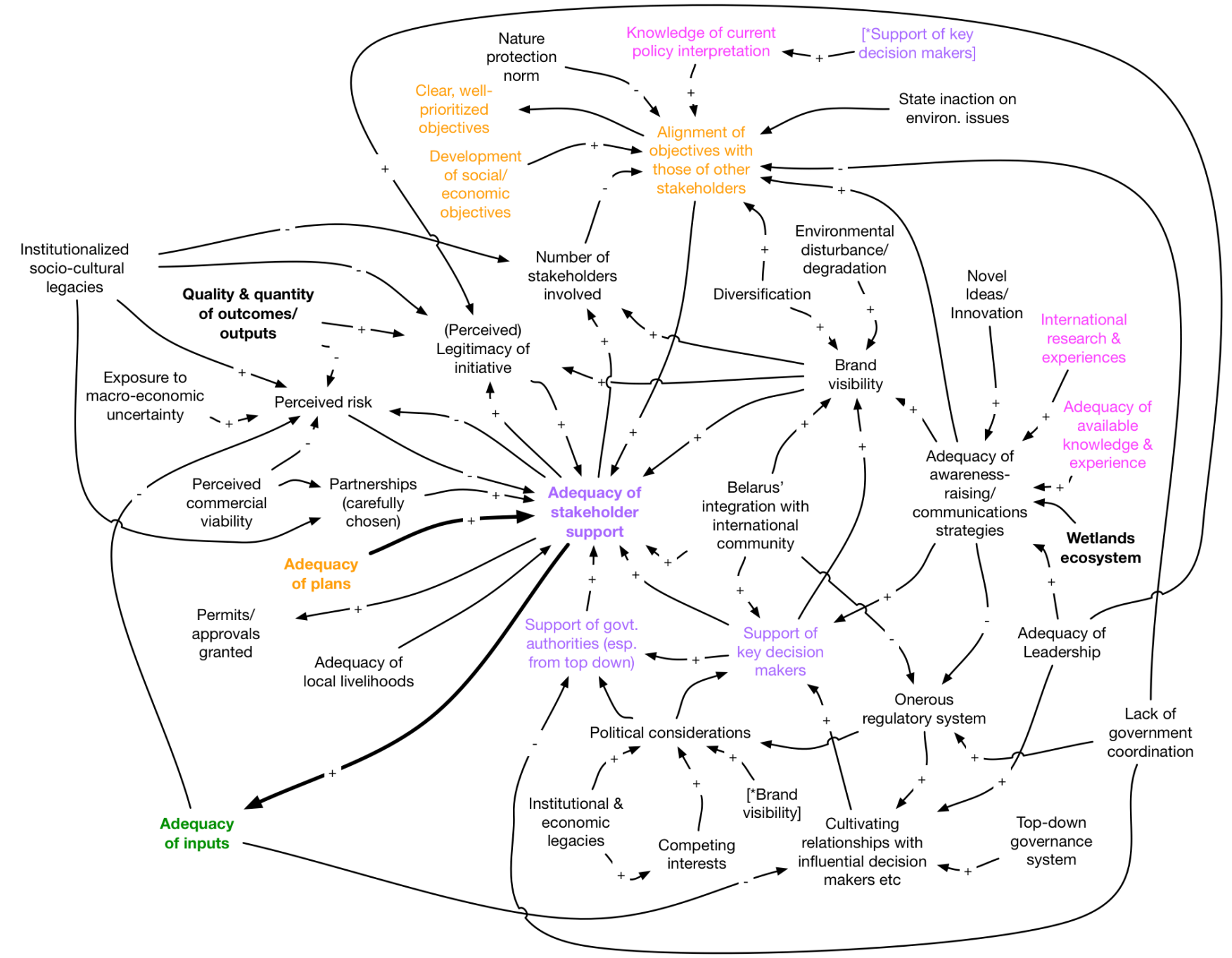

provided important knowledge and experience, but were often drained by an endless stream of administrative/bureaucratic paperwork, resulting from an onerous regulatory system.

Many of the planned activities in the studied cases were, directly or indirectly, aimed at increasing the number of wetland users, and/or the creation of local employment opportunities, and thus had important impacts on the adequacy of local livelihoods (Fig. 9). Some use-based activities involving active management measures, e.g., clearing vegetation, were obstructed by passive management requirements associated with nature protection norms or were restricted by other governmental regulatory systems. Activity rate and outcomes/outputs led to multiple direct and indirect feedbacks on stakeholder support (Figs. 5, 7, 9), including that of state authorities and key individual decision makers. In some cases, successful outcomes led to the adoption of new standards and procedures, and to invitations for initiative representatives to participate in regulatory system reform processes. These feedbacks were often slow.

Adequacy of available knowledge and experience (Fig. 8) was conceptualized as a clear understanding regarding problem scale, current interpretations of relevant government policies and strategies, key factors, system requirements, and potential solutions. Existing knowledge was accessed in a number of ways, from knowledgeable human resources, e.g., experts/specialists, competent staff and leaders; from formal sources such as national and international research organizations and databases; from informal sources such as excursions to analogue firms/initiatives, dialogue with other organizations who had relevant experiences. As such, access to existing knowledge could be obtained through support mechanisms, or was otherwise a factor of adequate financial resources. 
Fig. 7. Submodels unpacking causal dynamics influencing adequacy of inputs for wetland restoration initiatives. Inputs are disaggregated into four main types: Financial resources, Technology/fixed capital, Human resources, and Materials and other variable inputs. Fig 7 is separated into two submodels simply to reduce diagrammatic complexity and aid reader comprehension. Links from support to the various disaggregated types of inputs are aggregated into one main link in B.
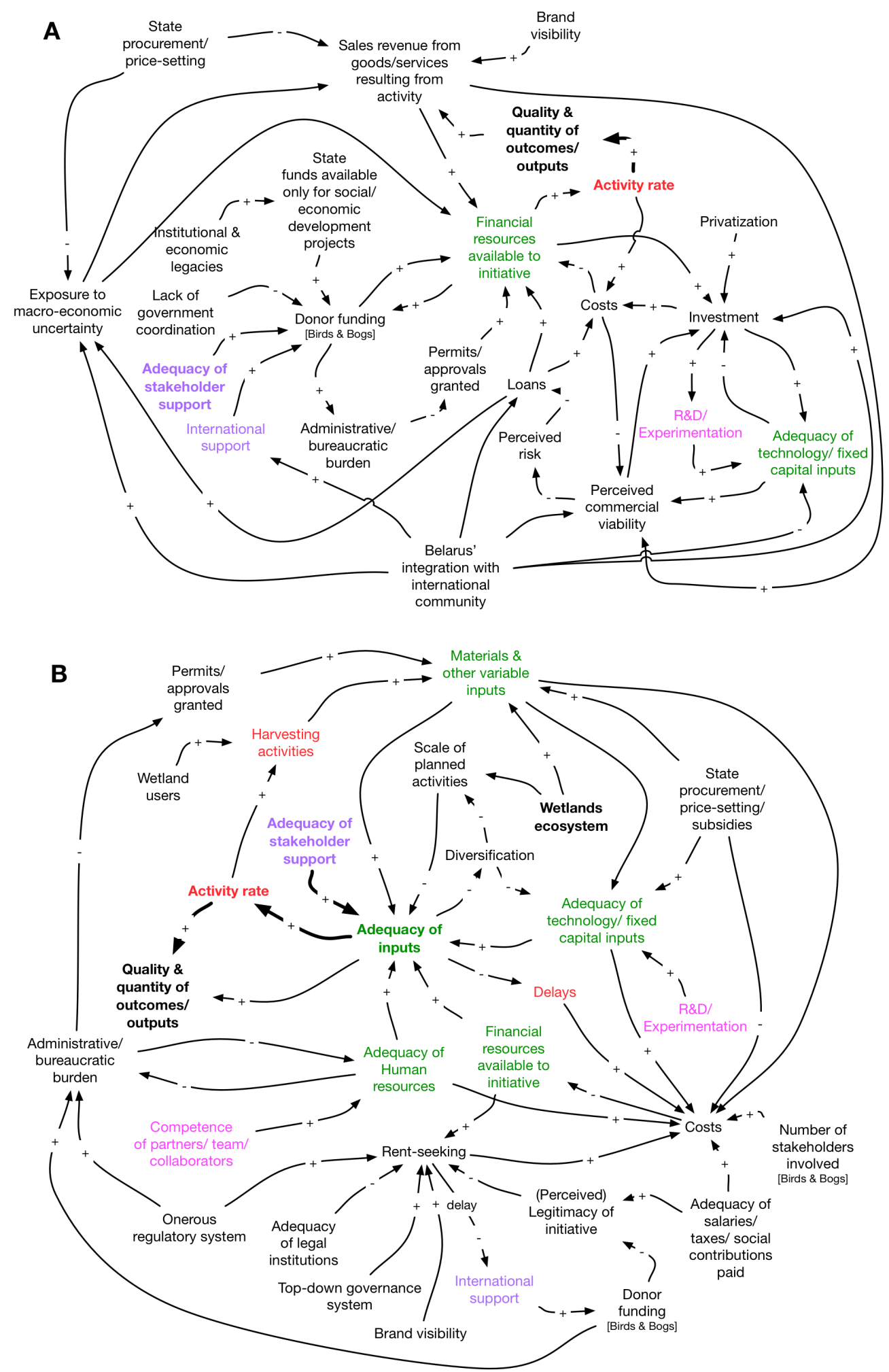
Fig. 8. Submodel unpacking causal dynamics influencing the adequacy of learning and knowledge for wetland restoration initiatives. Learning and knowledge/experience concepts are disaggregated in this submodel in order to clarify causal pathways. These concepts are otherwise aggregated together in the other submodels.

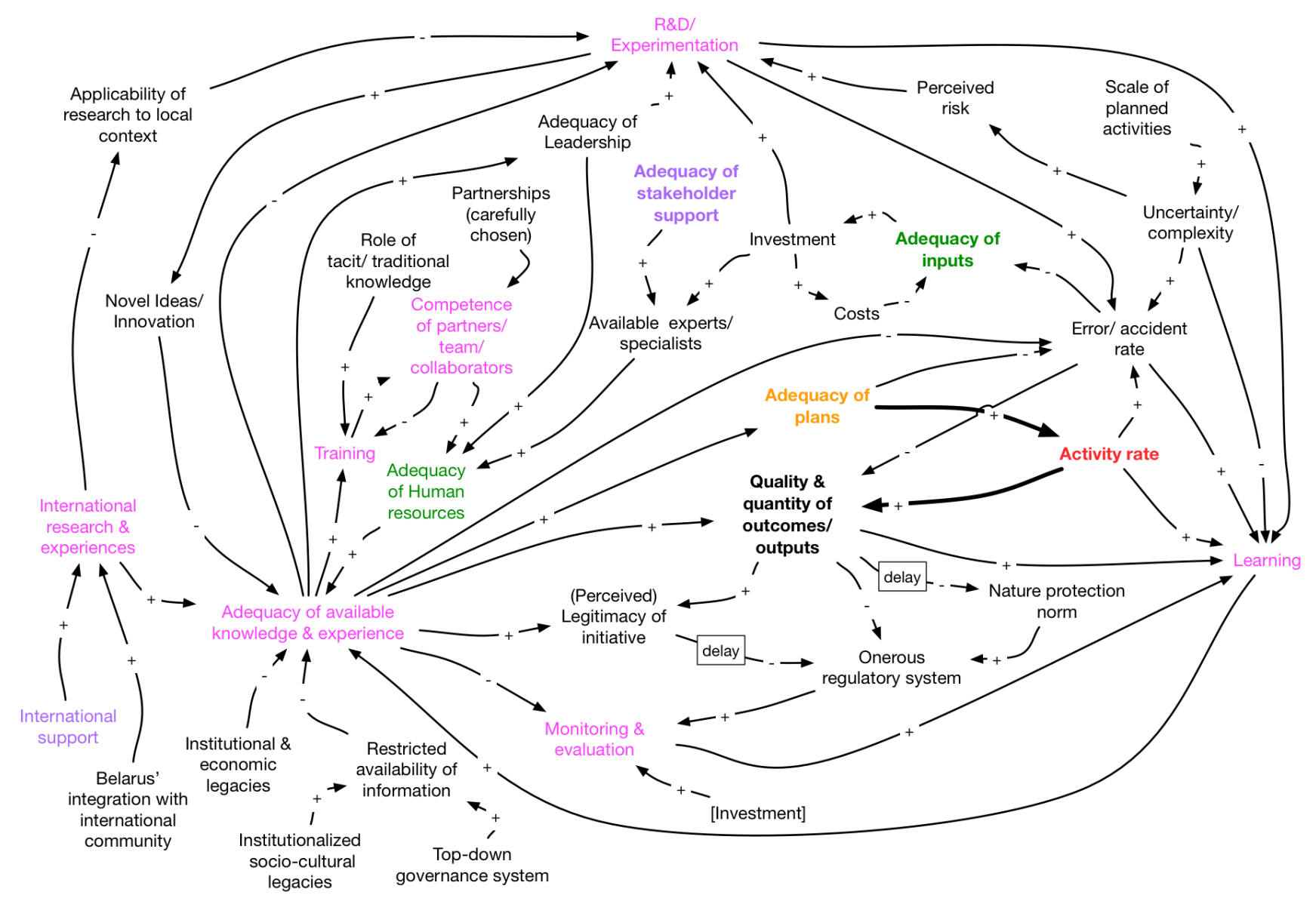

However, initiatives also adopted multiple modes of ongoing learning, and were keen to ensure the transfer of knowledge to partners, staff, collaborators, and other key stakeholders through training and communication strategies. Investment in active learning processes, e.g., $R \& D /$ experimentation, and activity rates were important determinants of learning processes. Experimentation was typically fused with implementation activities, i.e., learning by doing, with both balanced by identical feedback control from available inputs (primarily funds). However, learning by doing was complicated by factors of uncertainty and complexity, e.g., false positives/negatives or imperceptible causality.

Although the integration of Belarus with the international community, particularly regarding international research collaborations, was perceived by interviewees to have improved knowledge availability (Fig. 8), interviewees acknowledged limitations regarding the direct applicability of international research to local contexts. Initiatives used knowledge dissemination feedbacks, via awareness-raising and communication strategies (Fig. 6), to influence stakeholders in the wider system, e.g., political leaders, the general public, and consumers. However, initiatives differed in their approach to dissemination of internally generated knowledge. The leader for case Berries sought patents to protect innovations and intellectual property arising from investments in R\&D. The leader for case Bogs, on the other hand, sought to disseminate project-generated learning as freely as possible.

\section{DISCUSSION}

Opportunities and constraints for integrated and adaptive approaches to wetland restoration in state-centric, top-down contexts

\section{Opportunities}

Environmental crises are increasingly recognized as a potential trigger for institutional adaptations toward sustainability, by calling command-control management approaches into question and fragmenting political authority (Kronsell and Bäckstrand 2010, Bond et al. 2015, Pahl-Wostl 2015, Abson et al. 2017, IPBES 2018). In our case studies, various social and ecological crises, together with the collapse of the USSR, and an institutionalized lack of interest in environmental issues (Otto et al. 2011), provided windows of opportunity for the emergence of management approaches that differed in at least three ways from the state- 
Fig. 9. Submodel unpacking causal dynamics influencing the activity rate of wetland restoration initiatives in Belarus. Entrenched socio-cultural legacies of indifference and carelessness regarding the negative impacts of some users on wetlands were identified as a driver of environmental disturbance and degradation. All three cases sought, therefore, to shape public attitudes through a variety of direct awareness-raising and knowledge dissemination activities, and/or through indirect use of power, e.g., refusing to purchase unripe berries in order to affect change in picking behaviors. Brand visibility also influenced the number and types of users.

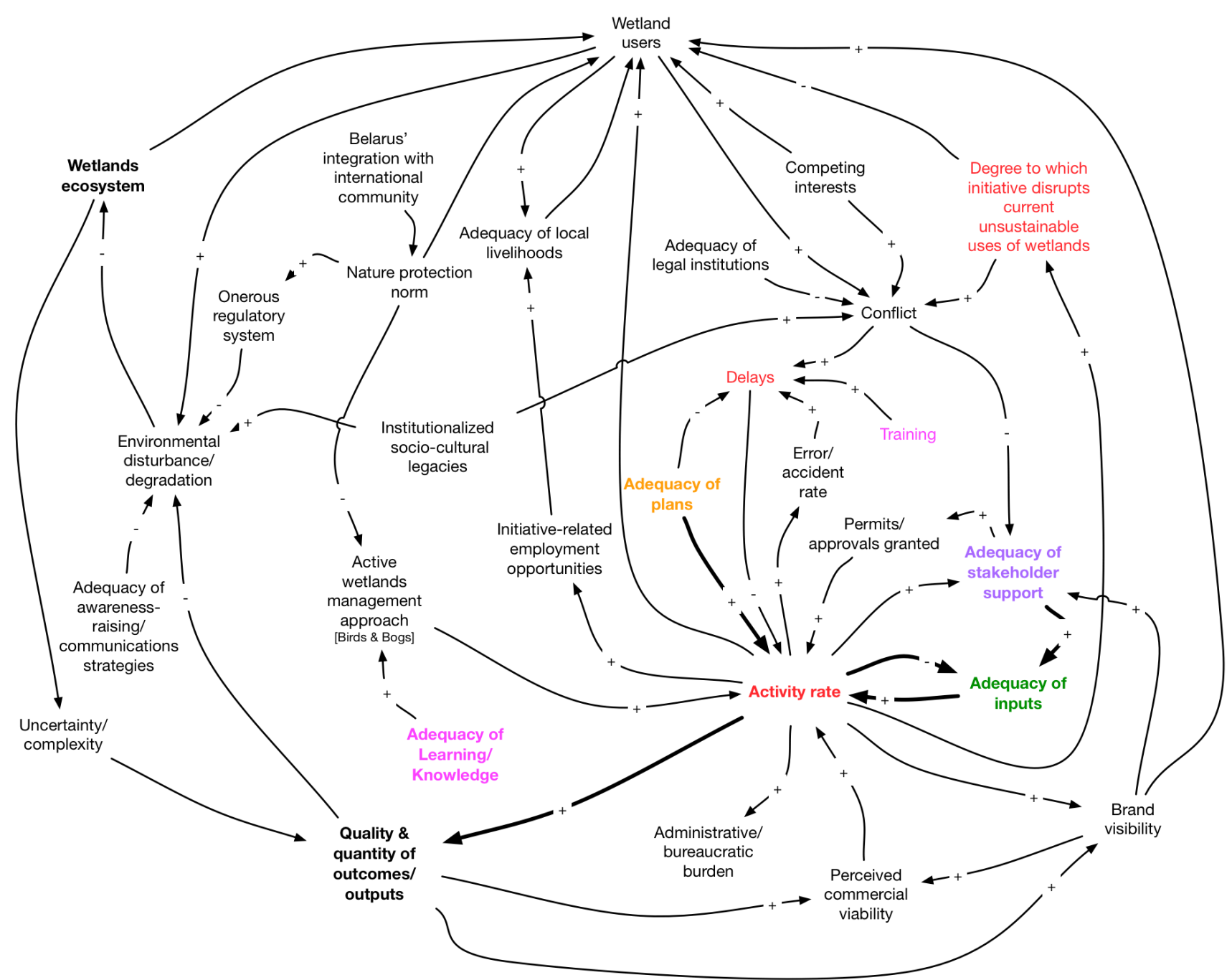

centric, top-down approaches of conventional wetlands management in Belarus (Figs. 4 and 5). First, social and ecological functions of wetlands were integrated, and management alternatives sought actively to deliver win-win outcomes. In contrast, state-centric, top-down approaches tend to dichotomize wetlands management as either resource extraction/use or biodiversity conservation/protection, managed through difficult trade-offs (Falkenmark 2004, McShane et al. 2011).

Second, in response to knowledge constraints, the studied wetlands initiatives adopted a learning-oriented mind-set in response to perceived risks and uncertainties (Fig. 8). This contrasts with the top-down flows of information that otherwise typify environmental governance and management in statecentric, top-down contexts (Elbakidze et al. 2018, Shkaruba and
Skryhan 2019). Reflexive learning processes sought to integrate multiple types of knowledge obtained through experimentation, research, and development, experts, formal participation processes, and state-compelled monitoring efforts. In our cases, knowledge obtained from international experiences was carefully assessed and adapted to local contexts, while active experimental programs shaped the emergence of innovative approaches that leveraged support across science-policy-industry interfaces.

Third, crisis-driven windows of opportunity enabled private- and civil-sector stakeholders to establish themselves as legitimate actors in wetland restoration, actively participating in decision making and coordinating roles. This indicates a partial redistribution of power and responsibilities in wetlands management systems. New stakeholders were able to further 
adapt the system from within by including new perspectives, knowledge, and inputs from a range of other nongovernmental stakeholders, including private enterprise, and through their eventual participation in regulatory reform processes. Although supporting findings in other contexts (e.g., Raik et al. 2008, Ruíz et al. 2011) and partly in line with recent results from Belarus (Niedziałkowski and Shkaruba 2018), these results contrast with earlier studies in Belarus, which highlight the exclusion of nongovernmental stakeholders from environmental governance and an increasing concentration of power around elites, preventing institutional reform (Grischenko et al. 2006, Kluvánková-Oravská et al. 2009).

Our results also show that the emergence of more integrated approaches to wetlands management was influenced by other changes in the broader institutional context, including Belarus's increased integration with the international community, where participatory norms are widely adopted (Figs. 5 and 6), e.g., EU cross-border and Eastern Neighbourhood policies, river basin cooperations, and Belarus's ratification of the Aarhus, Ramsar, Espoo, and Bern Conventions. A similar influence of international institutions on domestic environmental policy has been observed in other state-centric, top-down contexts, e.g., China (Mol and Carter 2006). National sustainable development strategies also explicitly endorse the strategic development of civil society, specifically regarding enhanced roles for domestic environmental NGOs, as well as outlining a need for institutional transformation regarding private ownership and entrepreneurship (Republic of Belarus 2004, 2015). For example, our case studies indicated that privatization of state-owned capital, often otherwise associated with adverse outcomes in post-Soviet transitions (e.g., Berberoglu 2003, Azarova et al. 2017, Brik and Shestakovskyi 2020), and the partial deregulation of state pricesetting regimes further enabled private stakeholders to emerge as new actors in wetland restoration (Figs. 7A and 7B). Taken together, these dynamics suggest an increased recognition of the need for improved cross-sectoral and multilevel integration in environmental governance in Belarus. Our case studies suggest, for example, that development of private-civil-public sector partnerships may offer a scaling-up factor for integrated, adaptive wetland restoration in state-centric, top-down contexts.

Integration with international projects and actors afforded Belarusian wetlands initiatives legitimacy, and embedded them in new contexts and networks that provided otherwise largely inaccessible channels to influential international actors, e.g., large NGOs and foreign research organizations. In line with Falaleeva and Rauschmayer (2013) and Zenchanka (2017), we therefore identify international organizations as important agents of change in wetland restoration in Belarus (Figs. 5-9). International partners provide important inputs (financial, knowledge, technological) that are otherwise often unavailable (Republic of Belarus 2004, 2015). The domestic affiliates of large-scale, wellfinanced, international organizations may be of particular importance in strongly state-centric, top-down contexts in this respect, as they appear to more easily bypass regulatory restrictions that otherwise hinder international partnerships. Governmental decision makers were also perceived to be more motivated to support high-profile projects (Fig. 6). Further support, and inputs, could thereby be leveraged, e.g., through domestic cofinancing (Fig. 7A), to drive emergent feedback loops.
Along with new arenas for being seen, international contexts provided new ways of "seeing" in terms of inspiration, new ideas, and alternate interpretations for initiatives (Fig. 5). This may be generally useful for bottom-up wetlands initiatives in order to overcome habituated blindness to the unique qualities of local wetlands.

\section{Constraints}

We identified several sets of path dependent constraints shaping the emergence of more integrated, adaptive approaches to wetland restoration in Belarus. First, institutional and regulatory frameworks surrounding wetland restoration in Belarus were perceived to be resistant to change. These frameworks remained rooted in a state-centric history, and were poorly equipped to integrate the active participation of private and civil sector actors. This supports findings regarding environmental management from other state-centric, top-down contexts (e.g., Werners et al. 2009, Costanza and Liu 2014). Although underdeveloped civil society institutions are a recognized threat to national sustainable development, reform processes remain inconsistent and direct controls continue to be concentrated in the hands of government authorities (Republic of Belarus 2004), which suffer from poor horizontal coordination (Shkaruba and Kireyeu 2013). Responsibilities for wetlands are divided across several governmental agencies, often pursuing heterogeneous, conflicting agendas. Our findings showed that wetlands initiatives sponsored by one authority could therefore be perceived as impinging on the mandate of another, risking interagency acrimony. Consequently, the support of one authority could constrain the support of another, impeding management efforts at integration at lower levels. This suggests that the establishment of flexible links (sensu Olsson et al. 2007, Pahl-Wostl 2015) between government authorities is a potentially important institutional intervention supporting wetland restoration in poorly coordinated statecentric, top-down contexts.

Despite some reforms, governmental regulatory systems were consistently described in our results as excessively onerous, opaque, and inflexible (Figs. 5-9). Regulatory control systems directly and indirectly steered wetlands planning, implementation, and learning processes, thereby constraining core feedback dynamics relating to integrated, adaptive management approaches. Echoing similar findings in China (Gaudreau and Cao 2015), new private-and civil-sector wetlands actors in Belarus must expend considerable human and financial resources navigating layers of government regulation while dealing with tremendous power asymmetries in favor of the state. Furthermore, active management measures (particularly those involving restoration or construction activities) encountered many regulatory obstacles. These findings suggest that the emergence of more integrated and adaptive approaches to wetland restoration in strongly state-centric, top-down contexts may be constrained by the lack of specialized bureaucratic knowledge necessary to efficiently navigate regulatory complexity (e.g., Shkaruba et al. 2017).

Given manifold direct and indirect regulatory constraints, and the strictly nonpartisan political stance new actors were obliged to maintain, the degree to which real power was redistributed in our cases remains debatable. Nevertheless, some nongovernmental actors persistently contest the administrative practices 
constraining nongovernmental participation in environmental management. This indicates that nongovernmental actors not only organize efforts toward more integrated and adaptive forms of management within existing conventional frameworks (e.g., Garmestani and Benson 2013), but also actively try to adapt existing frameworks via evolutionary feedback cycles driven by quality outcomes and perceived legitimacy (Figs. 5-9). Such adaptations are facilitated by awareness-raising, directed lobbying, and, as legitimacy grows, participation in regulatory reform processes. However, feedbacks to national level institutions remain tenuous.

Second, underlying these regulatory constraints are a set of sociocultural legacies perceived by our interviewees as having multiple, indirect negative influences on support for more integrated and adaptive wetlands initiatives (Figs. 6, 8, 9). Broadly, these legacies refer to entrenched attitudes of passivity, circumspection, distrust, and a widespread indifference to environmental issues, pervading society. The private sector, for example, is widely regarded as a refuge for "scoundrels" and the civil sector for "meddlers." Local people were perceived as generally indifferent to new initiatives and the utility of public input from formal participatory processes in our cases was said to be zero. Our results in these respects recall many recent studies (Otto et al. 2011, World Values Survey 2014, Shkaruba et al. 2015, Teorell et al. 2018, BuiWrzosińska 2019, Brik and Shestakovskyi 2020), which identify widespread negativism in Belarus and other former Soviet republics. Grischenko et al. (2006) contend that, outside of continued conformism, authoritarian regimes offer no possibilities for social adaptation. However, our results show heterogeneity amongst actors in this respect, with interviewees identifying the lack of indifference in certain key individuals or groups as an important factor in the success of their initiatives. Also, the existential threat to rural communities posed by depopulation (e.g., Nedelkin et al. 2017) was said to reduce opposition toward wetland restoration initiatives when contextualized as beneficial for local residents through job creation or conservation of important local natural resources. Despite local people having little power in strongly state-centric, top-down contexts, our findings suggest the importance of avoiding local opposition or conflicts because these can have unpredictable impacts. At best, such conflicts might result in delays. At worst, they may jeopardize the support of local authorities and lead to political difficulties for decision makers at higher levels.

Third, our interviewees referred to a number of specific economic constraints, including the lack of state funding for ecological initiatives, lack of an entrepreneurial sector, and inaccessibility of loans (Figs. 7A and 7B). Opaque regulatory requirements, and concomitant rent-seeking behavior, were perceived to constrain or deter international sponsorship, despite availability. Economic sanctions and fines were perceived as being arbitrarily meted out, with civil society actors especially vulnerable as well as being exposed to a high taxation burden. Although centralized procurement processes in state-centric, top-down contexts such as a Belarus may shield wetlands initiatives from some of the uncertainty of international markets, they were also perceived to curtail adaptive learning feedbacks related to market experience and thereby to reduce their self-reliance. Additionally, state pricesetting regimes may inadvertently constrain the commercial viability of production-focused initiatives. Even where nongovernmental actors are able to set their own prices, low domestic purchasing power may limit commercial viability.

Our results indicate that adequate capital inputs were key to a number of virtuous feedback loops, optimizing activity rates via efficiency improvements, reducing delays and thereby costs, increasing the perceived commercial viability of activity, and promoting support and potential inputs. Technological/fixedcapital intensity may therefore represent an important constraint to more integrated, adaptive approaches to wetland restoration in contexts where capital inputs are less readily accessible, such as Belarus. Although some capital investments are unavoidable, e.g., to meet standards requirements in new markets, large oneoff costs may be a stumbling block bringing planned activities to a halt.

Fourth, our findings show that institutional and economic legacies from the Soviet and post-Soviet eras constrain the availability of knowledge relevant to sustainable wetlands management activities, many of which rely on tacit and/or traditional forms of knowledge (Fig. 8). The ability to accumulate multiple kinds of relevant knowledge may therefore be a key factor toward the emergence of more integrated, adaptive initiatives for wetland management in Belarus and contexts with similar institutional/economic legacies, particularly where initiatives center around relatively novel concepts, e.g., ecological restoration and circular economy. International experiences are important in this respect. However, in line with earlier studies (Kluvánková-Oravská et al. 2009, Elbakidze et al. 2013, Falaleeva and Rauschmayer 2013), our results indicate that international ideas and practices require careful adaptation to ensure suitability to local biophysical and governance contexts.

Three key management strategies toward sustainable wetlands in state-centric, top-down contexts

Perception management

Our results indicate the importance of developing a flexible and adaptive approach to framing problems and solutions to identify and promote confluences of interest and synergies amongst the heterogeneous viewpoints and objectives of relevant stakeholders (Figs. 5 and 6). National environmental objectives in Belarus are often framed in the context of other policy objectives, e.g., economic growth, energy security (Republic of Belarus 2004, 2015, Grischenko et al. 2006). Alignment of wetland restoration initiatives with public sector interests is therefore largely synonymous with the inclusion of explicit social and/or economic objectives (Figs. 5 and 6). Such alignment is a key process for deriving support, knowledge, resources, and legitimacy for new initiatives. This requires adaptive leadership, especially given the lack of government coordination.

Echoing previous findings (e.g., Pahl-Wostl 2015, Dawson et al. 2017), our results indicate the importance of positioning wetland restoration at a cross-sectoral nexus between, e.g., science and business, or civil society and business. Our studied cases offered industrial partners experimental platforms to explore innovative concepts. However, cross-sectoral interfaces remain difficult to navigate, requiring experienced leadership to establish and maintain long-term partnerships. Although commercial viability is a key factor driving many such partnerships (de Blaeij et al. 
2011), this is typically difficult to prove, especially in early stages, and depends on the development trajectories of many internal and external factors, e.g., learning curves, markets, etc.

Garnering adequate support entails managing the perceived legitimacy of wetlands problems, and of the actors proposing to solve them. Legitimacy enables agency in otherwise contested domains (Bulkeley 2012). Similar to Deegan (2009) and Olsson et al. (2004), the background and professional circumstances of leadership figures provide initial legitimacy for nonstate wetlands management actors in state-centric, top-down contexts. Legitimacy is subsequently conferred by a variety of feedback processes, including by association with other legitimate actors, particularly state authorities, and by achieving successful outcomes (Figs. 5, 6, 7B, 8). This corroborates Ruíz et al. (2011) regarding the dynamic nature of legitimacy in wetlands management. Donation-reliant initiatives are particularly dependent on legitimizing strategies to ensure continuous financial support. Even financially self-reliant initiatives need to manage perceptions of their legitimacy in order to obtain permissions, as well as to attract staff, partners, and consumers.

Communications and awareness-raising strategies raised the visibility of wetlands "brands" through development of a broad set of targeted narratives concerning problem-framing, place, activities, and organizations, as well as outcomes and outputs (Fig. 6). Identification of unique selling points, e.g., innovative management approaches, charismatic species, provides a key focus for the development of creative, interactive, brand-focused communications and awareness-raising strategies. Beyond typical media campaigns, examples from case studies included field trips, expert-guided tours, and wetlands-themed festivals. High public visibility may indirectly support sustainable wetlands management in state-centric, top-down contexts by legitimizing initiatives, increasing political pressure via public opinion, providing public relations opportunities for partner organizations, and through long-term educational impacts.

Strongly vertical hierarchies throughout public sector authorities, and other key stakeholder organizations, in combination with relatively nontransparent regulatory frameworks, provide individual decision makers, e.g., ministers, with considerable personal influence as gatekeepers in Belarus and other strongly state-centric, top-down contexts (e.g., Kluvánková-Oravská et al. 2009). This study shows that the cultivation of personal relationships with gatekeepers, or otherwise tailoring communications and awareness-raising activities toward them, is an efficient strategy (Fig. 6). The support of such individuals in strongly state-centric, top-down contexts may provide a key source of legitimacy, ensuring alignment of plans and objectives with current policy interpretations, delivering support at subordinate levels, and consequently inputs and permissions. However, gatekeepers may also be influenced by competing interests, e.g., lobbying for peat mining, and changes in personal preferences. Personal relationships are also highly sensitive to disruption. Sudden changes in leadership may lead to reinterpretation of policies and strategies, thus altering the degree to which wetlands interests align.

\section{Risk management}

Apart from some technical risks due to inadequate knowledge, most risks identified by our cases related to systemic uncertainty in the external decision-making environment, outside of the direct control of initiatives. Along with good preparation and timely decision making, the diversification of planned activities and outputs promoted flexibility and adaptability. Diversification as a risk management strategy integrates a broad range of objectives, novel ideas, and the multiple perspectives of different stakeholders, thus promoting alignment of interests and objectives (Figs. 5, 6, 7B). A diverse portfolio of initiatives, tools, and approaches provides alternative pathways to key objectives, new arenas for brand visibility, and opportunities for waste minimization. On the downside, diversification often necessitates involvement of potentially conflicting interests, places additional demands on existing technology/capital inputs, and increases the leadership challenge.

Constraints relating to technology/fixed capital intensity expose wetlands initiatives to financial risks associated with large investments. The lack of a well-developed entrepreneurial sector, accustomed to engaging with such risks, may compound this constraint in strongly state-centric, top-down contexts such as Belarus. Our cases demonstrated innovative strategies to overcome such hurdles, including establishment of nonprofit organizations to assume capital risks, substitution, e.g., using human labor instead of machines, and steady reinvestment of profits into a continuous $\mathrm{R} \& \mathrm{D}$ program.

\section{Learning and knowledge management}

Knowledge adequacy played a central role in the system dynamics of studied wetlands initiatives, closing core feedback loops influencing adequacy of plans, legitimacy and support, as well as connecting successful outcomes to institutional and regulatory reform processes. This supports current theories concerning the importance of robust knowledge management mechanisms and the integration of learning and experimentation into institutions and policies to support the emergence of sustainable governance and management arrangements (Pahl-Wostl 2015, Popa et al. 2015, Abson et al. 2017). Studied initiatives were able to leverage their growing knowledge, and the legitimacy it conferred, to influence the behavior of other actors, either directly, e.g., via purchasing standards, or indirectly, through awareness-raising and/or lobbying campaigns. Additionally, leaders of successful initiatives amassed expert knowledge, and were thus invited to participate in policy reform processes, while successful practices were adopted as formal benchmarks. These findings indicate multiloop learning cycles (e.g., Argyris and Schön 1978, 1995, Johannessen et al. 2019), which are central to integrated, adaptive governance and management theories (Pahl-Wostl 2015). They also illustrate the scalable returns and positive spill-over effects (Sterman 2000) that investments in adaptive learning cycles and efficient forms of knowledge dissemination may have for wetland restoration in state-centric, top-down contexts. However, several authors warn that emergent processes, e.g., transformational learning, cannot be effectively planned or directed (e.g., Kurtz and Snowden 2003, Miller and Page 2007, Tosey et al. 2011). In line with Shkaruba et al. (2015), our findings indicate that strictly controlled information flows, strong top-down structures, indifferent socio-cultural norms, and intellectual property issues present significant obstacles to effective knowledge dissemination, and to transformational, learning-driven feedback loops for more integrated and adaptive approaches to wetland restoration and management in Belarus. 
Structured adaptive learning cycles are useful for managing complexity and mitigating risks, providing effective "safe-to-fail" strategies, particularly in rigid bureaucracies (Heifetz et al. 2009, Cilliers et al. 2013). Small, early, inexpensive mistakes, for example, help complex systems escape from less productive outcomes and converge upon more productive ones (Miller and Page 2007). In addition to such utility, our findings also indicate that small, early positive outcomes from learning cycles are important to drive key support feedback loops by reducing perceived risks and promoting the perceived legitimacy of initiatives. In line with Dawson et al. (2017), these results suggest that success factors for the emergence of more integrated, adaptive wetland restoration initiatives in state-centric, top-down contexts may include reducing the dimensionality of planned interventions and commencing implementation of smaller interventions as early as practicable.

\section{CONCLUSIONS}

Natural resource governance and management regimes are emergent phenomena embedded in the broader social-ecological systems from within which they emerge. Our analysis of wetland restoration initiatives in Belarus indicates that many aspects associated with integrated, adaptive approaches to natural resource governance and management may, to some degree, emerge in strongly state-centric, top-down contexts. Nevertheless, we identified a broad set of interconnected, path-dependent constraints that continue to shape approaches to wetland restoration and management in Belarus. Many of these constraints were related to institutional, socio-cultural, biophysical, and economic legacies of the Soviet and post-Soviet periods. Interactions among constraints over time were, however, shown to create windows of opportunity, e.g., crises, for the emergence of wetland restoration approaches that contrasted with state-centric, top-down approaches otherwise common in Belarus. Emergent approaches were enabled by the increased influence of domestic nongovernmental actors and the international community. However, the successful integration of active nongovernmental actors into wetland restoration remained strongly constrained by state-centric, top-down institutional and regulatory contexts. Other key constraints were availability of knowledge, financing difficulties, and the technology/capital intensity of sustainability initiatives. Three key enabling strategies were (1) perception management, e.g., regarding stakeholder perceptions of the legitimacy of nongovernmental participants, (2) risk management, e.g., large capital investments, and (3) learning and knowledge management, e.g., efficient forms of knowledge dissemination.

Accelerated reform processes toward a more flexible, transparent, and coordinated regulatory environment may be required to scale up more integrated, adaptive approaches to wetland management in pursuit of sustainable outcomes. Other factors for scaling up include provision of technology/capital inputs and/or financial support for such investments, improved access to markets for sustainably produced wetlands benefits, as well as recruitment of leaders with learning-oriented mindsets and appropriate sets of ecological, economic, and communications skills. Continued integration with the international community is a key ingredient in facilitating a sustainability transition in Belarusian wetlands.
${ }^{[1]}$ Although widely perceived as successful in the longer term, each of these initiatives suffered several set-backs along the way for a number of reasons, including insufficient support, inadequate knowledge, planning failures, and experimental errors. The result causal loop diagrams capture the dynamics of these failures, i.e., as the inverse of any normative concept. For example, where the alignment of objectives with those of other stakeholders was shown to contribute to the adequacy of support, the inverse is also true: where initiatives did not clearly align their objectives with those of other stakeholders, they also generally failed to garner sufficient support, which jeopardized their ability to obtain adequate inputs for implementation of planned activities.

[2] CLDs provide a concise format for describing complex interconnected system structures and behavioral directionality. CLDs use arrows to indicate direct causal relationships between independent and dependent variables. These relationships can either be in the same direction, represented by a positive (+) sign, or in the opposing direction, represented by a negative (-) sign. Thus, if independent variable A connects to dependent variable B by an arrow with a plus (+) sign, the underlying logic of the CLD is that an increase (decrease) in A's behavior will lead to an increase (decrease) in B's behavior. If the arrow connecting A to $\mathrm{B}$ is accompanied by a negative (-) sign then the CLD indicates that an increase (decrease) in A will lead to a decrease (increase) in $\mathrm{B}$.

Responses to this article can be read online at: https://www.ecologyandsociety.org/issues/responses. php/12139

\section{Acknowledgments:}

This work was supported by FORMAS [grant numbers 2011-1737 and 2017:1342] to Per Angelstam, by the Swedish Institute [grant number 10976/2013] to Marine Elbakidze, and by the EU Erasmus + Program (Jean Monnet Projects - grant 587697) to Anton Shkaruba.

\section{Data Availability:}

The datalcode that support the findings of this study are available on request from the corresponding author, LD. Anonymized intermediate data is available in an Electronic Appendix, published with this article. However, original data are not publicly available because they may contain information that could compromise the privacy of research participants.

\section{LITERATURE CITED}

Abson, D. J., J. Fischer, J. Leventon, J. Newig, T. Schomerus, U. Vilsmaier, H. von Wehrden, P. Abernethy, C. D. Ives, N. W. Jager, and D. J. Lang. 2017. Leverage points for sustainability transformation. Ambio 46(1):30-39. https://doi.org/10.1007/ s13280-016-0800-y

Allen, C. R., J. J. Fontaine, K. L. Pope, and A. S. Garmestani. 2011. Adaptive management for a turbulent future. Journal of Environmental Management 92(5):1339-1345. https://doi.org/10.1016/ j.jenvman.2010.11.019 
Angelstam, P., J. Munoz-Rojas, and T. Pinto-Correia. 2019. Landscape concepts and approaches foster learning about ecosystem services. Landscape Ecology 34(7):1445-1460. https:// doi.org/10.1007/s10980-019-00866-Z

Argyris, C., and D. A. Schön. 1978. Organizational learning: a theory of action perspective. Addison-Wesley, New York, New York, USA.

Argyris, C., and D. A. Schön. 1995. Organizational learning II: theory, method and practice. Addison-Wesley, Reading, Massachusetts, USA.

Armitage, D. 2005. Adaptive capacity and community-based natural resource management. Environmental Management 35 (6):703-715. https://doi.org/10.1007/s00267-004-0076-Z

Azarova, A., D. Irdam, A. Gugushvili, M. Fazekas, G. Scheiring, P. Horvat, D. Stefler, I. Kolesnikova, V. Popov, I. Szelenyi, D. Stuckler, M. Marmot, M. Murphy, M. McKee, M. Bobak, and L. King. 2017. The effect of rapid privatisation on mortality in mono-industrial towns in post-Soviet Russia: a retrospective cohort study. Lancet Public Health 2(5):231-238. https://doi. org/10.1016/S2468-2667(17)30072-5

Bäckstrand, K. 2004. Scientisation vs. civic expertise in environmental governance: eco-feminist, eco-modern and postmodern responses. Environmental Politics 13(4):695-714. https:// doi.org/10.1080/0964401042000274322

Bäckstrand, K., J. Khan, A. Kronsell, and E. Lövbrand. 2010. The promise of new modes of environmental governance. Pages 3-28 in K. Bäckstrand, J. Khan, A. Kronsell, and E. Lövbrand, editors. Environmental politics and deliberative democracy: examining the promise of new modes of governance. Edward Elgar, Cheltenham, UK. https://doi.org/10.4337/9781849806411.00009

Bambalov, N. N. 2009. Degradation of drained peat soils in Belarus. EGU General Assembly, Vienna, Austria.

Becker, E. 2009. Problem transformations in transdisciplinary research. Pages 30-56 in G. Hirsh Hadorn, editor. Unity in knowledge (in transdisciplinary research for sustainability). Volume 2. UNESCO EOLSS, Oxford.

BelTA. 2018. Peat extraction in Belarus up by $19 \%$ in 2018 up to almost 2.6m tons. BelTA, 19 September.

Berberoglu, B. 2003. Transnational capital and the impact of privatization and market-oriented reforms on East European agriculture: focus on Romania in transition, 1989-2000. International Review of Sociology 13(2):273-302. https://doi. org/10.1080/0390670032000117272

Bohn U., R. Neuhäusle, G. Gollub, C. Hettwer, Z. Neuhäuslová, T. Raus, H. Schlüter, and H. Weber. 2003. Map of the natural vegetation of Europe. German Federal Agency for Nature Conservation, Bonn, Germany. [online] URL: http://www. floraweb.de/vegetation/dnld_eurovegmap.html

Bond, A., A. Morrison-Saunders, J. A. E. Gunn, J. Pope, and F. Retief. 2015. Managing uncertainty, ambiguity and ignorance in impact assessment by embedding evolutionary resilience, participatory modelling and adaptive management. Journal of Environmental Management 151:97-104. https://doi.org/10.1016/ j.jenvman.2014.12.030
Bosch, O., K. Maani, and C. Smith. 2007. Systems thinking language of complexity for scientists and managers. Pages 57-66 in S. Harrison, A. Bosch, and J. Herbohn, editors. Improving the triple bottom line returns from small-scale forestry, Proceedings from an International Conference. The University of Queensland, Gatton, Queensland, Australia.

Brik, T., and O. Shestakovskyi. 2020. Attitudes about privatization and the shadow of communism: 25 years of antimarket scepticism. Pages 35-53 in A. Veira-Ramos, T. Liubyva, and E. Golovakha, editors. Ukraine in transformation. First edition. Palgrave Macmillan, Cham, Switzerland. https://doi. org/10.1007/978-3-030-24978-6 3

Bryman, A. 2004. Social research methods. Second edition. Oxford University Press, New York, New York, USA.

Bui-Wrzosińska, L. 2019. States of change: attitudes in Central and Eastern Europe 30 years after the fall of the Berlin Wall. Open Society Foundation, New York, New York, USA.

Bulkeley, H. 2012. Governance and the geography of authority: modalities of authorisation and the transnational governing of climate change. Environment and Planning A: Economy and Space 44(10):2428-2444. https://doi.org/10.1068/a44678

Bureš, V. 2017. A method for simplification of complex group causal loop diagrams based on endogenisation, encapsulation and order-oriented reduction. Systems 5(3):46. https://doi.org/10.3390/ systems 5030046

Chaffin, B. C., H. Gosnell, and B. A. Cosens. 2014. A decade of adaptive governance scholarship: synthesis and future directions. Ecology and Society 19(3):56. https://doi.org/10.5751/ES-06824-190356

Chaffin, B. C., and L. H. Gunderson. 2016. Emergence, institutionalization and renewal: rhythms of adaptive governance in complex social-ecological systems. Journal of Environmental Management 165:81-87. https://doi.org/10.1016/j.jenvman.2015.09.003

Checkland, P. 1981. Systems thinking, systems practice. Wiley, Chichester, UK.

Chu, D., R. Strand, and R. Fjelland. 2003. Theories of complexity. Complexity 8(3):19-30. https://doi.org/10.1002/ cplx.10059

Cilliers, P., H. C. Biggs, S. Blignaut, A. G. Choles, J. S. Hofmeyr, G. P. W. Jewitt, and D. J. Roux. 2013. Complexity, modeling, and natural resource management. Ecology and Society 18(3):1. https://doi.org/10.5751/ES-05382-180301

Corbin, J., and A. Strauss. 2008. Basics of qualitative research: techniques and procedures for developing grounded theory. Third edition. SAGE, Thousand Oaks, California, USA. https://doi. org/10.4135/9781452230153

Costanza, R., and S. Liu. 2014. Ecosystem services and environmental governance: comparing China and the U.S. Asia and the Pacific Policy Studies 1(1):160-170. https://doi. org/10.1002/app5.16

Coyle, G. 2000. Qualitative and quantitative modelling in system dynamics: some research questions. System Dynamics Review 16:225-244. https://doi.org/10.1002/1099-1727(200023)16:3<225:: AID-SDR $195>3.0$. CO;2-D 
Davidson, N. C. 2014. How much wetland has the world lost? Long-term and recent trends in global wetland area. Marine and Freshwater Research 65(10):934-941. https://doi.org/10.1071/ MF14173

Dawson, L., M. Elbakidze, P. Angelstam, and J. Gordon. 2017. Governance and management dynamics of landscape restoration at multiple scales: learning from successful environmental managers in Sweden. Journal of Environmental Management 197:24-40. https://doi.org/10.1016/j.jenvman.2017.03.019

de Blaeij, A. T., N. Polman, and S. Reinhard. 2011. Economic governance to expand commercial wetlands: within- and crossscale challenges. Ecology and Society 16(1):33. https://doi. org/10.5751/ES-03933-160133

Deegan, M. 2009. Developing causal map codebooks to analyze policy recommendations: a content analysis of floodplain management recommendations. Proceedings of the 27th International Conference of the System Dynamics Society. System Dynamics Society, Littleton, Massachusetts, USA.

Eden, C. 2004. Analyzing cognitive maps to help structure issues or problems. European Journal of Operational Research 159 (3):673-686. https://doi.org/10.1016/S0377-2217(03)00431-4

Elbakidze, M., T. Hahn, N. E. Zimmermann, P. Cudlín, N. Friberg, P. Genovesi, R. Guarino, A. Helm, B. Jonsson, S. Lengyel, B. Leroy, T. Luzzati, A. Milbau, A. Pérez-Ruzafa, P. Roche, H. Roy, R. Sabyrbekov, A. Vanbergen, and V. Vandvik. 2018. Direct and indirect drivers of change in biodiversity and nature's contributions to people. Pages 385-570 in M. Rounsevell, M. Fischer, A. Torre-Marin Rando, and A. Mader, editors. The IPBES regional assessment report on biodiversity and ecosystem services for Europe and Central Asia. Secretariat of the Intergovernmental Science-Policy Platform on Biodiversity and Ecosystem services, Bonn, Germany.

Elbakidze, M., T. Hahn, V. Mauerhofer, P. Angelstam, and R. Axelsson. 2013. Legal framework for biosphere reserves as learning sites for sustainable development: a comparative analysis of Ukraine and Sweden. Ambio 42(2):174-187. https://doi. org/10.1007/s13280-012-0373-3

Epstein, G., J. Pittman, S. M. Alexander, S. Berdej, T. Dyck, U. Kreitmair, K. J. Raithwell, S. Villamayor-Tomas, J. Vogt, and D. Armitage. 2015. Institutional fit and the sustainability of socialecological systems. Current Opinion in Environmental Sustainability 14:34-40. https://doi.org/10.1016/j.cosust.2015.03.005

Falaleeva, M., and F. Rauschmayer. 2013. Evaluating environmental governance in a Belarusian World Bank biodiversity project. Environmental Conservation 40(02):147-156. https://doi.org/10.1017/S0376892913000027

Falkenmark, M. 2004. Towards integrated catchment management: opening the paradigm locks between hydrology, ecology and policy-making. International Journal of Water Resources Development 20(3):275-281. https://doi. org/10.1080/0790062042000248637

Finlayson, C. M., and A. G. Spiers, editors. 1999. Global review of wetland resources and priorities for wetland inventory. Supervising Scientist Report 144 / Wetlands International Publication 53. Supervising Scientist, Canberra, Australia.
Folke, C., T. Hahn, P. Olsson, and J. Norberg. 2005. Adaptive governance of social-ecological systems. Annual Review of Environment and Resources 30(1):441-473. https://doi.org/10.1146/ annurev.energy.30.050504.144511

Garmestani, A. S., and M. H. Benson. 2013. A framework for resilience-based governance of social-ecological systems. Ecology and Society 18(1):9. https://doi.org/10.5751/ES-05180-180109

Gaudreau, M., and H. Cao. 2015. Political constraints on adaptive governance: environmental NGO networks in Nanjing, China. Journal of Environment and Development 24(4):418-444. https://doi.org/10.1177/1070496515602044

Gonzalès, R., and L. Parrott. 2012. Network theory in the assessment of the sustainability of social-ecological systems. Geography Compass 6:76-88. https://doi.org/10.1111/ j.1749-8198.2011.00470.x

Gregory, R., D. Ohlson, and J. Arvai. 2006. Deconstructing adaptive management: criteria for applications to environmental management. Ecological Applications 16(6):2411-2425. https:// doi.org/10.1890/1051-0761(2006)016[2411:DAMCFA]2.0.CO;2

Grischenko, J., N. Elsukova, and E. Kuchko. 2006. Local governance in Belarus during the regime of authoritarian democracy. Pages 205-230 in S. Szücs and L. Strömberg, editors. Local elites, political capital and democratic development: governing leaders in seven European countries. VS Verlag für Sozialwissenschaften, Wiesbaden, Germany. https://doi. org/10.1007/978-3-531-90110-7 7

Grubler, A., Y. Ermoliev, and A. Kryazhimskiy. 2015. Coping with uncertainties-examples of modeling approaches at IIASA. Technological Forecasting and Social Change 98:213-222. https:// doi.org/10.1016/j.techfore.2015.06.004

Halbe, J., C. Pahl-Wostl, J. Sendzimir, and J. Adamowski. 2013. Towards adaptive and integrated management paradigms to meet the challenges of water governance. Water Science and Technology 67(11):2651-2660. https://doi.org/10.2166/wst.2013.146

Heifetz, R., A. Grashow, and M. Linsky. 2009. The practice of adaptive leadership - tools and tactics for changing your organization and the world. Harvard Business, Boston, Massachusetts, USA.

Inam, A., J. Adamowski, J. Halbe, and S. Prasher. 2015. Using causal loop diagrams for the initialization of stakeholder engagement in soil salinity management in agricultural watersheds in developing countries: a case study in the Rechna Doab watershed, Pakistan. Journal of Environmental Management 152:251-267. https://doi.org/10.1016/j.jenvman.2015.01.052

Intergovernmental Science-Policy Platform on Biodiversity and Ecosystem Services (IPBES). 2018. The IPBES regional assessment report on biodiversity and ecosystem services for Europe and Central Asia. M. Rounsevell, M. Fischer, A. Torre-Marin Rando, and A. Mader, editors. IPBES, Bonn, Germany.

Jager, N., E. Challies, E. Kochskämper, J. Newig, D. Benson, K. Blackstock, K. Collins, A. Ernst, M. Evers, J. Feichtinger, O. Fritsch, G. Gooch, W. Grund, B. Hedelin, N. Hernández-Mora, F. Hüesker, D. Huitema, K. Irvine, A. Klinke, L. Lange, D. Loupsans, M. Lubell, C. Maganda, P. Matczak, M. Parés, H. Saarikoski, L. Slavíková, S. van der Arend, and Y. von Korff. 2016. 
Transforming European water governance? Participation and river basin management under the EU Water Framework Directive in 13 member states. Water 8(4):156. https://doi. org/10.3390/w8040156

Jahn, T., M. Bergmann, and F. Keil. 2012. Transdisciplinarity: between mainstreaming and marginalization. Ecological Economics 79:1-10. https://doi.org/10.1016/j.ecolecon.2012.04.017

Johannessen, A., A. Gerger Swartling, C. Wamsler, K. Andersson, J. T. Arran, D. I. Hernández Vivas, and T. A. Stenström. 2019. Transforming urban water governance through social (tripleloop) learning. Environmental Policy and Governance 29 (2):144-154. https://doi.org/10.1002/eet.1843

Joosten, H. 2010. The global peatland $\mathrm{CO}_{2}$ picture: peatland status and drainage related emissions in all countries of the world. Wetlands International, Wageningen, The Netherlands.

Juarrero, A. 2000. Dynamics in action: intentional behavior as a complex system. Emergence 2(2):24-57. https://doi.org/10.1207/ $\underline{\mathrm{s} 15327000 \mathrm{em} 0202 \quad 03}$

Kininmonth, S., A. Bergsten, and Ö. Bodin. 2015. Closing the collaborative gap: aligning social and ecological connectivity for better management of interconnected wetlands. Ambio 44 (1):138-148. https://doi.org/10.1007/s13280-014-0605-9

Kirschke, S., J. Newig, J. Völker, and D. Borchardt. 2017. Does problem complexity matter for environmental policy delivery? How public authorities address problems of water governance. Journal of Environmental Management 196:1-7. https://doi. org/10.1016/j.jenvman.2017.02.068

Kluvánková-Oravská, T., V. Chobotová, I. Banaszak, L. Slavikova, and S. Trifunovova. 2009. From government to governance for biodiversity: the perspective of Central and Eastern European transition countries. Environmental Policy and Governance 19(3):186-196. https://doi.org/10.1002/eet.508

Koontz, T. M., D. Gupta, P. Mudliar, and P. Ranjan. 2015. Adaptive institutions in social-ecological systems governance: a synthesis framework. Environmental Science and Policy 53(Part B):139-151. https://doi.org/10.1016/j.envsci.2015.01.003

Kozulin, A., N. Tanovitskaya, and N. Minchenko. 2018. Developing a national strategy for the conservation and sustainable use of peatlands in the Republic of Belarus. Mires \& Peat 21(1):1-17.

Kozulin, A., S. Zuyonok, and V. Rakovich. 2010. Local and global impacts of mire drainage: an impetus for hydrology restoration: Yelnia Mire, Belarus. Pages 355-366 in M. Eiseltová, editor. Restoration of lakes, streams, floodplains, and bogs in Europe: principles and case studies. Springer, Dordrecht, The Netherlands. https://doi.org/10.1007/978-90-481-9265-6 17

Kronsell, A., and K. Bäckstrand. 2010. Rationalities and forms of governance: a framework for analysing the legitimacy of new modes of governance. Pages 28-46 in E. Bäckstrand, K. Khan, J. Kronsell, and A. Lövbrand, editors. Environmental politics and deliberative democracy. Examining the promise of new modes of governance. Edward Elgar, Cheltenham, UK. https://doi. org/10.4337/9781849806411.00010
Kurtz, C. F., and D. J. Snowden. 2003. The new dynamics of strategy: sense-making in a complex and complicated world. IEEE Engineering Management Review 31(4):110-130. https:// doi.org/10.1109/emr.2003.24944

Kvale, S., and S. Brinkmann. 2008. Interview - introduktion til et håndvark. Hans Reitzels Forlag, Copenhagen, Denmark.

Kvale, S., and S. Brinkmann. 2009. Interviews: learning the craft of qualitative research interviewing. Second edition. SAGE, Los Angeles, California, USA.

Lade, S. J., and S. Niiranen. 2015. Generalized modeling of empirical social-ecological systems. Natural Resource Modeling 30:e12129. https://doi.org/10.1111/nrm.12129

Lemos, M. C., and A. Agrawal. 2006. Environmental governance. Annual Review of Environment and Resources 31(1):297-325. https://doi.org/10.1146/annurev.energy.31.042605.135621

Lövbrand, E., and J. Khan. 2010. The deliberative turn in green political theory. Pages 47-66 in E. Bäckstrand, K. Khan, J. Kronsell, and A. Lövbrand, editors. Environmental politics and deliberative democracy. Examining the promise of new modes of governance. Edward Elgar, Cheltenham, UK. https://doi. org/10.4337/9781849806411.00011

Macleod, C. J. A., D. Scholefield, and P. M. Haygarth. 2007. Integration for sustainable catchment management. Science of the Total Environment 373(2-3):591-602. https://doi.org/10.1016/ j.scitotenv.2006.12.029

Manton, M., and P. Angelstam. 2018. Defining benchmarks for restoration of green infrastructure: a case study combining the historical range of variability of habitat and species' requirements. Sustainability 10(2):326. https://doi.org/10.3390/ $\underline{\text { su10020326 }}$

McShane, T. O., P. D. Hirsch, T. C. Trung, A. N. Songorwa, A. Kinzig, B. Monteferri, D. Mutekanga, H. Van Thang, J. L. Dammert, M. Pulgar-Vidal, M. Welch-Devine, J. P. Brosius, P. Coppolillo, and S. O'Connor. 2011. Hard choices: making tradeoffs between biodiversity conservation and human well-being. Biological Conservation 144(3):966-972. https://doi.org/10.1016/ j.biocon.2010.04.038

Meli, P., J. M. R. Benayas, P. Balvanera, and M. M. Ramos. 2014. Restoration enhances wetland biodiversity and ecosystem service supply, but results are context-dependent: a meta-analysis. PLoS ONE 9(4):e93507. https://doi.org/10.1371/journal.pone.0093507

Miller, J. H., and S. E. Page. 2007. Complex adaptive systems: an introduction to computational models of social life. Princeton University Press, Princeton, New Jersey, USA. https://doi. org/10.1515/9781400835522

Mol, A. P. J., and N. T. Carter. 2006. China's environmental governance in transition. Environmental Politics 15(2):149-170. https://doi.org/10.1080/09644010600562765

Nedelkin, A. A., S. V Novikov, V. A. Titov, D. V Sannikov, A. V Mikhailova, and L. N. Popova. 2017. Development of human resources of agro-industrial complex. Journal of Applied Economic Sciences XII:1932-1942.

Niedziałkowski, K., and A. Shkaruba. 2018. Governance and legitimacy of the Forest Stewardship Council certification in the 
national contexts - a comparative study of Belarus and Poland. Forest Policy and Economics 97:180-188. https://doi.org/10.1016/ j.forpol.2018.10.005

Olsson, P., C. Folke, V. Galaz, T. Hahn, and L. Schultz. 2007. Enhancing the fit through adaptive co-management: creating and maintaining bridging functions for matching scales in the Kristianstads Vattenrike Biosphere Reserve, Sweden. Ecology and Society 12(1):28. https://doi.org/10.5751/ES-01976-120128

Olsson, P., C. Folke, and T. Hahn. 2004. Social-ecological transformation for ecosystem management: the development of adaptive co-management of a wetland landscape in southern Sweden. Ecology and Society 9(4):2. https://doi.org/10.5751/ ES-00683-090402

Olsson, P., L. H. Gunderson, S. R. Carpenter, P. Ryan, L. Lebel, C. Folke, and C. S. Holling. 2006. Shooting the rapids: navigating transitions to adaptive governance of social-ecological systems. Ecology and Society 11(1):18. https://doi.org/10.5751/ES-01595-110118

Ostrom, E. 2010. Polycentric systems for coping with collective action and global environmental change. Global Environmental Change 20(4):550-557. https://doi.org/10.1016/j.gloenvcha.2010.07.004

Ostrom, E., and M. Cox. 2010. Moving beyond panaceas: a multitiered diagnostic approach for social-ecological analysis. Environmental Conservation 37(4):451-463. https://doi.org/10.1017/ $\underline{\mathrm{S} 0376892910000834}$

Otto, I. M., A. Shkaruba, and V. Kireyeu. 2011. The rise of multilevel governance for biodiversity conservation in Belarus. Environment and Planning C: Government and Policy 29 (1):113-132. https://doi.org/10.1068/c09196

Pahl-Wostl, C. 2007. Transitions towards adaptive management of water facing climate and global change. Pages 49-62 in E. Craswell, M. Bonnell, D. Bossio, S. Demuth, and N. Van De Giesen, editors. Integrated assessment of water resources and global change: a north-south analysis. Springer, Dordrecht, The Netherlands. https://doi.org/10.1007/978-1-4020-5591-1 4

Pahl-Wostl, C. 2009. A conceptual framework for analysing adaptive capacity and multi-level learning processes in resource governance regimes. Global Environmental Change 19(3):354-365. https://doi.org/10.1016/j.gloenvcha.2009.06.001

Pahl-Wostl, C. 2015. A theory on water governance dynamics. Pages 159-180 in C. Pahl-Wostl. Water governance in the face of global change: from understanding to transformation. Springer, Cham, Switzerland. https://doi.org/10.1007/978-3-319-21855-7_

Pahl-Wostl, C., L. Lebel, C. Knieper, and E. Nikitina. 2012. From applying panaceas to mastering complexity: toward adaptive water governance in river basins. Environmental Science and Policy 23:24-34. https://doi.org/10.1016/j.envsci.2012.07.014

Popa, F., M. Guillermin, and T. Dedeurwaerdere. 2015. A pragmatist approach to transdisciplinarity in sustainability research: from complex systems theory to reflexive science. Futures 65:45-56. https://doi.org/10.1016/j.futures.2014.02.002

Raik, D., A. Wilson, and D. Decker. 2008. Power in natural resources management: an application of theory. Society \&
Natural Resources 21(8):729-739. https://doi.org/10.1080/08941$\underline{920801905195}$

Reed, J., J. Van Vianen, E. L. Deakin, J. Barlow, and T. Sunderland. 2016. Integrated landscape approaches to managing social and environmental issues in the tropics: learning from the past to guide the future. Global Change Biology 22:2540-2554. https://doi.org/10.1111/gcb.13284

Reichel, A., M. Kennedy, G. W. Winch, R. S. Langer, J. I. Rowe, and J. M. Yanni. 2004. (Re-)structuration of system dynamics. Proceedings of the 22nd International Conference of the System Dynamics Society System Dynamics Society, Littleton, Massachusetts, USA.

Republic of Belarus. 2004. National strategy for sustainable development for the period Tto 2020 of the Republic Of Belarus. Republic of Belarus, Minsk, Belarus.

Republic of Belarus. 2015. National strategy of the Republic of Belarus for sustainable socio-economic development for the period until 2030. Pages 6-99 in Economic Bulletin (Экономический Бюллетень). Fourth edition. The National Sustainable Development Commission of Belarus, Minsk, Belarus.

Ribot, J. C. 2003. Democratic decentralisation of natural resources: institutional choice and discretionary power tranfers in sub-Saharan Africa. Public Administration and Development 23:53-65. https://doi.org/10.1002/pad.259

Rijke, J., R. Brown, C. Zevenbergen, R. Ashley, M. Farrelly, P. Morison, and S. van Herk. 2012. Fit-for-purpose governance: a framework to make adaptive governance operational. Environmental Science \& Policy 22:73-84. https://doi.org/10.1016/ j.envsci.2012.06.010

Rippon, S. 2000. The transformation of coastal wetlands: exploitation and management of marshland landscapes in north west Europe during the Roman and medieval periods. Oxford University Press, New York, New York, USA.

Rist, L., B. M. Campbell, and P. Frost. 2013. Adaptive management: where are we now? Environmental Conservation 40 (1):5-18. https://doi.org/10.1017/s0376892912000240

Roodbergen, M., B. van der Werf, and H. Hötker. 2012. Revealing the contributions of reproduction and survival to the Europewide decline in meadow birds: review and meta-analysis. Journal of Ornithology 153:53-74. https://doi.org/10.1007/s10336-011-0733$\mathrm{y}$

Ruíz, A. G., E. Hes, and K. Schwartz. 2011. Shifting governance modes in wetland management: a case study of two wetlands in Bogotá, Colombia. Environment and Planning C: Government and Policy 29(6):990-1003. https://doi.org/10.1068/c10144

Scholz, G., M. Austermann, K. Kaldrack, and C. Pahl-Wostl. 2015. Evaluating group model building exercises: a method for comparing externalized mental models and group models. System Dynamics Review 31:28-45. https://doi.org/10.1002/sdr.1538

Sending, O. J., and I. B. Neumann. 2006. Governance to governmentality: analyzing NGOs, states, and power. International Studies Quarterly 50(3):651-672. https://doi. org/10.1111/j.1468-2478.2006.00418.x 
Shkaruba, A., and V. Kireyeu. 2013. Recognising ecological and institutional landscapes in adaptive governance of natural resources. Forest Policy and Economics 36:87-97. https://doi. org/10.1016/j.forpol.2012.10.004

Shkaruba, A., V. Kireyeu, and O. Likhacheva. 2017. Rural-urban peripheries under socioeconomic transitions: changing planning contexts, lasting legacies, and growing pressure. Landscape and Urban Planning 165:244-255. https://doi.org/10.1016/j. landurbplan.2016.05.006

Shkaruba, A., and H. Skryhan. 2019. Chernobyl science and politics in Belarus: the challenges of post-normal science and political transition as a context for science-policy interfacing. Environmental Science and Policy 92:152-160. https://doi. org/10.1016/j.envsci.2018.11.024

Shkaruba, A., H. Skryhan, and V. Kireyeu. 2015. Sense-making for anticipatory adaptation to heavy snowstorms in urban areas. Urban Climate 14:636-649. https://doi.org/10.1016/j.uclim.2015.11.002

Stave, K. 2010. Participatory system dynamics modeling for sustainable environmental management: observations from four cases. Sustainability 2(9):2762-2784. https://doi.org/10.3390/ $\underline{\text { su2092762 }}$

Sterman, J. D. 2000. Business dynamics: systems thinking and modeling for a complex world. Irwin/McGraw-Hill. Boston, Massachusetts, USA.

Stringer, L. C., A. J. Dougill, E. Fraser, K. Hubacek, C. Prell, and M. S. Reed. 2006. Unpacking "participation" in the adaptive management of social-ecological systems: a critical review. Ecology and Society 11(2):39. https://doi.org/10.5751/es-01896-110239

Stryamets, N., M. Elbakidze, M. Ceuterick, P. Angelstam, and R. Axelsson. 2015. From economic survival to recreation: contemporary uses of wild food and medicine in rural Sweden, Ukraine and NW Russia. Journal of Ethnobiology and Ethnomedicine 11:53. https://doi.org/10.1186/s13002-015-0036-0

Tanneberger, F., and W. Wichtmann, editors. 2011. Carbon credits from peatland rewetting - climate-biodiversity-land use. Schweizerbart Science Publishers, Stuttgart, Germany.

Teorell, J., N. Charron, S. Dahlberg, S. Holmberg, B. Rothstein, P. Sundin, and R. Svensson. 2018. The quality of government standard dataset. Online dataset. University of Gothenburg, Gothenburg, Sweden.

Tosey, P., M. Visser, and M. N. Saunders. 2011. The origins and conceptualizations of 'triple-loop' learning: a critical review. Management Learning 43:291-307. https://doi.org/10.1177/1350$\underline{507611426239}$

Turner, R. K., J. C. J. M. van den Bergh, T. Söderqvist, A. Barendregt, J. van der Straaten, E. Maltby, and E. C. van Ierland. 2000. Ecological-economic analysis of wetlands: scientific integration for management and policy. Ecological Economics 35 (1):7-23. https://doi.org/10.1016/S0921-8009(00)00164-6

United Nations Development Programme (UNDP). $2016 a$. Voices of impact: speaking for the global commons. UNDP, Global Environmental Finance, New York, New York, USA.
United Nations Development Programme (UNDP). $2016 b$. Conservation-oriented management of forests and wetlands to achieve multiple benefits. UNDP, Global Environmental Finance, Belarus.

United Nations Economic and Social Commission for Asia and the Pacific (UNESCAP). 2009. What is good governance? UNESCAP, Bangkok, Thailand.

USAID. 2001. Biodiversity assessment for Belarus (BIOFOR). USAID, Kiev, Ukraine.

Valasiuk, S., M. Giergiczny, T. Żylicz, A. Klimkowska, and P. Angelstam. 2018. Conservation of disappearing cultural landscape's biodiversity: are people in Belarus willing to pay for wet grassland restoration? Wetlands Ecology and Management 26 (5):943-960. https://doi.org/10.1007/s11273-018-9622-y

van Bueren, E., and E. ten Heuvelhof. 2005. Improving governance arrangements in support of sustainable cities. Environment and Planning B: Planning and Design 32(1):47-66. https://doi.org/10.1068/b31103

Verhoeven, J. T. A. 2014. Wetlands in Europe: perspectives for restoration of a lost paradise. Ecological Engineering 66:6-9. https://doi.org/10.1016/j.ecoleng.2013.03.006

Walters, C. J. 2007. Is adaptive management helping to solve fisheries problems? Ambio 36(4):304-307. https://doi. org/10.1579/0044-7447(2007)36[304:iamhts]2.0.co:2

Weigle, M. A., and J. Butterfield. 1992. Civil society in reforming communist regimes: the logic of emergence. Comparative Politics 25(1):1-23. https://doi.org/10.2307/422094

Werners, S. E., Z. Flachner, P. Matczak, M. Falaleeva, and R. Leemans. 2009. Exploring earth system governance: a case study of floodplain management along the Tisza River in Hungary. Global Environmental Change 19(4):503-511. https://doi. org/10.1016/j.gloenvcha.2009.07.003

White, D., and J. Fortune. 2009. The project-specific formal system model. International Journal of Managing Projects in Business 2(1):36-52. https://doi.org/10.1108/17538370910930509

Wichtmann, W., C. Oehmke, S. Baerisch, F. Deschan, U. Malashevich, and F. Tanneberger. 2013. Combustibility of biomass from wet fens in Belarus and its potential as a substitute for peat in fuel briquettes. Mires and Peat 13(SI):1-10.

Wolstenholme, E. F., and R. G. Coyle. 1983. The development of system dynamics as a methodology for system description and qualitative analysis. Journal of the Operational Research Society 34(7):569-581. https://doi.org/10.1057/jors.1983.137

World Values Survey. 2014. World values survey: all rounds country-pooled datafile version. C. Inglehart, R., A. Haerpfer, C. Moreno, K. Welzel, J. Kizilova, M. Diez-Medrano, P. N. Lagos, E. Ponarin, and B. Puranen, editors. JD Systems Institute, Madrid, Spain.

Zenchanka, S. 2017. Development of green economy in Belarus - new possibilities. Pages 321-331 in W. Leal Filho, D.-M. Pociovalisteanu, and A. Q. Al-Amin, editors. Sustainable economic development: green economy and green growth. First edition. Springer International, Cham, Switzerland. https://doi. org/10.1007/978-3-319-45081-0 18 


\section{Appendix 1. Case study descriptions}

\subsection{Case 1: Bogs}

Jeĺnia is a very large complex $(23,200$ ha) of raised bogs and transitional mires in northern Belarus (Fig. 2). This wetland's hydrological balance was dramatically altered by drainage schemes in the 1960's, although some drainage channels for peat mining date back more than 100 years (Kozulin et al. 2010). Since 1975, more than 77\% of Jeĺnia's area has been burned by peat fires, including a major conflagration in 2002 .

The Jeĺnia bog restoration (hereafter Case Bogs) initiative commenced in 1999, coordinated by local ornithological NGO APB Birdlife Belarus, due the importance of Jeĺnia for birdlife. The area provides both breeding sites for birds rare to Belarus, and an important stop-over site for migrating cranes (Grus grus L.) and geese in spring and autumn, which forage on adjacent fields and use the large bog as a safe resting place. Management efforts have primarily focused on delivering ecological outcomes. Bog restoration has occurred at the local scale, although communication activities occur across local-to-national scales.

Initial funding, provided by the Dutch Ministry of Foreign Affairs and the Royal Society for Protection of Birds (UK NGO), led to the construction of 18 dams by 2007. Volunteer labour camps, held annually between 2007-2014, as well as a series of new projects from 2009, led to a further 50 dams being built and later repaired. A visitor's centre, and eco-trails were also constructed to support environmental education and bird-watching and fishing tourism activities. These latter projects were financed initially through the GEF and by Coca-Cola, with later contributions through UNDP.

\subsection{Case 2: Birds}

At present, Zvanets and Sporovo protected areas are among the largest natural fen mire peatlands in Europe at 15,000ha and 18,000 ha and form Important Bird Areas (Republic of Belarus 2012), supporting remaining breeding populations of globally threatened species (e.g., Acrocephalus paludicola L.). These two protected areas are located in south-west Belarus, and have been subjects of restoration efforts since 2006. Large-scale peatland fires in 1999 and 2002 triggered a peatland restoration and management initiative (hereafter - Case Birds). Initial objectives focused on re-elevation of ground water levels, which have prevented further fires, 
restored ecological integrity for bird conservation, and allowed resumption of local livelihoods and recreational activities (UNDP 2016a).

Peatland restoration activities were supported by UNDP and funded by the Global Environment Fund, and has been managed as a public-private partnership, through an NGO (civil sector). A major achievement has been the approval by the Belarusian Council of Ministers of the Strategy for Sustainable Use and Conservation of Peatlands. This strategy serves to balance national interests in respect of the environment and sustainable economic development, whilst fulfilling commitments under the Convention on Biological Diversity (CBD) and the Ramsar Convention. Activities occur at the local scale but are organised at the regional scale. Permanent sources of funding were required to maintain wetlands openness in order to retain functionality for biodiversity. This requirement led to subsequent initiatives to develop and demonstrate a feasible circular model for wetlands management, using the outputs of management measures (e.g. biomass for energy production, reeds for construction materials) in order to finance continued management. Initiatives have included development of commercial enterprises using wetland resources leading to local job creation.

\subsection{Case 3: Berries}

Aržanica enterprise (arzhanitsa.by; hereafter - Case Berries) represents a successful and unique private small-scale enterprise based on value-added production of wild foods harvested from wetlands - mainly berries (Oxycoccus), but also mushrooms. Its primary focus is delivering economic and social benefits (e.g. developing a profitable business) but the firm explicitly aims to promote wetland sustainability by e.g. participating in internationally-sponsored wetlands conservation management initiatives (UNDP 2016b) and implementing indirect ecological objectives in order to secure a sustainable supply of wild foods. The firm employs 20-30 people and has been operating in the Belarusian market since 1992, developing innovative technologies to produce a diverse range of natural, high-quality wild foods. Early technical developments occurred in collaboration with the national Institute for Nutrition. The firm was initially supported by local district authorities and provided with public-owned facilities, which were later privatised. Direct production activity occurs mainly at the local scale, in the small town of Hlubokaje near Jeĺnia bog, although berries are sourced locally-nationally (Fig.1). Sugar is sourced from centralised, state-based commodity procurement agencies. Marketing is focused 
at the national scale, although international demand is growing, primarily in neighbouring countries. 


\section{Appendix 2. Individual case dynamics}

This appendix contains causal loop diagrams (CLDs) detailing the dynamics of each of the three wetlands restoration and management case studies. Individual direct causal relationships were identified in the raw data and then integrated into networks of causal relationships (i.e. CLDs). These networks were then thematically aggregated within cases, i.e. highly similar concepts were aggregated and conceptually similar dynamics were grouped into rough themes using open coding techniques. These themes correspond largely to the core processes and key drivers identified in the final analysis. The CLDs presented in this appendix illustrate this thematic coding process, although there is considerable overlap between the CLDs, with many concepts repeated throughout the figures (i.e. these concepts bridge across the thematic groups).

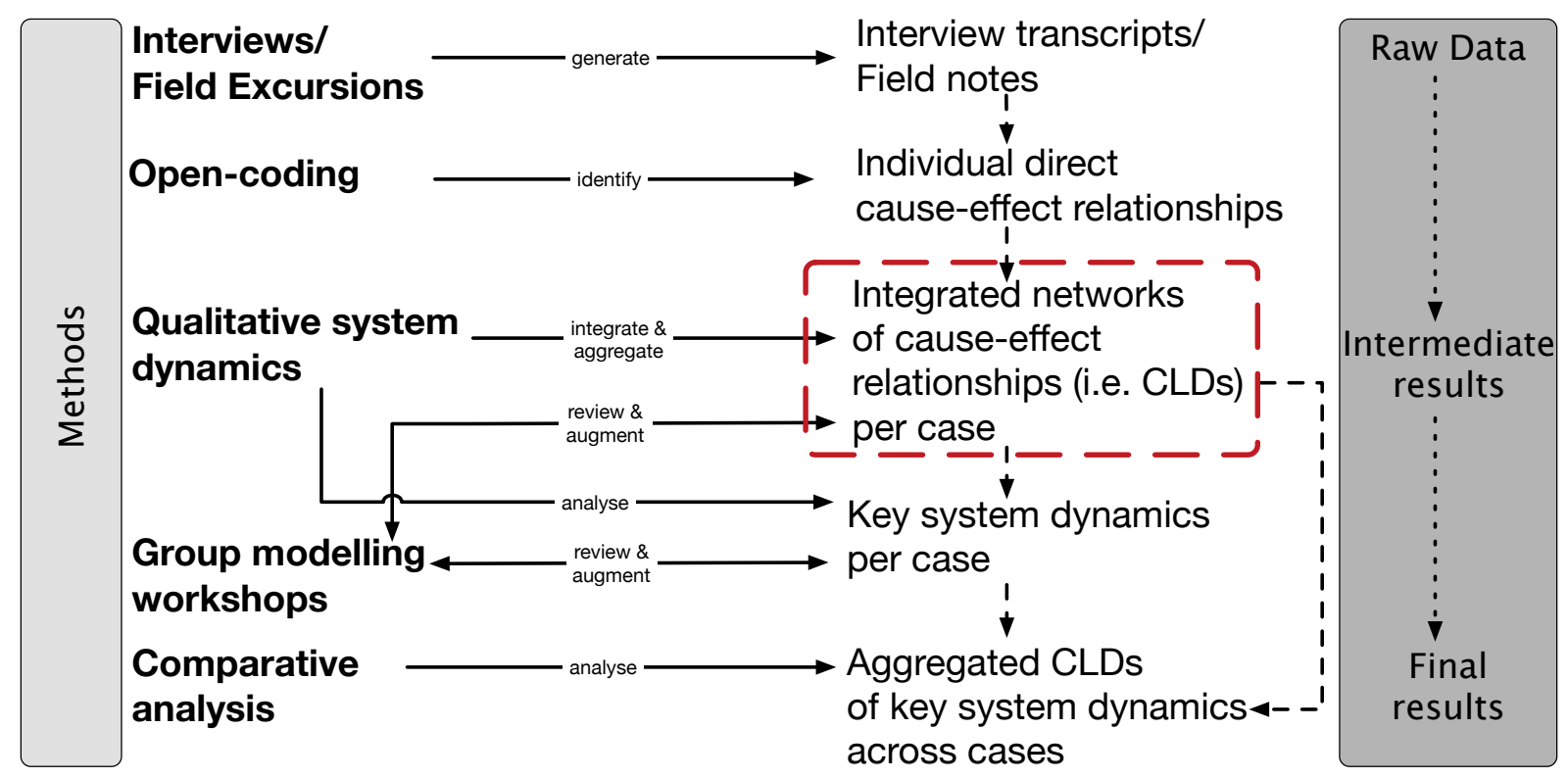

Figure 3 (from main paper). The CLDs in this appendix describe intermediate results, i.e. integrated networks of cause-effect relationships per case, prior to analysis of key system dynamics and across case aggregation.

It is important for readers to keep in mind that these CLDs represent an intermediate step in our analytical process, i.e. prior to subsequent aggregation procedures across the cases to identify the core dynamics, and have not been "cleaned up" for publication. These intermediate data are provided as an appendix to allow readers to more easily understand how the raw data has been transformed towards the final results, and for readers to glean additional insights from more detailed accounts of the dynamics of different wetlands restoration and management initiatives. 


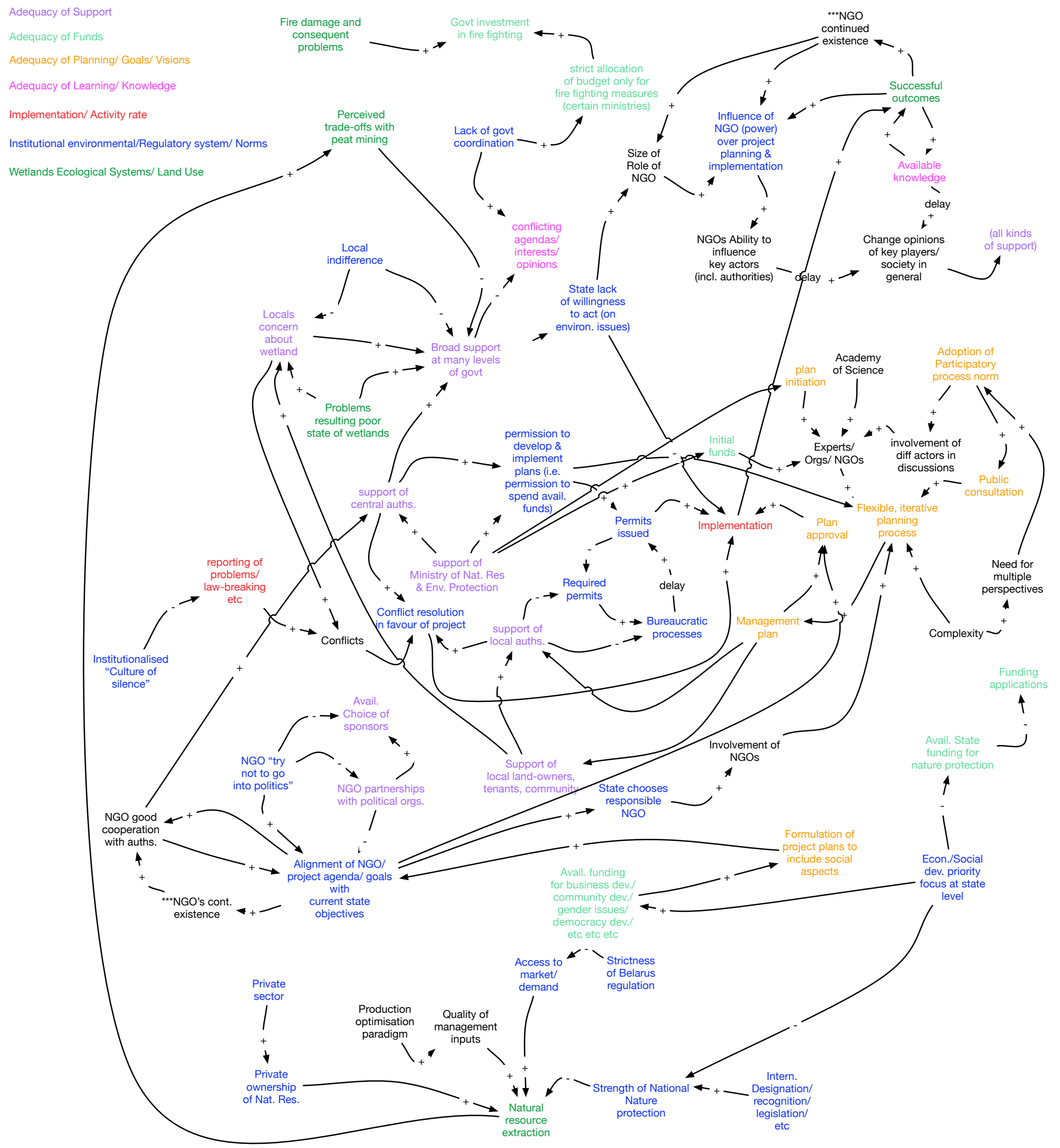

\section{Figure A2:1. Case Bogs, Theme: Institutional and regulatory frameworks}



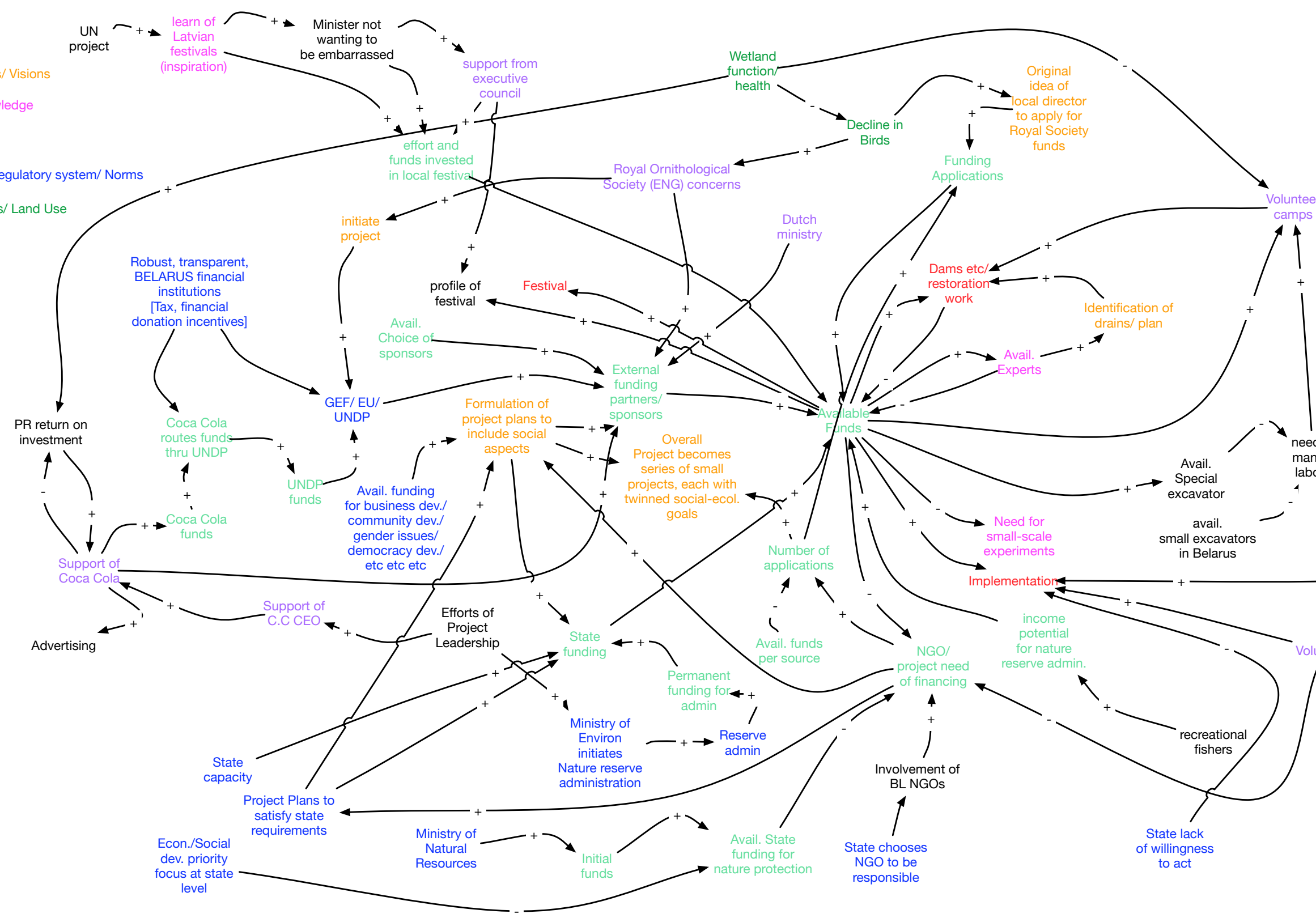$$
\text { Adrating }
$$

\section{Figure A2:2. Case Bogs, Theme: Financing, funds, inputs}




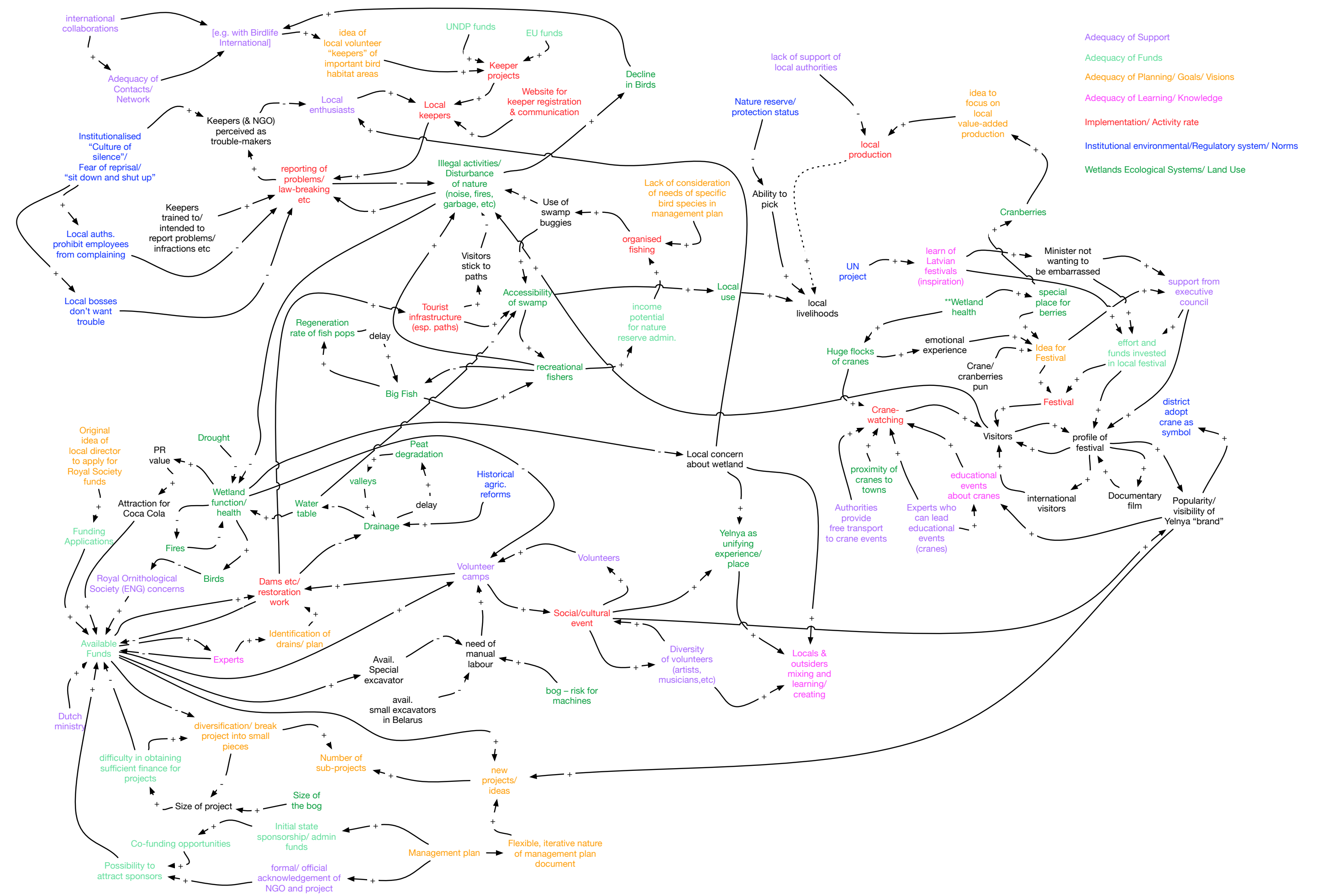




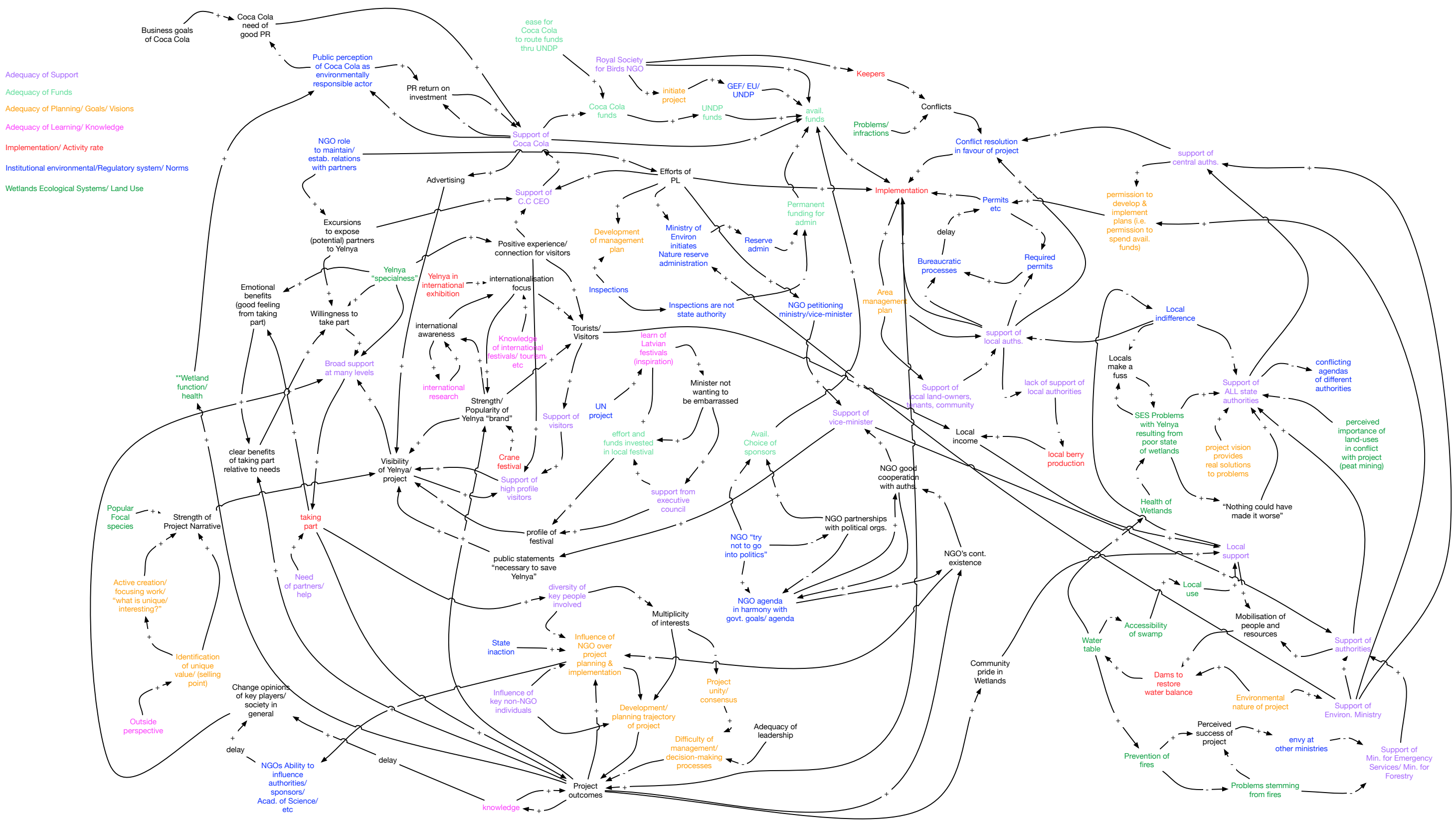




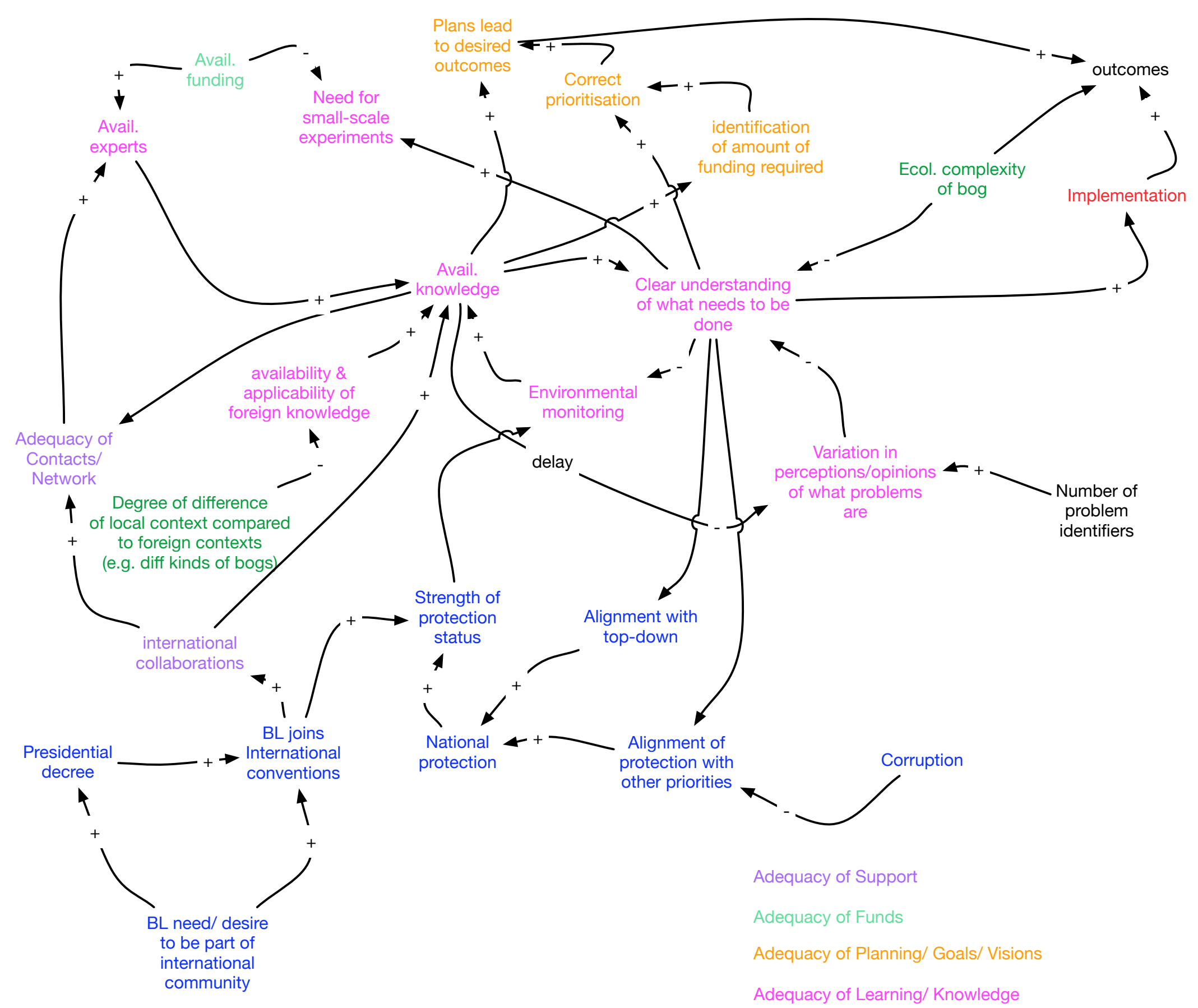

Implementation/ Activity rate

Figure A2:6. Case Bogs, Theme: Learning, Knowledge

Institutional environmental/Regulatory system/ Norms 


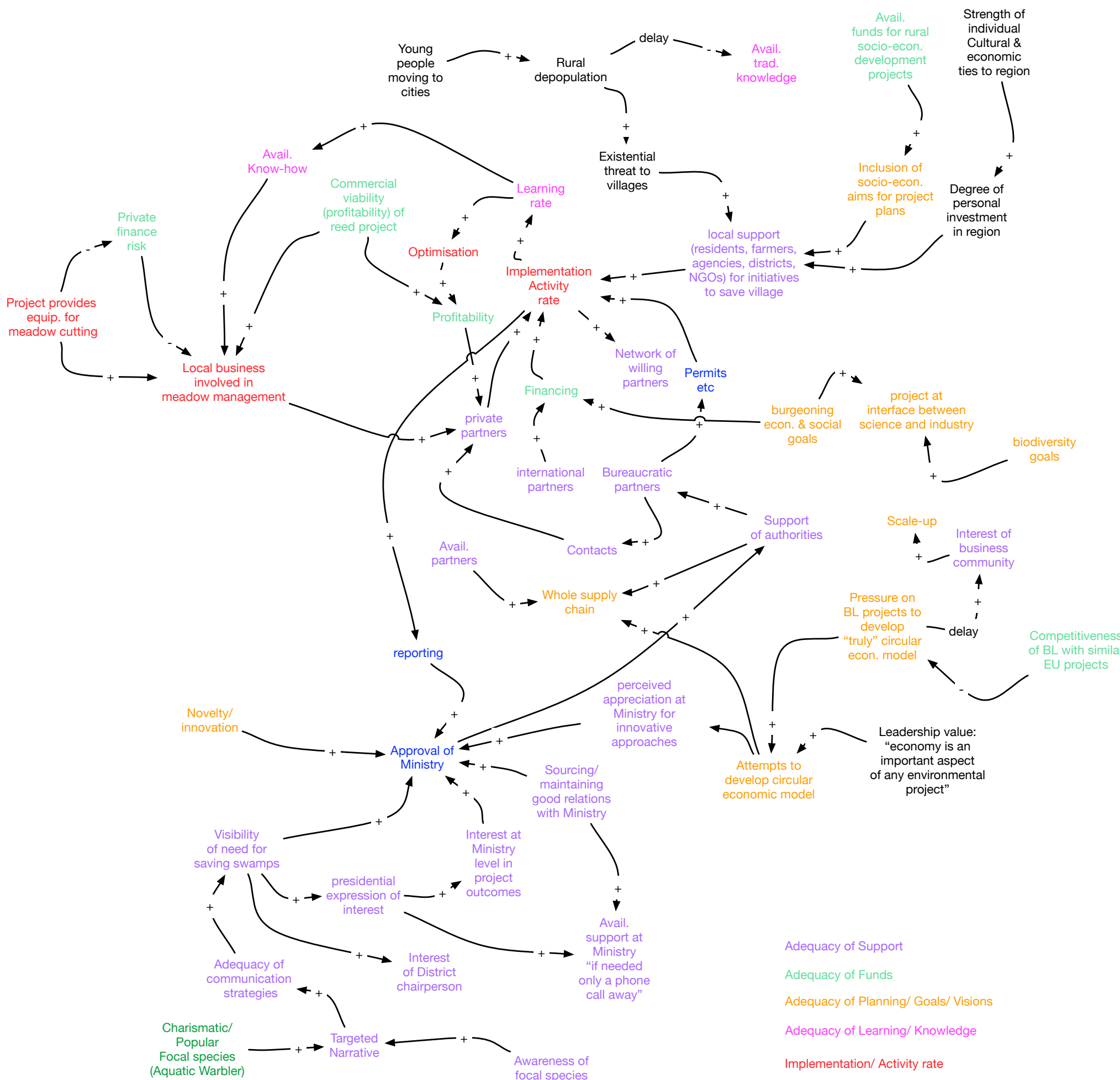

Figure A2:7. Case Birds, Theme: Support

Institutional environmental/Regulatory system/ Norms Wetlands Ecological Systems/ Land Use 


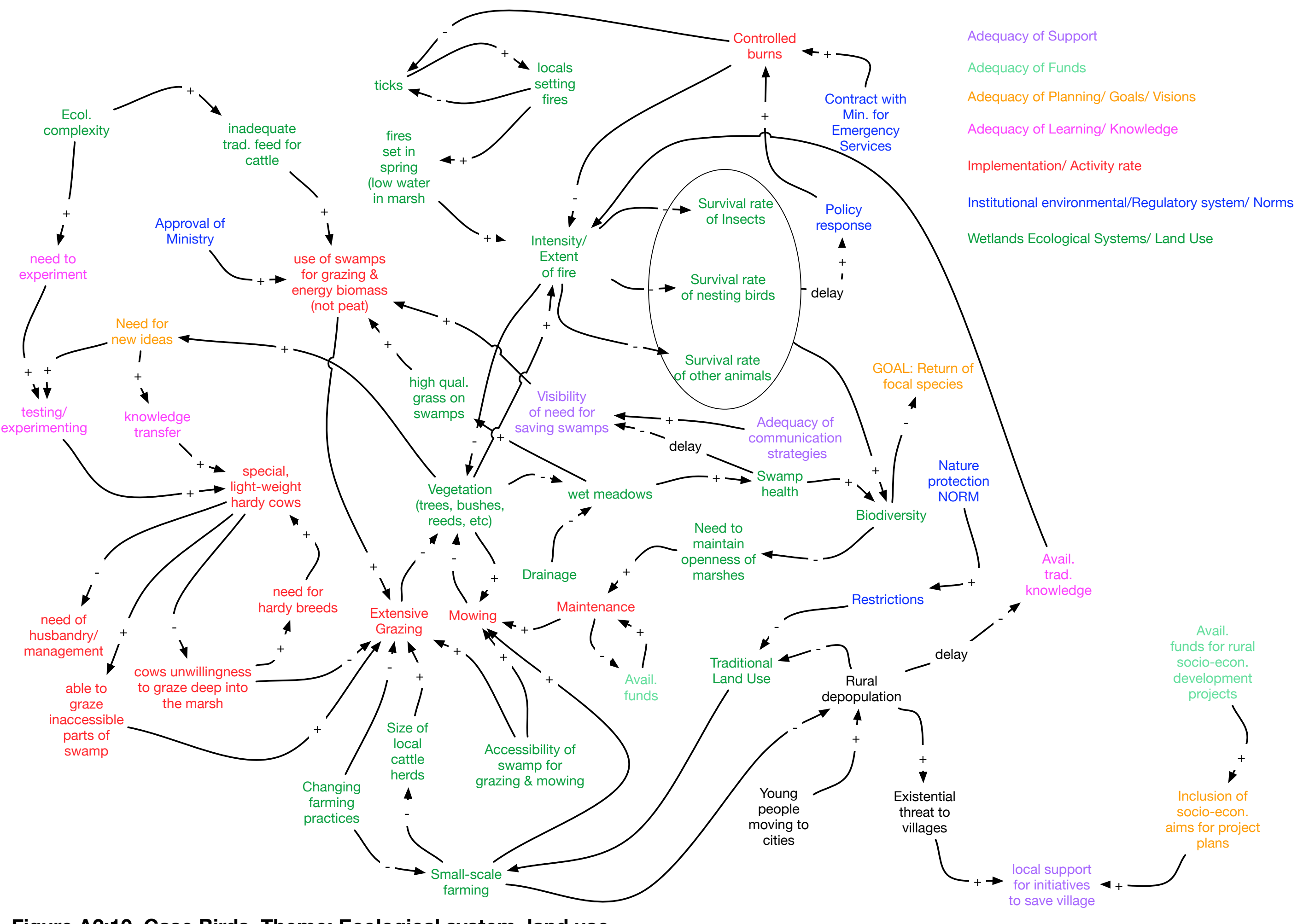

Figure A2:10. Case Birds, Theme: Ecological system, land use 


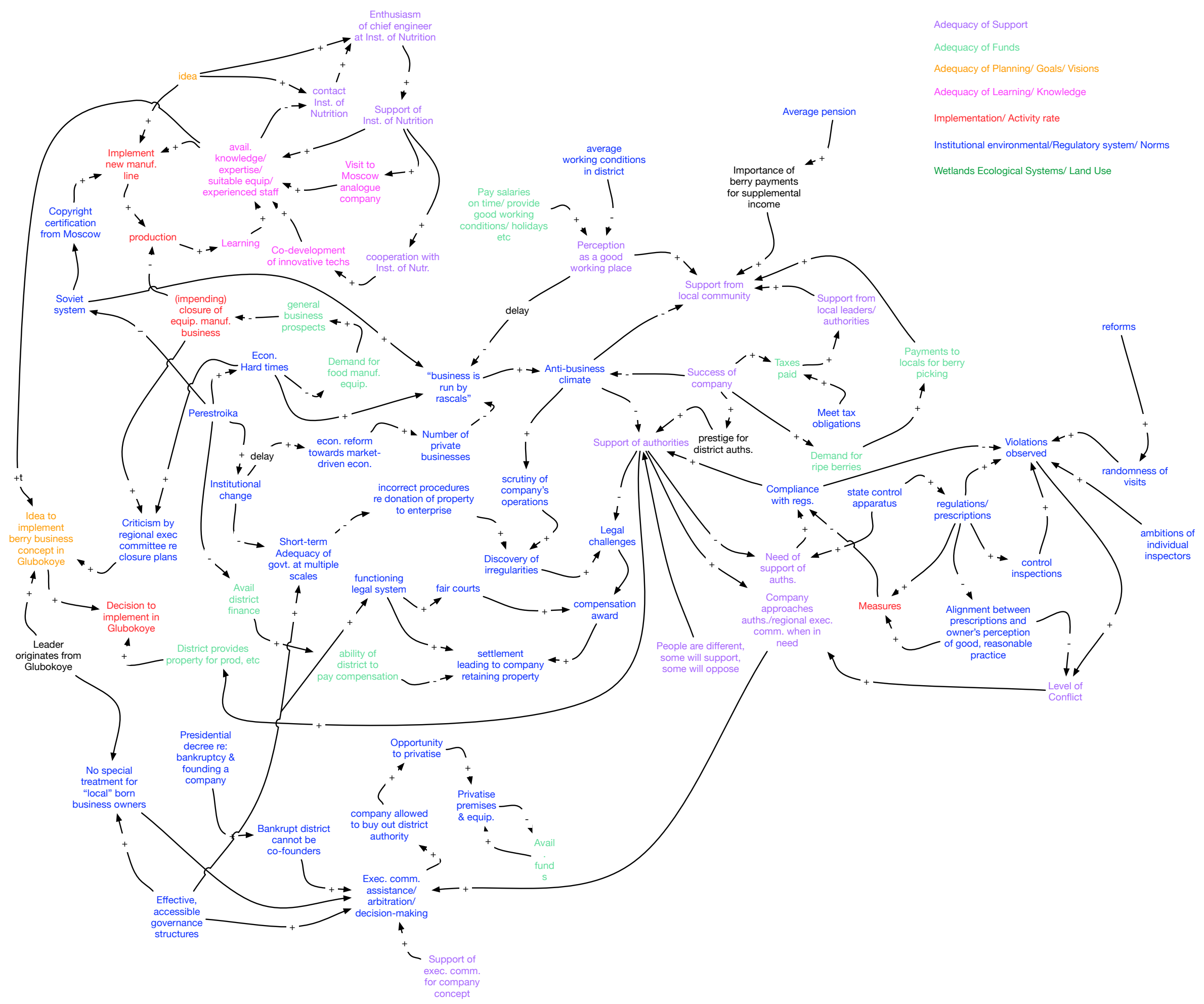

Figure A2:13. Case Berries, Theme: Support 


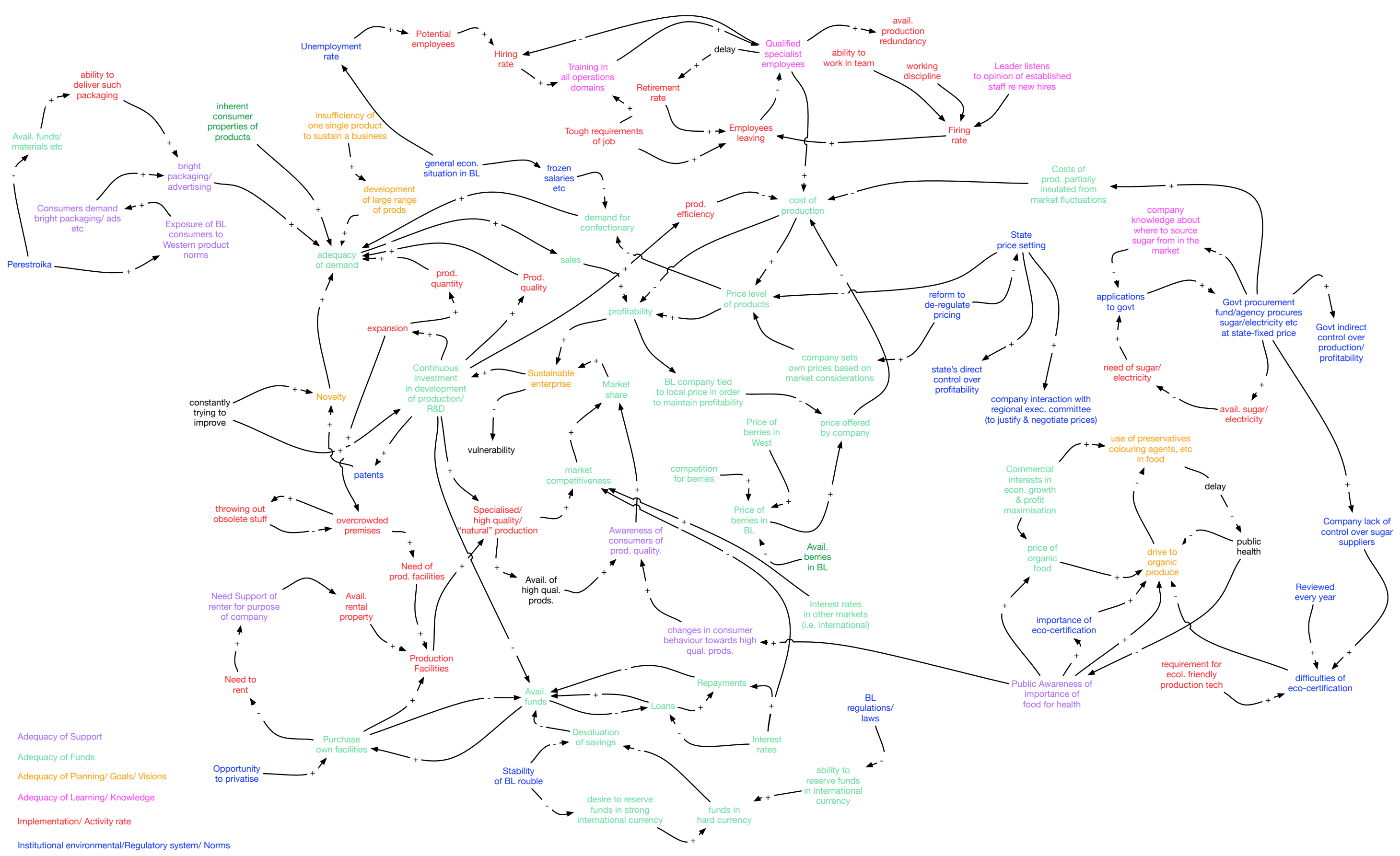




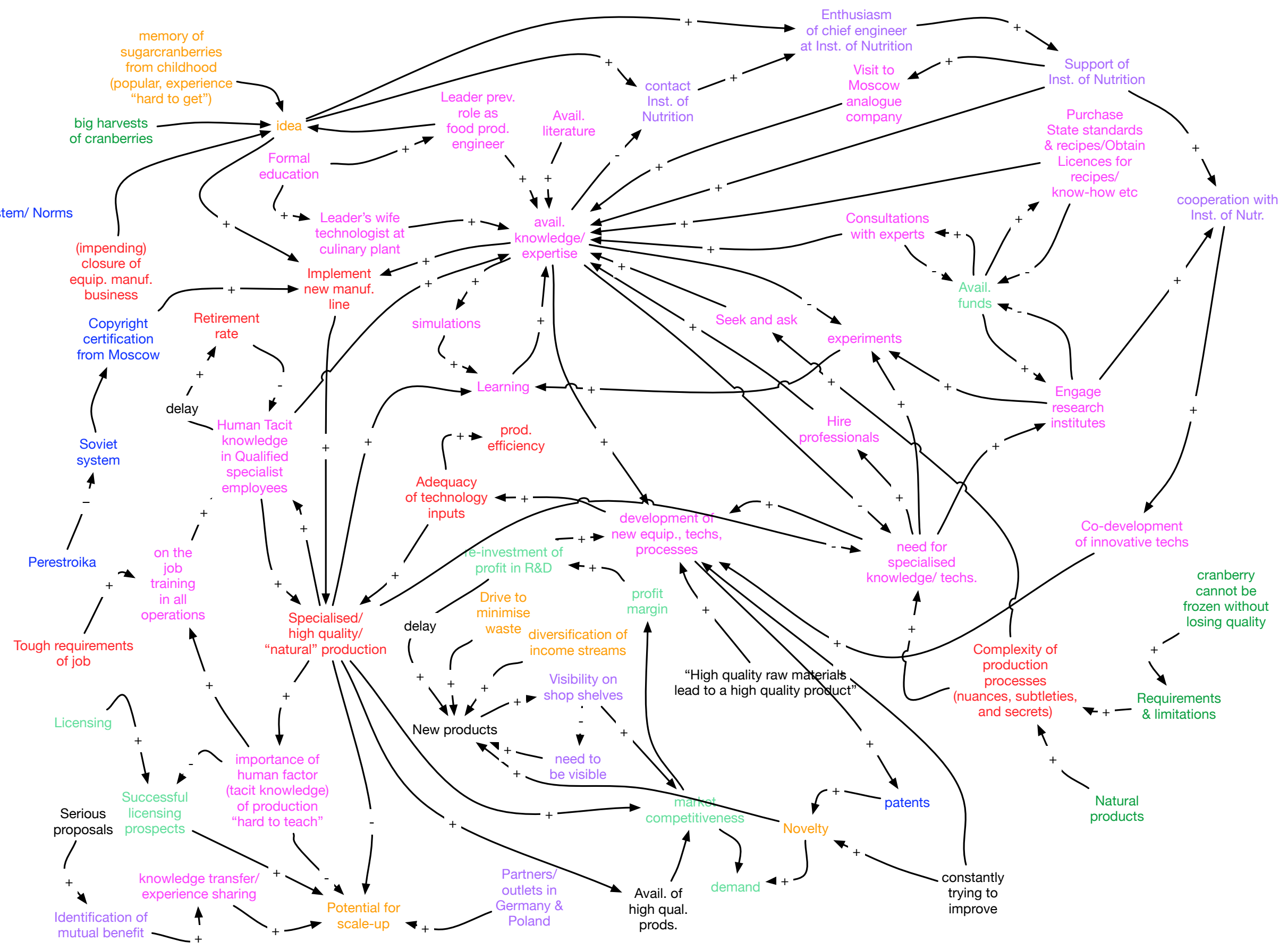




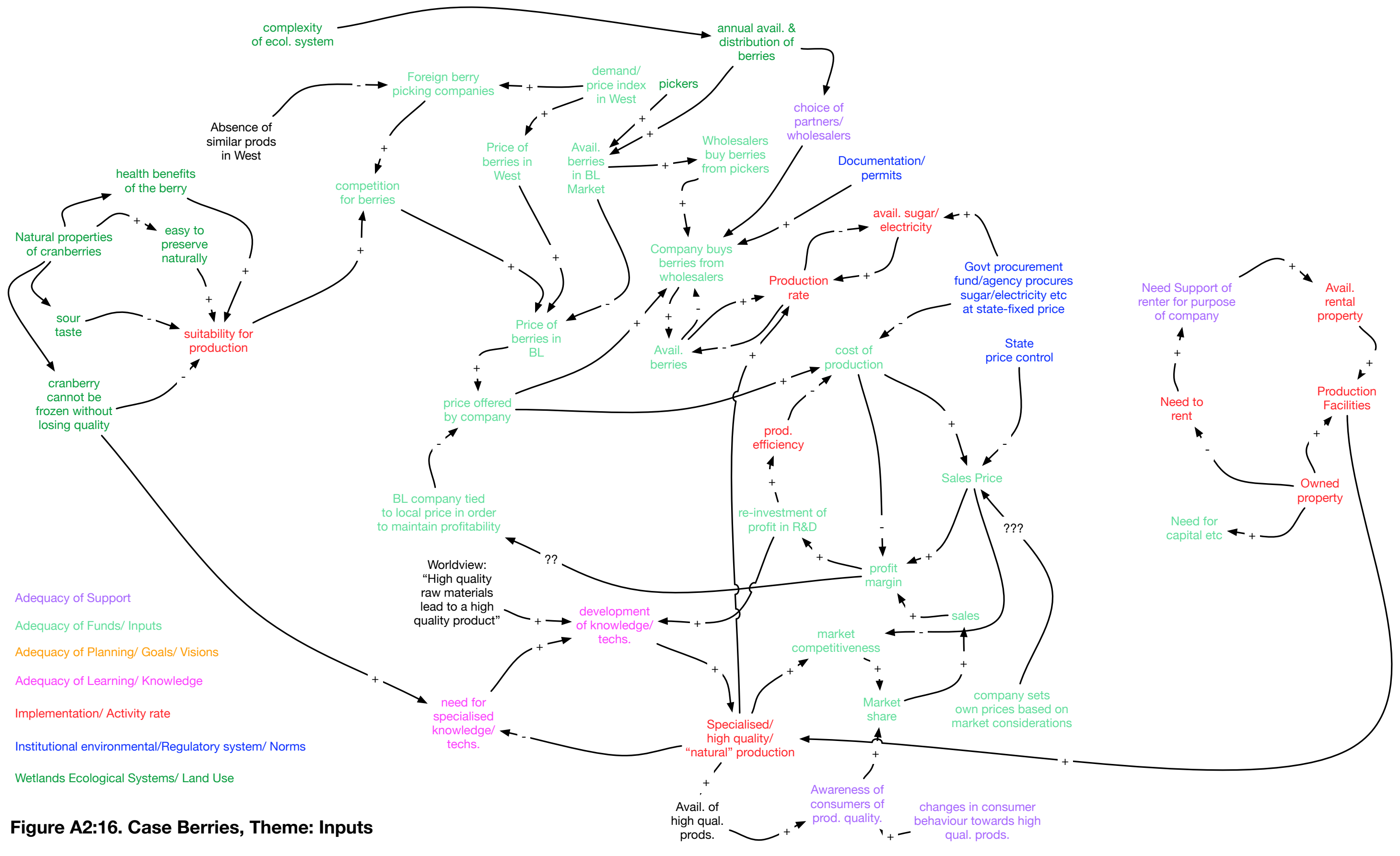


Adequacy of Support

\section{Adequacy of Funds}

Adequacy of Planning/ Goals/ Visions

Adequacy of Learning/ Knowledge

Implementation/ Activity rate

Institutional environmental/Regulatory system/ Norms

Wetlands Ecological Systems/ Land Use

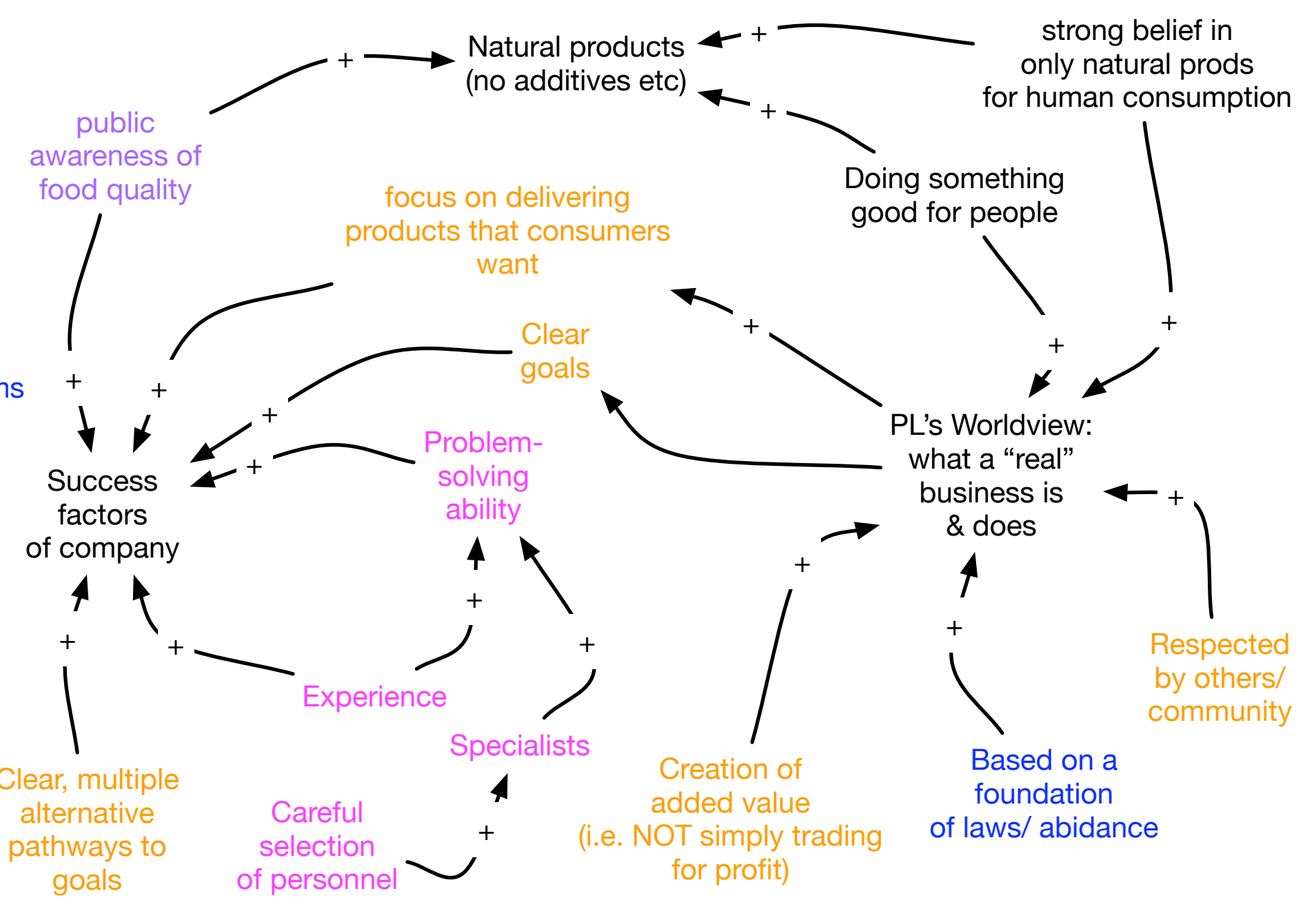

\section{Figure A2:17. Case Berries, Theme: Leadership, values}




\section{Appendix 3: Results}

\subsection{Key drivers and core processes of wetland restoration initiatives in Belarus}

At the overview level, each case comprised an inter-connected system (Fig. 4) consisting of three sets of key drivers: a) the institutional environment and regulatory system, b) adequacy of leadership, and c) the wetlands ecosystem itself; and five core processes, relating to the adequacy of 1) plans, 2) support, 3) inputs, 4) activity rates, and 5) learning and knowledge processes. Sections $4.2-4.6$ unpack the dynamics of each of the core processes and relationships with drivers.

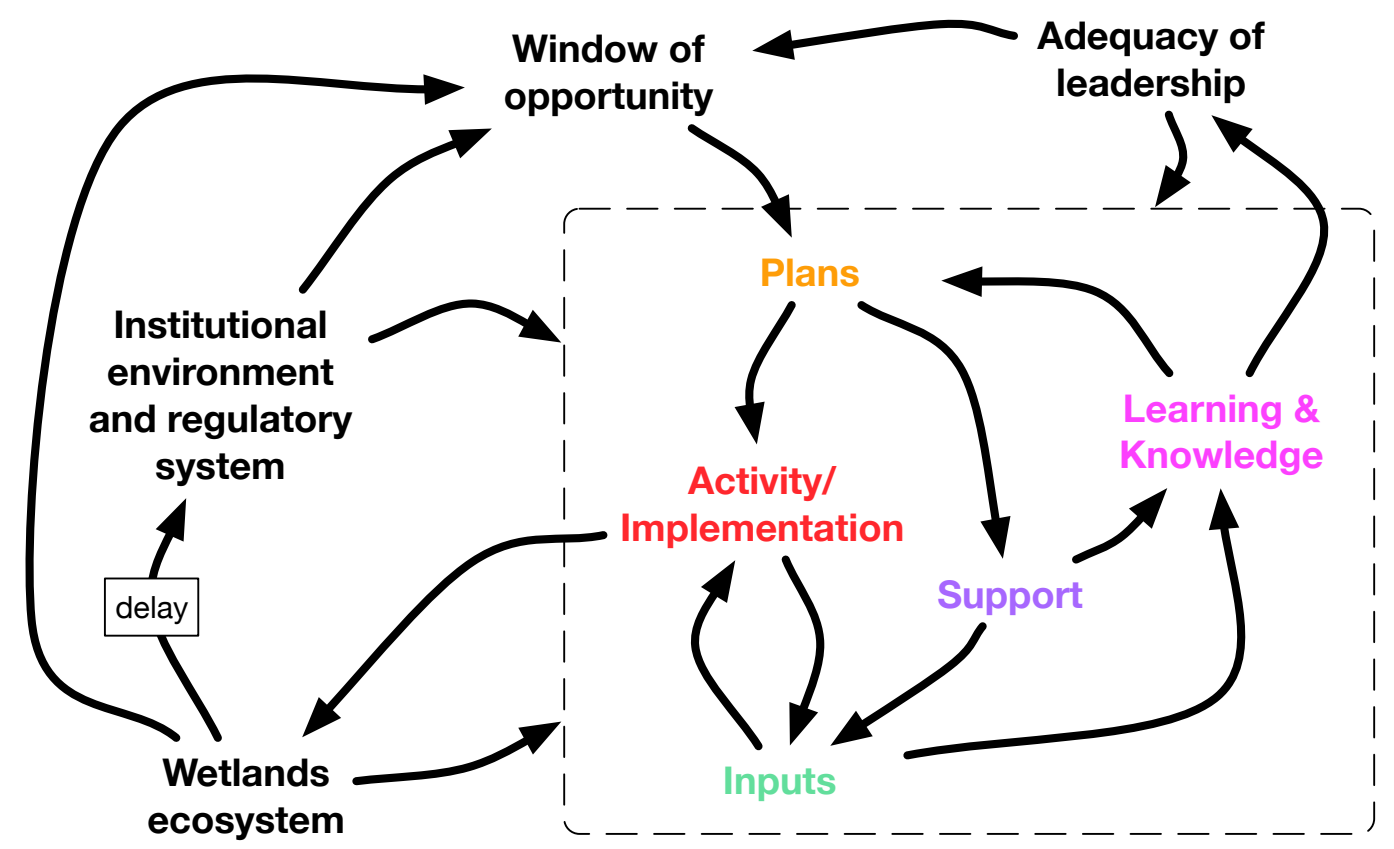

Figure 4 (from main paper). An overview level CLD, synthesising the core dynamics of studied wetland restoration initiatives in Belarus. Three sets of drivers triggered windows of opportunity and subsequently influenced five core management processes (in dashed box). Arrows connecting directly to dashed box indicate the influence of a given driver on multiple processes within the box. Figures $5-9$ unpack the dynamics of each of the core processes and relationships with drivers.

Interviewees frequently referred to historical institutional legacies, regarding the Soviet Union, its dissolution, and subsequent rapid changes in land use. Soviet-era land-use practices and mismanagement were identified as a primary cause of the generally deteriorated state of many natural wetlands. Key economic drivers, such as lack of state funding for ecological initiatives, were linked to the continued fallout of the post-Soviet transition. Soviet-/ transition-era policies were also identified as underlying rural depopulation trends, which impacted local livelihoods 
and availability of relevant knowledge. Such legacies underscored a variety of contemporaneous drivers (e.g. focus on domestic energy security) leading to the development of plans in each case.

Interactions between these legacies created windows of opportunity triggering sustainability initiatives, and shaped the main thrust of key long-term objectives. For example, Soviet drainage and land-use regimes led to catastrophic bog fires when combined with intentional fire-setting behaviours among local peoples to reduce tick abundance. The scale and frequency of these fires became a call to action. The apparent failure of initial state-based responses, such as investment in fire-fighting infrastructure, provided opportunities for fire prevention through hydrological restoration.

The ability to perceive these windows of opportunity required specific educational and professional backgrounds, personal interests and value systems, and employment status. Project initiators were all situated in decision-making capacities (e.g. director of $\mathrm{NGO}$, chief engineer, etc).

\subsection{Adequacy of plans}

Adequacy of plans (Fig. 5) encompassed a spectrum of formal and informal documents and processes, intended for either internal and external use. According to interviewees, adequate plans included clear, well-prioritised objectives, and novel ideas and innovations, and were developed through iterative planning processes. Adequate plans integrated broad sets of knowledge (e.g. regarding problem urgency, or financial requirements and opportunities), and were able to sufficiently identify and mitigate perceived risk ${ }^{1}$.

\footnotetext{
${ }^{1}$ Results regarding knowledge and risk are presented separately in subsequent sections.
} 


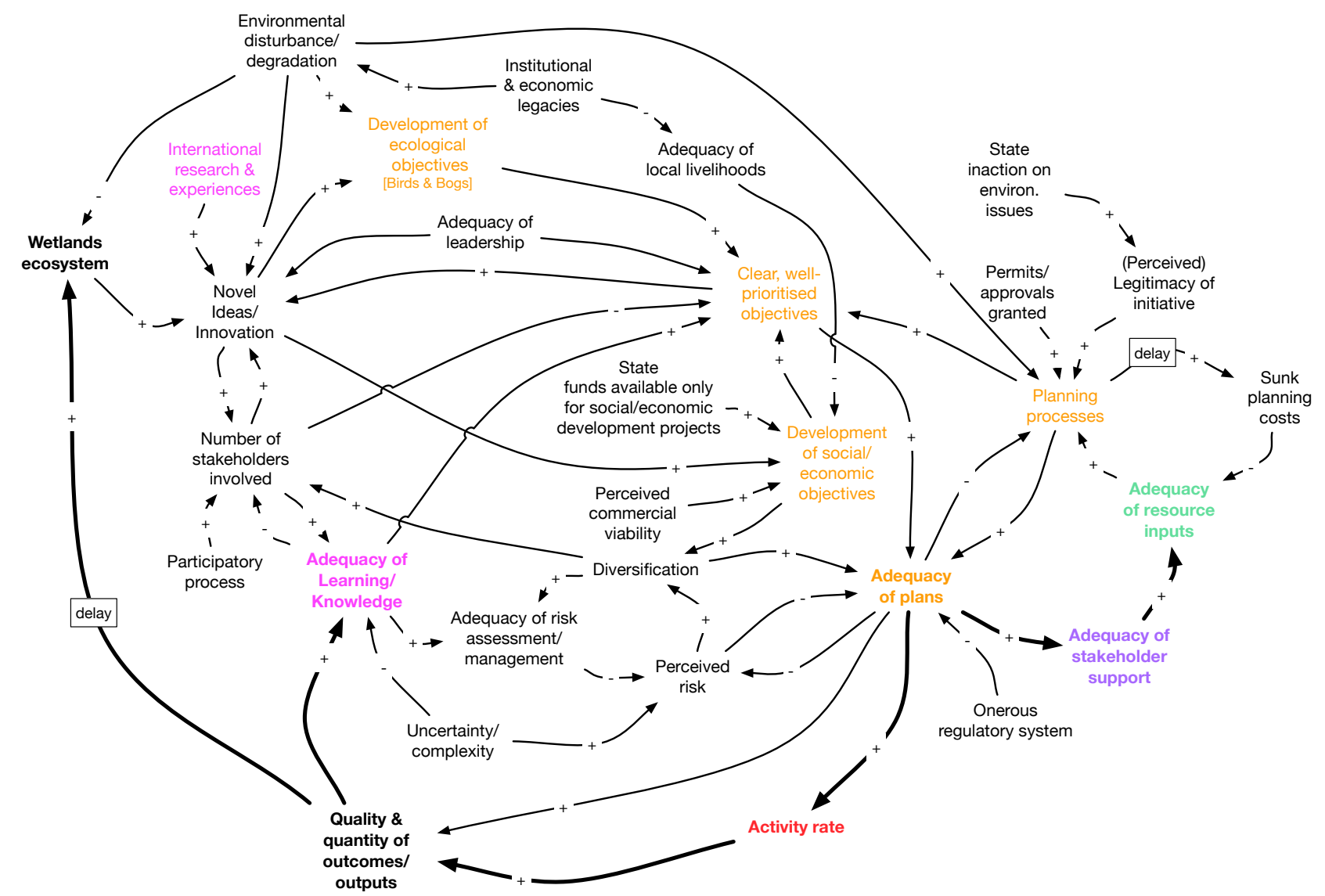

Figure 5 (from main paper). Sub-model unpacking the causal dynamics influencing the Adequacy of plans for wetland restoration initiatives in Belarus. Core processes are in bold. Coloured non-bolded variables represent specific concepts unpacked from within respective core processes. E.g. Clear, well-prioritised objectives is a facet of Adequacy of plans. Thick lines represent links between core processes. Several variables recur throughout Figures 5-9, representing points where core process dynamics link together in an integrated model?

\subsubsection{Clear, well-prioritised objectives}

Cases Bogs \& Birds were initially driven by a set of ecological objectives focused on restoration and sustainable management of degraded wetlands ecosystems. These were subsequently expanded to encompass social/economic objectives. Case Berries focused initially on achieving the latter, although well aware of the importance of a functional ecological system as a basis for material inputs into his production system. Interviewees stated that the inclusion of social and/or economic objectives was an important factor to provide clearer alignment with the objectives of other key stakeholders (Fig. 5), especially state authorities at various levels, who were perceived by interviewees to strongly prioritise socio-economic development. Very few

\footnotetext{
${ }^{2}$ Result CLDs here represent artificially disconnected parts of an interconnected system, separated diagrammatically for the convenience of the reader in accordance with the core processes identified. However, a fully interconnected model is diagrammatically inefficient for the purposes of this article.
} 
state funds, or other forms of state support, were available for initiatives with solely ecological aims. Objectives were therefore developed and framed in terms of positive outcomes for local livelihoods. Explicit socio-economic rationales were also highly prioritised by other stakeholders, e.g. small businesses.

\subsubsection{Novel ideas and innovations}

A keen motivation to innovate or seek novel solutions to complex challenges was a personal characteristic of leaders. Novel ideas (Figs. 5, $6 \& 8$ ) were often inspired by components of wetlands ecosystems, e.g. the abundance of species or natural materials. Otherwise, international research and experiences were an important source of novel ideas, which attracted the involvement of other stakeholders, provided the basis for diversification strategies, and stimulated cross-sectoral collaboration. The iterative development of objectives and the input and/or limitations of various stakeholders also provided a frame upon which further ideas and innovations were constructed.

"We have already started two production lines, and are now looking for an opportunity to use the remaining swamp biomass. We are already considering a new project, in which the main issue is the sustainable use of the biomass." [Case Birds]

\subsubsection{Iterative planning process}

Planning processes (Fig. 5) concerned the development of strategic and operational objectives, and identifying the knowledge and input requirements, processes and organisational structures necessary to achieve these. In all cases, planning was a dynamic, iterative process changing over time as new ideas, knowledge, stakeholders and inputs came to hand. For example, changes in governmental regulatory systems necessitated plan revisions. However, planning was highly dependent on adequate resource inputs, primarily human and financial resources. Thus, whilst all interviewees suggested that iterative planning was important to incorporate new knowledge and adapt to changing circumstances, they also identified an unwillingness amongst stakeholders to continue to revise plans if significant time and other resources had already been spent developing them. As such, a sunk cost effect effectively set in, limiting further planning. Planning was generally undertaken by the initiating organisation, before plans were presented to key stakeholders, usually government authorities, for approval. In some cases, permissions were required prior to the commencement of planning. As such, the perceived legitimacy of the 
initiative was an important factor in greenlighting planning processes. For example, the leader for case Bogs petitioned government authorities to be allowed to develop a management plan for Jeĺnia wetland. Subsequent governmental permission recognised the NGO as responsible for coordinating plan development, although further permits were required to approve the plans for implementation. In cases Bogs and Birds, planning processes were often highly bureaucratic, including formal participatory processes. The roles for stakeholders in such processes varied. Central authorities provided an important source of knowledge in terms of data. Public involvement, however, was essentially cosmetic, providing little or no real contribution to planning processes. Planning in Case Berries, on the other hand, had become less formal and/or more unilateral with time, as partnerships with state authorities were wound down for a variety of reasons, e.g. privatisation of state-owned land, elimination of state-fixed prices on confectionary planning, etc.

"In the early stages, when prices were regulated, we were directly dependent [on the authorities]... Today we handle everything ourselves. The only thing is: we are very strictly controlled by the state." [Case Berries]

\subsection{Adequacy of stakeholder support}

Adequate support (Fig. 6) of external and internal stakeholders was essential for the provision of a wide variety of essential permits and approvals. The degree of dependency on stakeholder support varied across the cases. The leader for case Berries, for example, perceived a considerable degree of self-sufficiency, albeit remaining dependent on permissions. Both leaders for cases Birds and Bogs expressed a greater need for stakeholder support, partly due to an increased exposure to regulatory requirements, and also for inputs (especially financial).

\subsubsection{Cultivating relationships with governmental decision makers}

The support of lower-level authorities was influenced by support from above. For this reason, the support of key governmental decision-makers was crucial. The support of such individuals was also important to the initiative's brand visibility, indirectly driving additional support, or quelling potential opposition.

"I quickly found support in the chief engineer at the Institute of Nutrition. He became enthusiastic about the idea and we began to develop a serious production line." [Case Berries] 
"We have very good relations with the Ministry. [Senior official] has a Ph.D., worked at the Institute of Experimental Botany. He understands all these issues and is interested in what we are doing. He is a fisherman and owns a house in the village so it is very easy to work with him. And among all other Ministries, all of our novelties and innovations are perceived with great appreciation and interest." [Case Birds]

"The word from the Ministry means a lot at the district level...Vice Minister [name] supported us and said that it was necessary to save Jeĺnia. They never refused to support... [Former NGO Director] convinced him. It was fast.” [Leader for case Bogs]

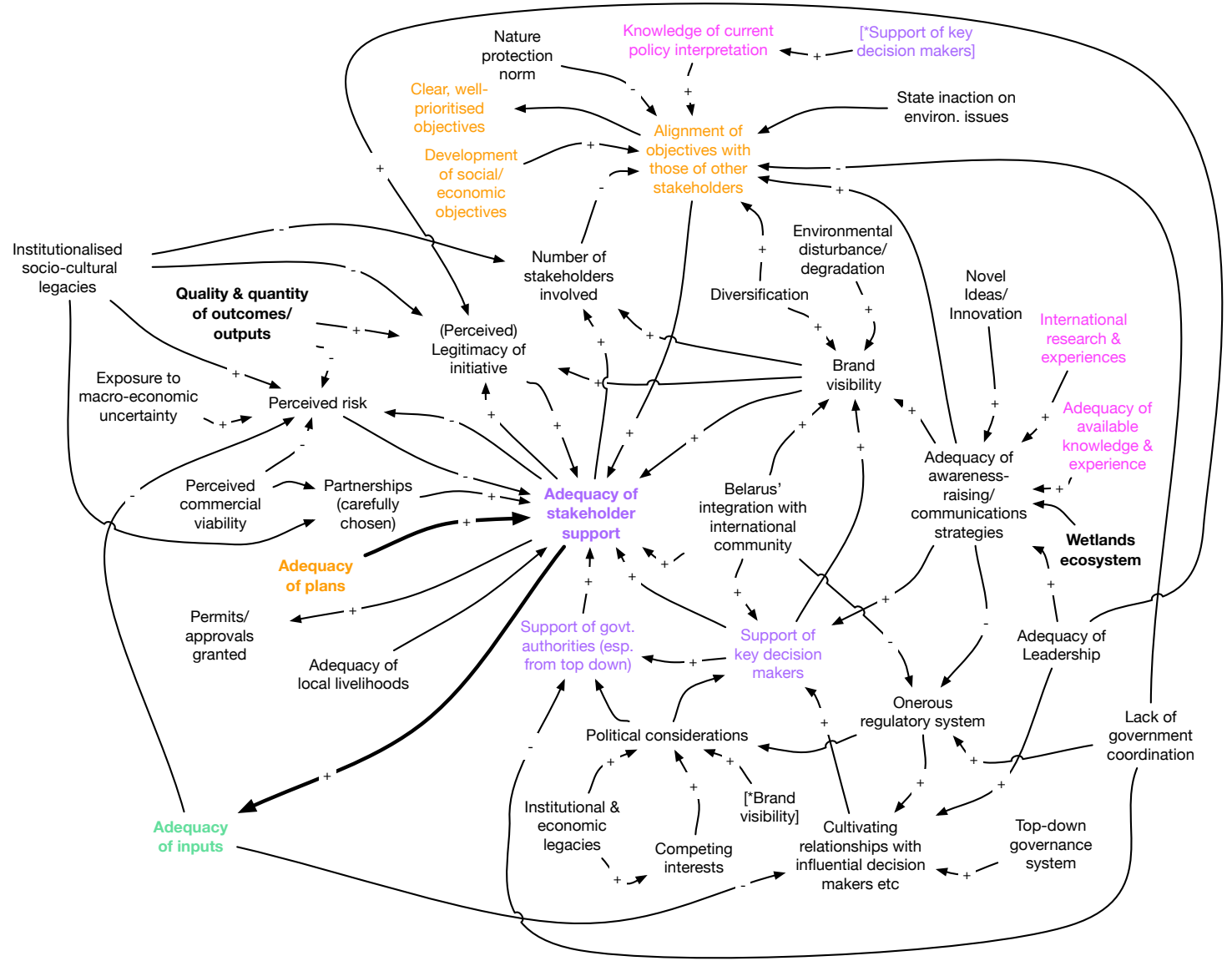

Figure 6 (from main paper). Sub-model unpacking causal dynamics influencing Adequacy of stakeholder support, which is partially disaggregated in this diagram to clarify key dynamics relating to the support of two important stakeholder types, government authorities and key decision-makers. Whilst other drivers of support, e.g. brand visibility, or legitimacy of initiative, also influence these sub-concepts, these relationships are not explicitly represented here, for the sake of diagrammatic clarity and to avoid double-accounting.

Cultivation of personal relationships with influential decision-makers was an efficient means to leverage support from lower instances without expending resources convincing each of them. In addition to imbuing legitimacy, the support of a higher government authority effectively limited the risk exposure of lower bureaucratic instances. Importantly, personal relationships 
with key decision-makers provided valuable knowledge of current interpretations of policies and strategies, so that plans and objectives could be aligned to secure inputs and/or permissions. However, personal relationships were not always a guarantee of continuous support. Key decision-makers were also influenced by a range of political considerations, including a spectrum of socio-economic development challenges and the objectives of competing interests, e.g. resource extraction lobbies. Political considerations also captured a broader set of political dynamics e.g. inter-agency envy or embarrassment. Brand visibility and the adequacy of awareness-raising/communications strategies were also factors identified as influencing the support of central authorities and decision-makers.

The identity of key decision-makers differed amongst the cases. Although government authorities were always important, interviewees identified a temporal aspect, stating that who was key depended on the development phase of the initiative. Following price deregulation of the confectionary industry, The leader for case Berries perceived no further need of contact with upper echelons of power. The leader for case Bogs stated that rather than one single key decision-maker there was a chain of relationships among key individuals that was important to maintain, including the initiating person, the minister for natural resources and environmental protection, the CEO of the main sponsor (Coca Cola), and the director of the NGO.

\subsubsection{Alignment of objectives with those of other stakeholders}

The leaders for all cases stated that support was highly influenced by the degree to which objectives aligned with those of a given authority, or other influential stakeholders, and by extension with those of the individual persons representing that authority.

"We can't do anything without the authorities, because they regulate everything. It was difficult in the 1990s, but their orientation has changed: now it is important to develop the business sector. Our company is like a business card for the district. Now we don't have problems with the authorities." [Leader for case Berries]

Leaders for all cases identified cross-sectoral benefits resulting from their initiatives. The leaders of cases Berries \& Birds positioned themselves, from opposite directions, at a scienceindustry nexus, in order to develop innovation-based collaborations. The leader for case Bogs identified a complementarity of resources and requirements amongst various actors. 
"We [NGO] have ideas but lack resources. The government has no money and no ideas. UNDP have money but no ideas. Coca Cola needs PR. For the little money they invest into Jeĺnia, they would never receive this kind of PR anywhere else.” [Leader, case Bogs] However, a general lack of policy coordination and integration across different sectors was perceived to lead to conflicting objectives amongst government authorities, who otherwise operated within tightly restricted fields of action. Thus, a greater number of stakeholders involved presented a potential barrier to alignment, increasing the difficulty to identify potential "win-wins".

According to interviewees, most stakeholders conflated environmental projects with nature protection, which was perceived as helpful in terms of providing regulatory controls to curb environmental degradation (Fig. 9). However, the "protection mentality" of some stakeholders was said to restrict management alternatives and the freedom of projects to identify, innovate and frame novel "win-win" solutions.

"Any restrictive actions must be accompanied by real economic activities that sustain nature conservation.” [Case Birds]

Support at the local level, in terms of residents, land users and local authorities, was strongly influenced by the degree to which planned activities might improve local livelihoods (Figs. 5\&6). Active awareness-raising and communication efforts were tailored to highlight goal alignment and to more generally shape perceptions by managing brand visibility.

Despite having little power, interviewees remained wary of agitating local rural residents. Support in several instances across the three cases was characterised by the lack of opposition, from local residents or authorities.

"In contrast to many other districts, neither the local population nor the local authorities were indifferent...I do not remember anybody strongly complaining." [Leader, case Bogs]

\subsubsection{Brand visibility and communication strategies}

Brand visibility (Figs. 6, 7A \& 7B) referred primarily to the visibility of initiative-driven activities, outcomes and products, and of the organisation chiefly responsible for planning and implementation. Additionally, it related to the visibility of underlying environmental problems 
stemming from wetland degradation. Brand visibility was an important driver of legitimacy and stakeholder support.

On the downside, greater visibility had implications for political considerations, potentially agitating stakeholders with alternate agendas or competing interests. Visibility was also said to attract rent-seekers (Fig. 7B) and raised the stakes of failure or other negative outcomes.

The adequacy of public awareness-raising and communications strategies were instrumental in growing brand visibility. Available knowledge and experience as well as adequate leadership were important factors in the development and implementation of these strategies (Fig. 6). Active communication of initiative-derived knowledge established the profile of the initiative in new forums and with other similar organisations.

Unique selling points were central to communication and awareness-building. To this end, international research and experiences helped counteract the habituated blindness of locals to identify unique aspects of the ecosystem, e.g. abundance of charismatic species, or its consumer-friendly benefits, e.g. wild foods. Novel ideas and innovative approaches, e.g. circular economy, also provided useful talking points and grabbed attention.

"We always get help and support, because the aquatic warbler is on everyone's lips. We came to the swamp and saw an old lady asking: Guys, do you know that the aquatic warbler appeared here? Yesterday, the chairman of the district executive committee asked: How is the aquatic warbler? It's very helpful to have this targeted flow of information to create mutual understanding and solve problems." [Leader, case Birds]

The degree to which Belarus sought to integrate with the international community was identified as an important driver of international support and brand visibility. International actors were often engaged as formal partners, e.g. as donors and/or co-organisers, or otherwise as informal sources of support and other inputs.

"The international level is reached through research programs. Many foreign experts come and praise us...Jeĺnia is involved in exhibitions...Even our Parliament wants its members to see Jeĺnia. It's visible enough and there's interest in it.” [Case Bogs]

International norms were said to exert soft-power influence on environmental and other norms at the national level, and the ratification of international agreements to influence national regulatory system reforms. However, a field of tension was identified regarding national 
identity contra international influence, which in some instances also led to suspicion and/or rejection of international norms and practices.

\subsection{4. $\quad$ Perceived legitimacy of initiative}

Support, especially from key stakeholders, had an important legitimising influence for organisations and activities. "All our organisations cooperate well with the authorities. Otherwise they would not exist.” Leader, case Bogs

Legitimacy provided a key source of agency, and in turn had a mutually reinforcing influence on support. The adequacy of leadership was an important determinant of perceived legitimacy, providing a knowledgeable, solution-oriented face for the organisation. Delivery of planned outcomes/ outputs and increased brand visibility were usually commensurate with increases in perceived legitimacy. Legitimacy was also affected by perceptions of the initiative as a good “corporate citizen”, e.g. providing a good workplace, making appropriate social contributions (Fig. 7B).

"We employ 20-30 people. We always pay salaries on time and provide adequate working conditions...We have no problem providing holidays, we're competitive, and people see that we are successful. This becomes a turning point in peoples' consciousness." [Case Berries]

A set of institutionalised socio-cultural legacies (Fig. 6), including distrust of private enterprise and NGOs, often negatively coloured stakeholders' perceptions. Interviewees perceived these pervasive attitudes to pose obstacles to support-building due to the many ways in which they, in addition to impacting legitimacy, shaped perceptions of risk and conflict (Fig. 6).

\subsubsection{Perceived risk}

Risks identified by interviewees included adverse changes in natural (e.g. weather or climate), technical (e.g. due to inadequate knowledge), financial (e.g. macro-economic turbulence), and governance (e.g. regulatory) systems. Whilst interviewees generally attempted to curtail exposure to some identified risks, e.g. macro-economic uncertainty, they considered other risks to be unavoidable and attempted to manage these by preparedness and timely decision-making. Risk was also a perceived quality. Perceived risk (Figs. 5, 6 \& 7A) was partly a bi-product of a set of institutionalised socio-cultural legacies encompassing fear of change and/or reprisal, unwillingness to engage, an anti-business climate, a culture of indifference/passivity, lack of 
open society, and 'tall poppy syndrome'. Fear of state reprisal ensured, for example, that interviewees assiduously maintained a non-partisan political stance in plans and activities. This extended to the careful selection of potential partners, to ensure the absence of untoward political affiliations or association with politically sensitive sentiments.

"We try not to go into politics. Our Central Council may reject joining with any political organisations or unions in case it is dangerous for our organisation." [Leader, case Bogs]

Adequate inputs (especially financial resources and fixed capital), the commercial viability of planned activities, and demonstrated delivery of expected outcomes and outputs were all suggested to reduce perceptions of risk, especially those related to production-based initiatives.

"The private sector is weak and there are few business people." [Case Berries]

Interviewees devised innovative solutions to risks associated with inadequate inputs. For example, the leader for case Birds established a non-profit organisation to provide initial knowledge and capital inputs, as well as coordinating planning and implementation, in order to reduce the initial risk exposure of private local partners. These partners were expected to assume greater responsibility for management activities and expenses once commercial viability was established.

"Next year we will look for money to buy a [reed-processing] machine and help business people to develop in this direction. New technology and new businesses are unpredictable. People are afraid to take loans, so they need help. That is, we must give them a fishing rod, bait and fish and even more - they will get salaries until the project is going. And later, - 'fish yourself!'” [Leader, case Birds]

\subsection{Adequacy of inputs}

Inputs referred to a variety of financial, material, human, and technological/ fixed capital resources (Figs. 7A \& 7B). Support, including partner organisations, was a key determinant of input adequacy, which was also heavily influenced by the scale of planned activities.

\subsubsection{Financial resources available to initiatives}

Financial resources available to initiatives was a key input, enabling other inputs and thereby activity rates and delivery of outcomes/outputs (Fig. 7A). Interviewees referred to two main sources of financial resources, donor funding and internally-generated sales revenue. State 
funds were scarcely available, and then generally only to projects with a clear social/economic dimension.

Some co-funding opportunities were available, whereby successful applications could be leveraged for supplementary funds. Indirect state funding was available for certain activities in the form of subsidies or tax exemptions, e.g. for energy production equipment. Loans were also a potential source of funds, but interviewees considered these relatively inaccessible due to the high cost of credit in Belarus and other constraints e.g. exposure to macro-economic uncertainty in currency markets.

Case Bogs was heavily reliant on support from a variety of donors, including international NGOs, multinational corporations, and some government agencies. Efforts at self-financing in Case Bogs were otherwise focused on fund-raising activities (e.g. large-scale tourist events), which were subsidised by donors. Earlier plans for the development of a value-added production company based on wild foods had failed to eventuate. Donor-funding - especially from international donors - increased regulatory exposure, creating a heavy administrative burden (Figs. 7A \& 7B). Strict controls regarding international financial transactions required long and paperwork-intensive permitting processes with uncertain outcomes, and with no access to these funds before permissions were granted. Interviewees perceived this as one means by which state authorities exercised control over NGOs. Other examples included the sudden freezing of bank accounts and highly disadvantageous taxation rules for NGOs. Donorfunding also had a potentially negative feedback on the perceived legitimacy of the initiative (Fig. 7B), which leaders for cases Birds and Berries connected with financial self-reliance. All organisations were expected by authorities to make a variety of social and charitable contributions. However, interviewees indicated that donor-funded NGOs were more likely to be subject to rent-seeking behaviour (Fig. 7B). Internationally-funded initiatives were suggested as being especially targeted, and increasingly disincentivised, by such behaviour.

"Permissions are required for many things...We don't have the right to spend [funds] if the authorities don't permit it. We need to register. That is, the Ministry should approve. Otherwise we have to give the money back [to donors]. Even if you have money, you still need support of the authorities." [Leader, case Bogs]

"To ask for money from the Ministry all the time is not trustworthy...Economics is a very, very important part of any environmental project.” [Leader, case Birds] 

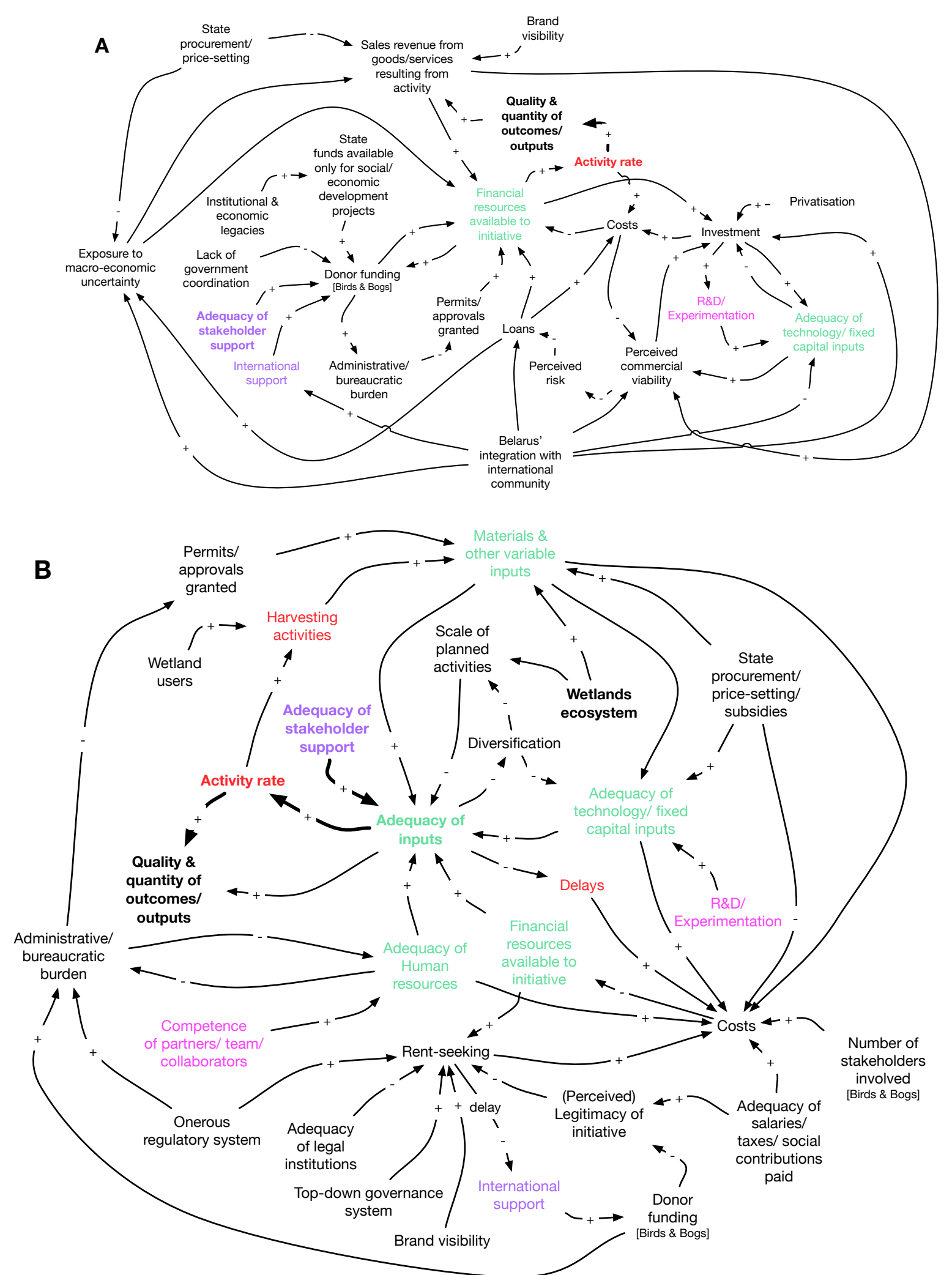

Figure 7A \& B (from main paper). Sub-models unpacking causal dynamics influencing Adequacy of inputs for wetland restoration initiatives. Inputs are disaggregated into four main types: Financial resources, Technology/ fixed capital, Human resources, and Materials and other variable inputs. Fig. 7 is separated into two sub-models simply to reduce diagrammatic complexity and aid reader comprehension. Links from support to the various disaggregated types of inputs are aggregated into one main link in $B$. 
In addition to donor funds, the leader for case Birds sought to develop a circular economic model, with sales revenues iteratively financing a loop of sustainable harvesting activities and material production. Sales revenues were the prime source of financial resources in Case Berries. Profits were partly re-invested into internal research and development $(R \& D) / e x p e r i m e n t a t i o n$. This was influenced by the values of the leader for case Berries regarding "good business" (e.g. financial self-reliance), the dangers of debt, and a strong belief in continuous improvement through learning. Deregulation of state price-setting on confectionary allowed the leader for case Berries to set his own sales prices, although these remained constrained by domestic purchasing power. State price control of other inputs exerted indirect control over potential revenues.

\subsubsection{Materials and other variable inputs}

Materials and other variable inputs (Fig. 7B) refer to various materials harvested from wetlands and utilised in value-added production chains, but also to natural capital used in other initiativedriven activities e.g. cranes for bird-watching tourism. The quality and abundance of these inputs depended on biophysical aspects of the wetlands ecosystems themselves and/or the rate of harvesting activity, where applicable. In some cases, harvesting was conducted by the initiative. Otherwise it was dependent on other users, e.g. berry pickers. Permits were required to acquire materials and other variable inputs, e.g. berries from wholesalers. State procurement/ subsidies were important for the provision of inexpensive electricity and sugar for Case Berries.

\subsubsection{Adequacy of technology/ fixed capital inputs}

The inherent properties, quality and abundance of case specific material inputs determined whether available technology/ fixed capital inputs were adequate (Fig. 7B). Diversification could lead to multiple uses of the same capital, but often led to the need for additional inputs.

"There are a lot of nuances building a technological chain along three biomass lines, which must be used in different directions. The major problem is always - money." [Leader, case Birds]

For Cases Berries \& Birds, investments in production technologies, equipment and other forms of fixed capital (Fig. 7A) were seen to improve efficiency, optimise processes, minimise delays and hasten production of outputs, which could in turn be sold, or otherwise marketed, to recruit new financial revenues. The perceived commercial viability of an initiative was an important 
factor motivating investment. The realisation of technology/capital investments added to stakeholders' perceptions regarding adequacy of inputs, further reinforcing perceptions of commercial viability. However, operational and investment costs relating to these inputs also drained financial resources.

Privatisation (Fig. 7A) of previously state-owned fixed capital provided the opportunity for the leadership of case Berries to own the factory and production processes outright. This investment reduced dependence on state support, a move that the leader for case Berries perceived as central to his ability to implement his own plans and objectives.

The institutional integration of Belarus with the international community also provided opportunities, e.g. access to potential markets for wetlands-derived products. Participation in international markets could, however, necessitate expensive upgrades to technical processes to meet new norms and standards. As such, whilst formal access to international markets incentivised capital investment, inadequate capital stocks constrained market participation.

\subsubsection{Adequacy of human resources}

In most cases, human resources (Figs. 7B \& 8) referred to internal team members or those of partner organisations although volunteers also provided important contributions in Case Bogs, e.g. providing a low-cost substitute to otherwise unavailable financial and capital inputs. Human resources provided important knowledge and experience, but were often drained by an endless stream of administrative/ bureaucratic paperwork, resulting from an onerous regulatory system.

“Almost every year between 2007 and 2014 we organised volunteer labour camps. About 50 dams were built and repaired... It was only possible to do by manual labour, as small, specialised excavators did not exist in Belarus at that time." [Leader, case Bogs]

\subsection{Activity rate}

Many activities (Fig. 9) were, directly or indirectly, aimed at increasing the number of wetland users, and/or the creation of local employment opportunities, and thus had important impacts on the adequacy of local livelihoods. Some use-based activities involving active management measures, e.g. clearing vegetation, were obstructed by passive management requirements associated with nature protection norms or were restricted by other governmental regulatory systems. 


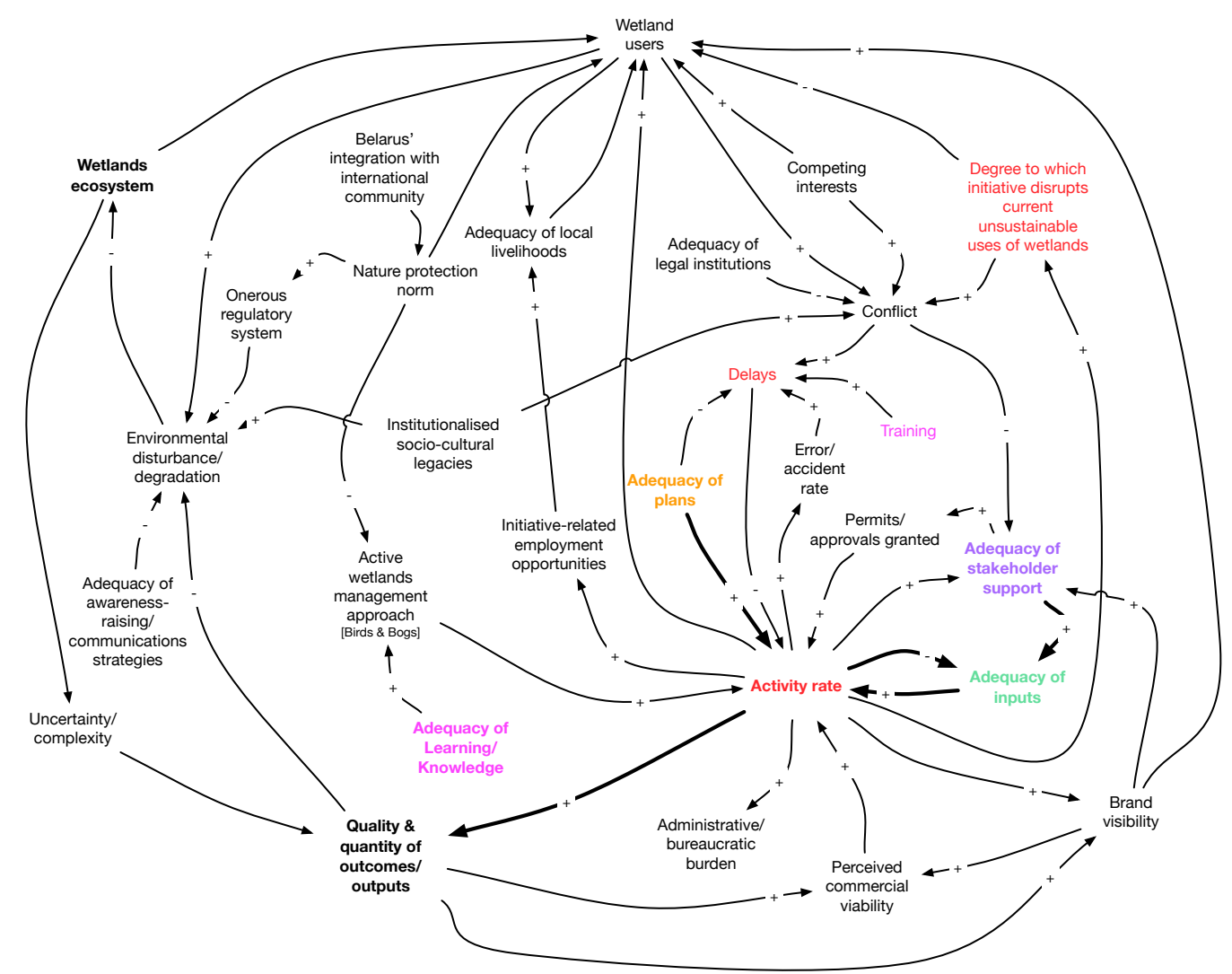

Figure 9 (from main paper). Sub-model unpacking causal dynamics influencing the Activity rate of wetland restoration initiatives in Belarus. Entrenched socio-cultural legacies of indifference and carelessness regarding the negative impacts of some users on wetlands were identified as a driver of environmental disturbance \& degradation. Leader for all three cases sought therefore to shape public attitudes through a variety of direct awareness-raising and knowledge dissemination activities, and/or through indirect use of power, e.g. refusing to purchase unripe berries in order to affect change in picking behaviours. Brand visibility also influenced the number and types of users.

"The reserve gladly helps fishermen because it earns money for the reserve...But this causes anxiety because they bring garbage and the danger of fires, and disturb the birds." [Leader, case Bogs]

Adequate planning and knowledge reduced delays (Figs. 8\&9) due to e.g. training requirements, errors and accidents, or conflicts regarding other, generally deleterious, wetland uses. This latter encompassed large- and small-scale competing interests, e.g. peat mining, illegal fishing/hunting, or commercial berry picking. Conflicts were exacerbated by the degree to which local livelihoods depended on disrupted uses, and also by socio-cultural legacies, which caused implementing organisations to be perceived as meddlers. Conflict risked support. The leader for case Berries perceived legal institutions, commercial courts in particular, to 
provide a generally fair arena for conflict resolution and redress, even in cases involving local authorities.

\subsection{1. $\quad$ Feedbacks to support}

Activity rate and outcomes/outputs led to multiple direct and indirect feedbacks on stakeholder support (Figs. 6, 8\&9), including that of state authorities and key individual decision-makers. High quality outcomes and various kinds of activity promoted brand visibility, leading to increased support, and thereby inputs and/or permissions. In some cases, successful outcomes led to the adoption of new standards and procedures, and to invitations for initiative representatives to participate in regulatory system reform processes. These feedbacks were often slow. Activity was also seen as a means to directly derive additional support, by way of exposure to new contacts and networks. According to leaders from cases Birds and Berries, profits - as evidence of commercial viability - were an important motivator of activity. For this reason, these leaders preferred private sector partners over state actors. "Proof of concept" loops occurred as a result of a feedback from outcomes to commercial viability.

"Experience shows that it is better to work with businesses. They don't receive money from the state. They understand that how much they earn depends on themselves, and are therefore active." [Leader, case Birds]

\subsection{Adequacy of learning and knowledge}

Adequacy of available knowledge \& experience (Fig. 8) was conceptualised as a clear understanding regarding problem scale, current interpretations of relevant government policies and strategies, key factors, system requirements, and potential solutions. Existing knowledge was accessed in a number of ways - from knowledgeable human resources, e.g. experts/specialists, competent staff and leaders; from formal sources such as national and international research organisations and databases; from informal sources such as excursions to analogue firms/ initiatives, dialogue with other organisations who had relevant experiences. As such, access to existing knowledge could be obtained through support mechanisms, or was otherwise a factor of adequate financial resources. 


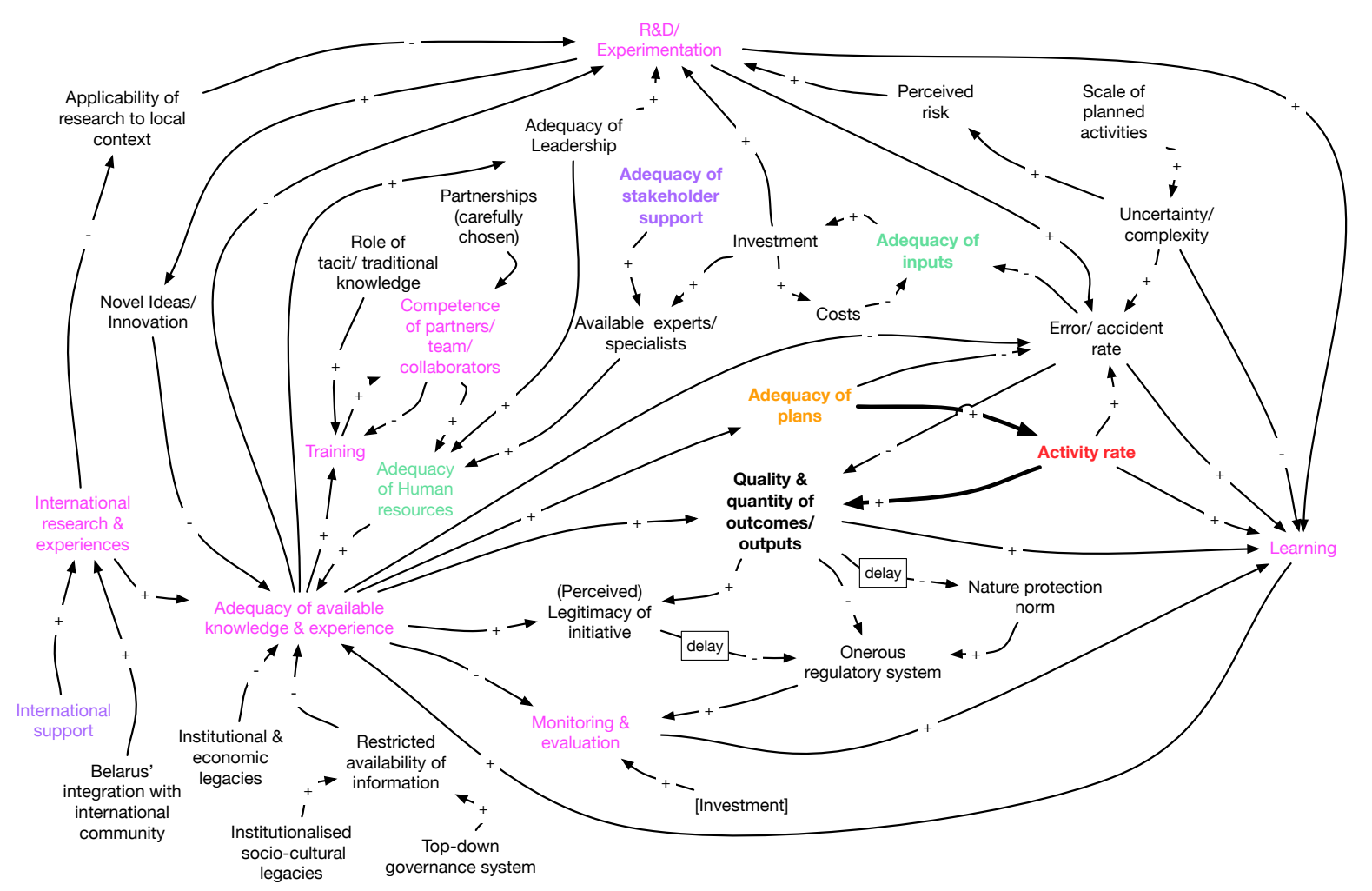

Figure 8 (from main paper). Sub-model unpacking causal dynamics influencing the Adequacy of Learning and Knowledge for wetland restoration initiatives. Learning and knowledge/experience concepts are disaggregated in this sub-model in order to clarify causal pathways. These concepts are otherwise aggregated together in the other sub-models.

\subsubsection{Learning}

Interviewees were clearly personally motivated by a desire to learn and to find innovative solutions to difficult management problems. Initiatives therefore adopted multiple modes of ongoing learning, and were keen to ensure the transfer of knowledge to partners, staff, collaborators and other key stakeholders through training and communication strategies. Training was especially important in activities involving a high degree of tacit or traditional knowledge. Investment in active learning processes (e.g. R\&D/experimentation) and activity rates were important determinants of learning processes. Delays, e.g. due to errors and accidents, whilst occasionally costly, were viewed as valuable learning opportunities. Experimentation was typically fused with implementation activities - i.e. learning by doing with both balanced by identical feedback control from available inputs (primarily funds). However, learning by doing was complicated by factors of uncertainty and complexity (e.g. false positives/negatives, imperceptible causality). 
Perceived risk, in part due to uncertainty/complexity, was a key motivating factor for investments in R\&D and experimentation, as was leaders' beliefs regarding the long-term value of R\&D for commercial enterprises. Learning also resulted from monitoring and evaluation efforts, often a regulatory system requirement. Leaders for cases Birds and Bogs suggested that compliance with regulatory documentation requirements provided a wealth of material for knowledge sharing and awareness-raising across NGO networks and to other interested parties.

\subsubsection{Availability of experts and specialists}

Experts and specialists were highly respected by interviewees as essential knowledge inputs. In some instances, specialists were employed as team members or consultants, whereas in others they were merely supporters who were persuaded to contribute without charge. Costs associated with retaining experts could otherwise be prohibitive. Investment in their services was often on an ad hoc basis.

"We didn't have a lot of money to fully explore this [hydrological] issue... We have only \$4000. We cannot say: 'please, do the hydrography of the marshes.' We say: 'please, tell us what to do first."' [Leader, case Bogs]

\subsubsection{International research and experiences}

The integration of Belarus with the international community, particularly regarding international research collaborations, was perceived by interviewees to have improved knowledge availability (Fig. 8). However, interviewees acknowledged limitations regarding the direct applicability of international research to local contexts.

"[UK] bogs have quite different problems... they do not have convex bogs, they have blanket bogs. That is why their experts do not know what to do [here]." [Leader, case Bogs]

\subsubsection{Knowledge-driven feedbacks}

Along with feedbacks to support and regulatory system reform mentioned above, initiatives used knowledge dissemination feedbacks, via awareness-raising and communication strategies (Fig. 6), to influence stakeholders in the wider system - e.g. political leaders, the general public, consumers. However, initiatives differed in their approach to dissemination of internallygenerated knowledge. The leader for case Berries sought patents to protect innovations and 
intellectual property arising from investments in R\&D. The leader for case Bogs, on the other hand, sought to disseminate project-generated learning as freely as possible.

"As a result of the project, the government adopted a policy which stipulates that at the end of its economic life our project area must be turned back into a peatland and not into a reservoir or forest as used to be the case." [Leader, case Birds]

"We see a goal that we want to achieve in other territories in Belarus. We are moving authorities, donors and the Academy of Sciences in this direction, [by] shaping opinions...Gradually people change and their knowledge grows.” [Leader, case Bogs] 